QUANTITATIVE ANALYSIS OF ELEMENTARY PRE-SERVICE TEACHER AND EDUCATOR PREPARATION PROGRAM PERFORMANCE ON THE MISSOURI CONTENT ASSESSMENTS BY RACE, ETHNICITY, GENDER, PROGRAM SELECTIVITY AND MINORITY-SERVING INSTITUTION STATUS

\author{
A Dissertation \\ Presented to \\ the Faculty of the Graduate School \\ at the University of Missouri-Columbia \\ In Partial Fulfillment \\ of the Requirements for the Degree \\ Doctor of Education \\ by \\ MICHAEL A. McBRIDE \\ Dr. Timothy J. Wall, Dissertation Supervisor \\ DECEMBER, 2016
}


The undersigned, appointed by the dean of the Graduate School, have examined the dissertation entitled

\section{QUANTITATIVE ANALYSIS OF ELEMENTARY PRE-SERVICE TEACHER AND EDUCATOR PREPARATION PROGRAM PERFORMANCE ON THE MISSOURI CONTENT ASSESSMENTS BY RACE, ETHNICITY, GENDER, PROGRAM SELECTIVITY AND MINORITY-SERVING INSTITUTION STATUS}

presented by Michael A. McBride

a candidate for the degree of doctor of education

and hereby certify that, in their opinion, is worthy of acceptance.

Professor Timothy Wall

Professor Carole A. Edmonds

Professor Matthew Symonds

Professor Dave Oehler 


\section{QUANTITATIVE ANALYSIS OF MCA}

\section{DEDICATION}

I would like to begin my dedications with my wife, Brooke. You have exhibited patience, kindness and understanding through this entire process. I hope that the

completion of this dissertation will bring you as much joy and relief as it does me. Thank you for being a wonderful wife, mother to our son, companion and confidant. You are my inspiration and the shade tree in our garden. I love you B, always and forever.

To my son Bryant, who even at the age of 9 months is an inspiration to me, I say thank you. You are proof of so much goodness to me. Wherever you go, whatever you do, whoever you become know that I love you and always will, no matter what.

I must thank my parents for preparing me for this. My father taught me how to work hard and to love family. He is a great example of what a man and father should be and I hope to live up to him as much as I am able. My mother taught me how to dream and believe in myself, to show kindness and patience. She is an example of what love should be. I could not have asked for a better childhood and I thank you both for it. I love you both more than I say.

To my siblings, I love all of you. Jimmie, you've taken care of me in so many ways, trying to show me how to be a grown up for 40 years and taking care of nearly every vehicle I've ever owned. Angela, you have been an enormous inspiration to me. You have truly shown that faith is power. And to Michele, Bruce, Claire, Autumn, and Vivian... all I can say is that I love all of you very much. Thank you for welcoming me and making me part of your family for two summers. Hanging out with you was my favorite part of those summers! 


\section{QUANTITATIVE ANALYSIS OF MCA}

To Justin, you are an inspiration to me and everyone you know. You are proof that when the worst happens, you can rise above it. You have been to the other side of the world and back. I hope you have many more travels.

To the stockmen, my oldest friends, you're still my brothers. To TJ, Leroy, Erik, you are the guys I will never forget and the times we spent together were some of the best of my life. To Dan, you taught me that life is very, very fragile, even for the best people I know. It took me years to learn this lesson. I hope to see you again someday. 
QUANTITATIVE ANALYSIS OF MCA

\section{ACKNOWLEDGEMENTS}

I would like to acknowledge Dr. Tim Wall, my mentor, advisor and friend. If I have success in this program or as a professional it is due to you. Also, I would like to acknowledge the kindness and generosity of Dr. Carole Edmonds, who has helped so many reach this goal. Finally, I would like to thank Dr. Dave Oehler, Dr. Matt Symonds, and all of the faculty and colleagues who have contributed to this work. 
QUANTITATIVE ANALYSIS OF MCA

TABLE OF CONTENTS

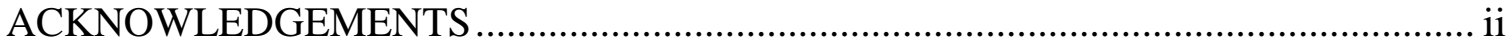

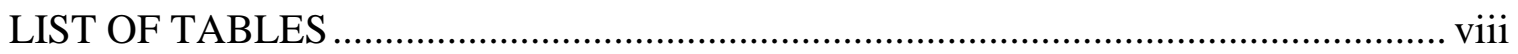

LIST OF FIGURES ………………………………......................................... ix

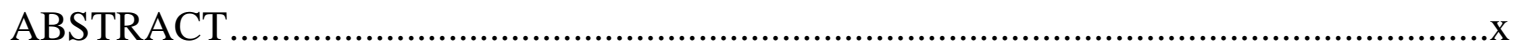

Section

1. INTRODUCTION TO THE BACKGROUND OF THE STUDY ...........................1

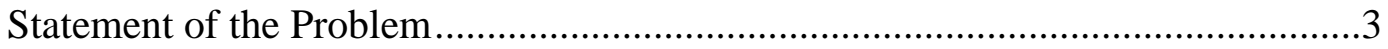

Purpose of the Study …………………….....................................................

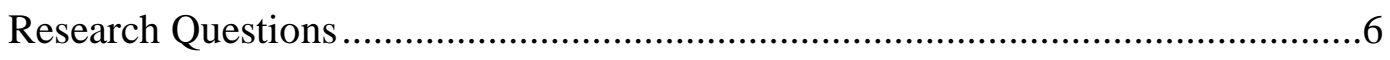

Conceptual Framework ………………………............................................

Accountability: Function and issues ............................................................

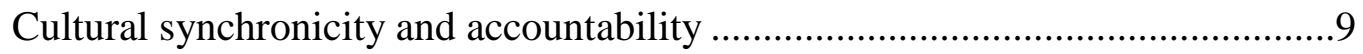

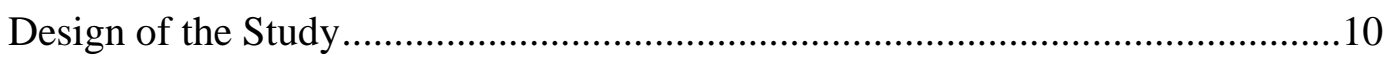

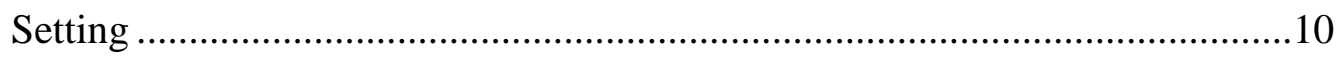

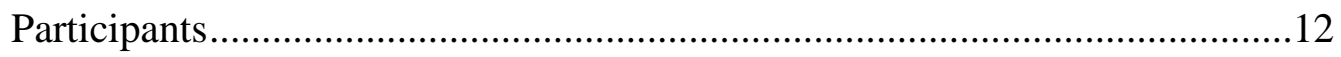

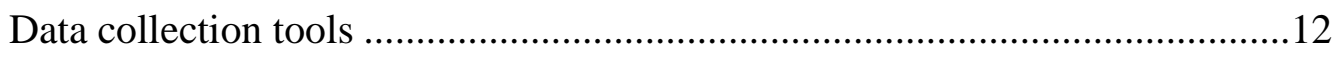

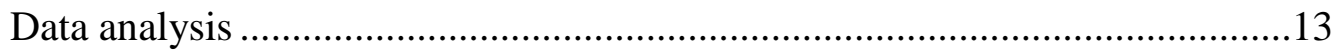

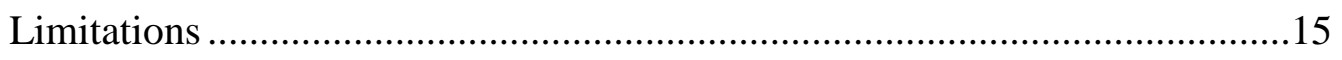

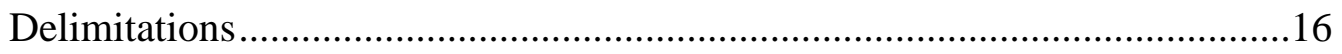




\section{QUANTITATIVE ANALYSIS OF MCA}

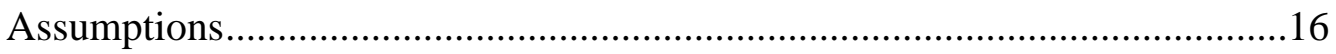

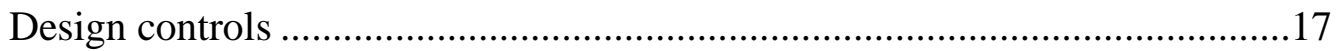

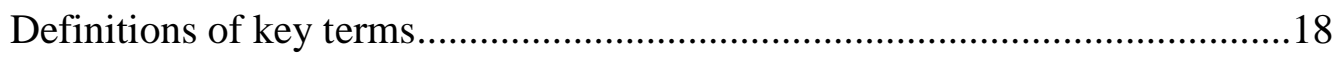

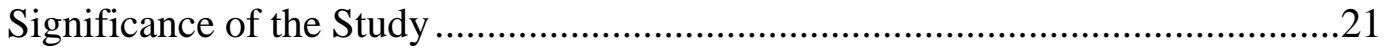

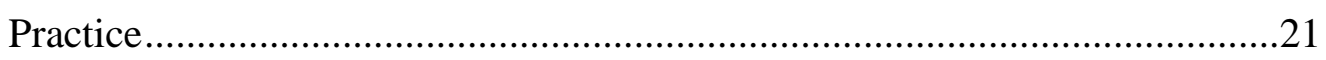

Impact on educator preparation programs ..........................................21

Minority-serving institution educator preparation programs ....................22

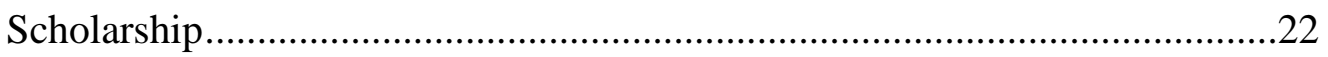

Achievement gaps by race/ethnicity ...............................................22

Achievement gaps by gender .....................................................23

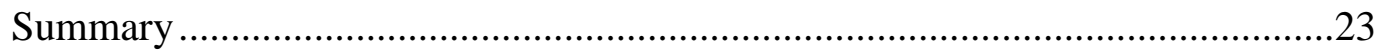

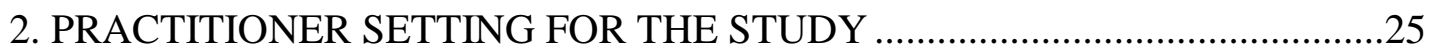

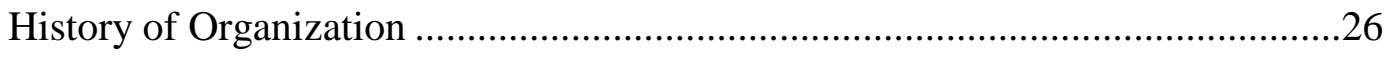

Department of Elementary and Secondary Education ................................26

Educator preparation program history .................................................26

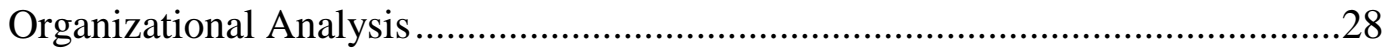

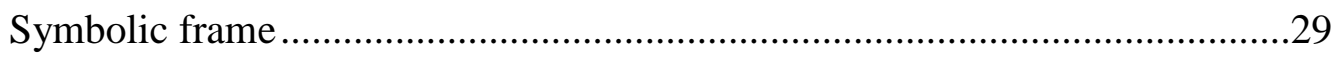

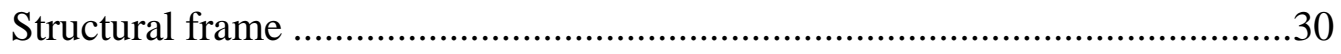

Human resources frame ....................................................................... 31

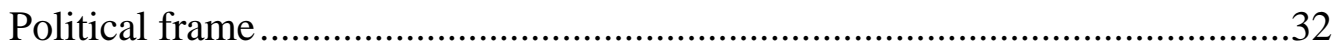

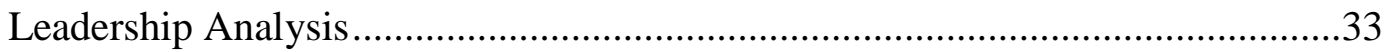

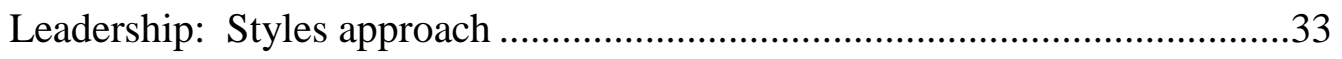

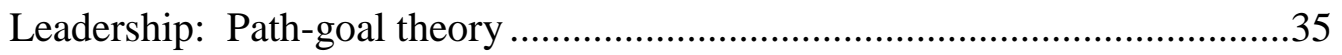




\section{QUANTITATIVE ANALYSIS OF MCA}

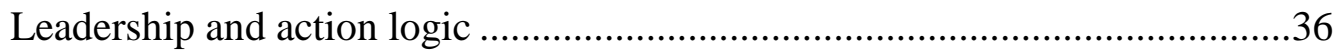

Implications for Research in the Practitioner Setting ............................................37

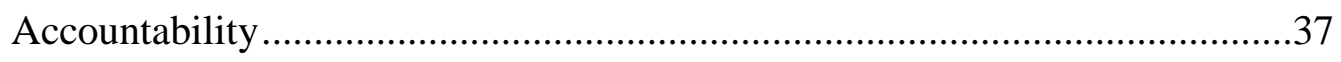

Cultural synchronicity ....................................................................................

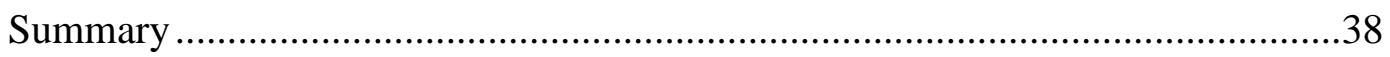

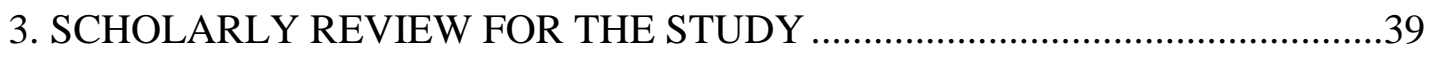

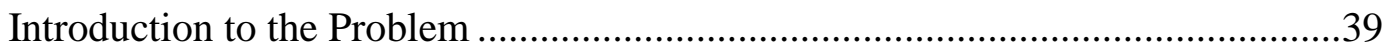

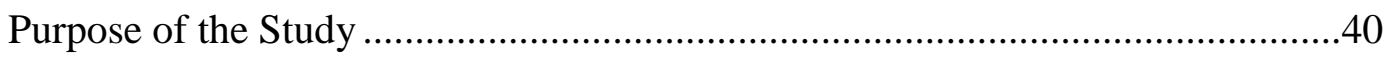

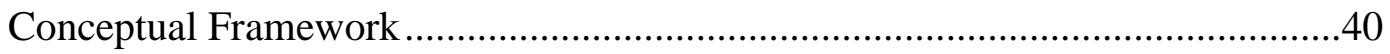

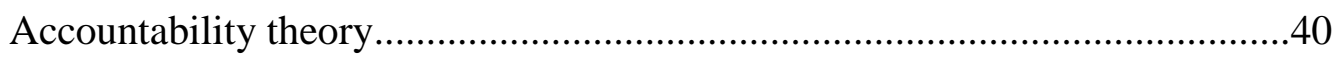

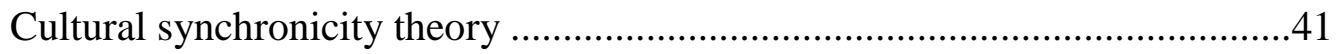

Elementary Education Pre-Service Teachers.......................................................41

International elementary education pre-service teachers .................................42

National elementary education pre-service teachers........................................43

Missouri and elementary education pre-service teachers ..................................45

Successful preparation of elementary teachers ................................................47

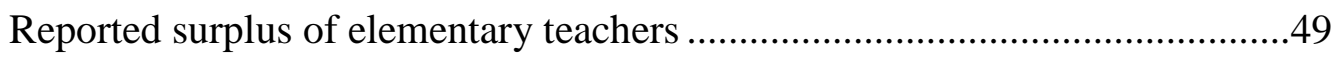

Evidence for the need for elementary education teachers. ......................50

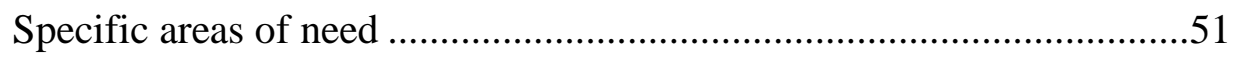

Elementary teacher certification and race .............................................5

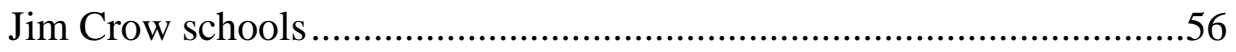

Race and high school graduation ......................................................56

Race and high school performance ......................................................56 


\section{QUANTITATIVE ANALYSIS OF MCA}

Achievement gaps and school environment

Assessment of Educator Preparation Programs

Educator preparation program types

Educator preparation program accountability policy.

Educator preparation program accrediting organizations

External pressures .62

Educator preparation program detractors

Missouri Educator Gateway Assessments

Accountability Foundations

Accountability: Shortcomings ........................................................67

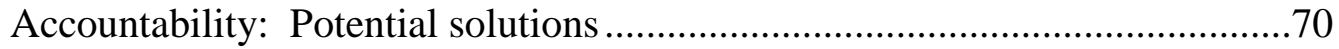

Accountability and pre-service teacher certification ................................70

Accountability and educator preparation programs ..................................72

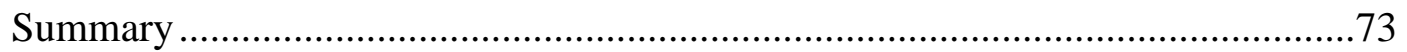

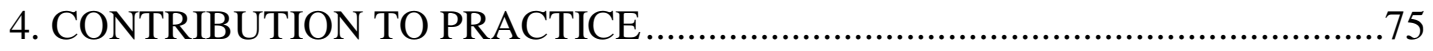

Quantitative Analysis of Missouri Teacher Licensure Exams through the Lens of

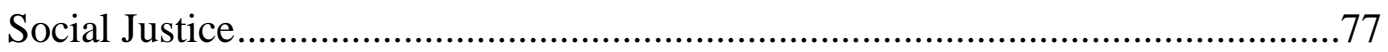

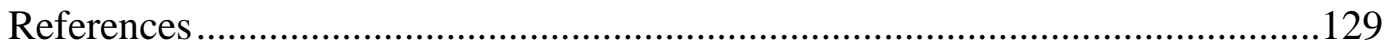

5. CONTRIBUTION TO SCHOLARSHIP ......................................................

Elementary Pre-Service Teacher and Educator Preparation Program Performance on the Missouri Content Assessments by Race, Ethnicity, Gender, Program

Selectivity and Minority-Serving Institution Status

References 


\section{QUANTITATIVE ANALYSIS OF MCA}

6. SCHOLARLY PRACTITIONER REFLECTION .............................................168

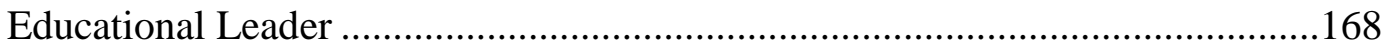

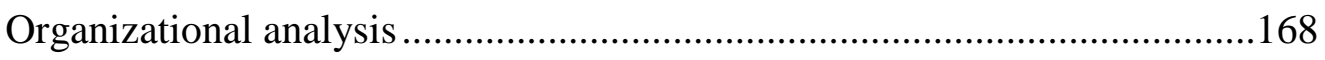

Growth as a leader ....................................................................................170

Educational leadership opportunities ............................................................173

Campus leadership ………………………………………...................173

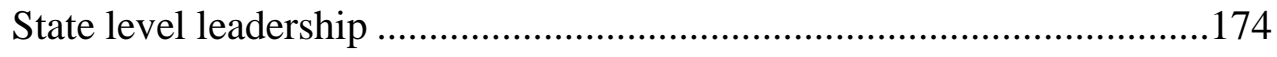

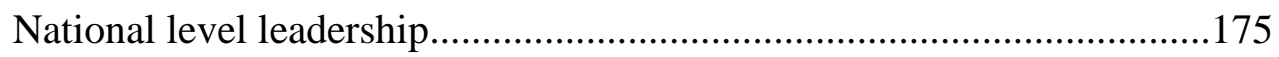

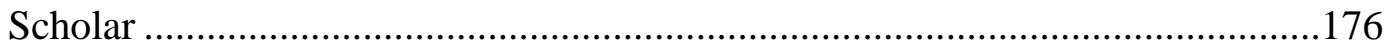

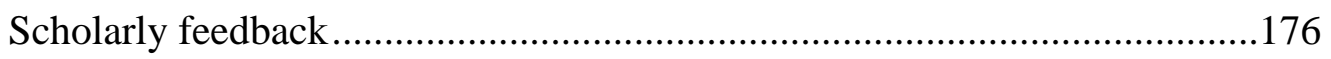

Reading and writing as a scholar ...............................................................177

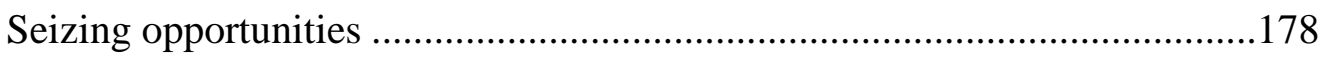

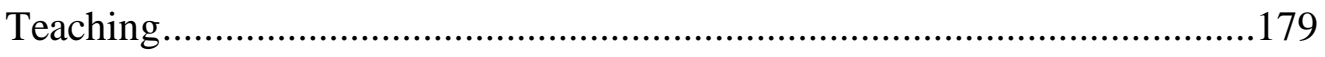

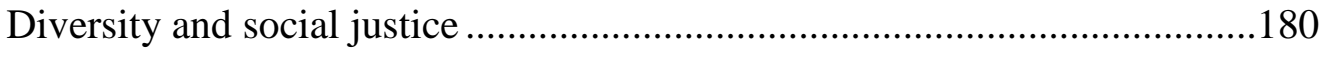

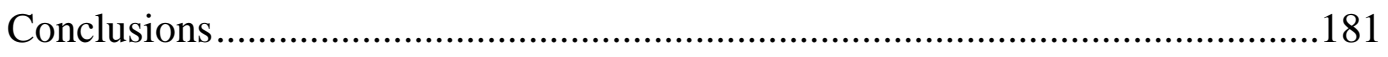

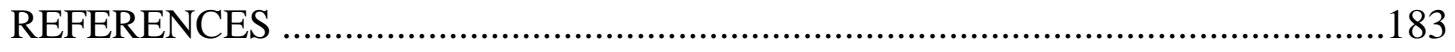

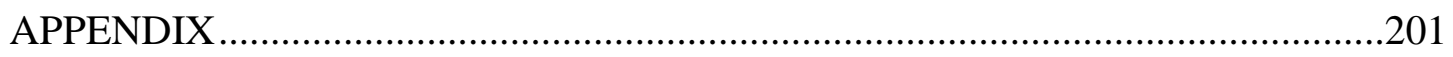

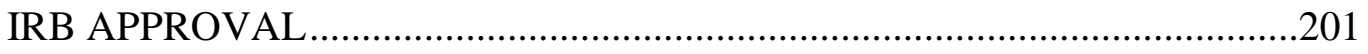

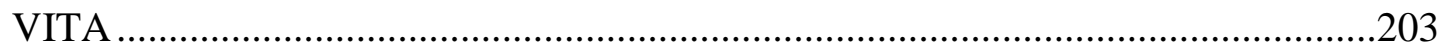


QUANTITATIVE ANALYSIS OF MCA

\section{LIST OF TABLES}

\section{TABLES}

1. Table 1. Research Questions and Null Hypotheses.......................... 6

2. Table 2. Summary of Analyses Used by Research Question.................13 
QUANTITATIVE ANALYSIS OF MCA

\section{LIST OF FIGURES}

\section{FIGURES}

1. Figure 1. Preparation Program Foci and Potential Outcomes............... 9

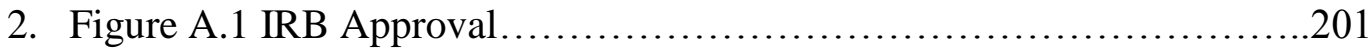




\begin{abstract}
This study investigated whether differences existed in Missouri teacher certification assessment scores based on Elementary Pre-Service Teacher race, ethnicity and gender, as well as the selectivity level or Minority-Serving Institution status of Educator Preparation Program attended by the Elementary Pre-Service Teacher. These assessment scores were used as accountability measures in Missouri. Elementary PreService Teachers were certified to teach in Missouri based partially on their certification assessment scores. These scores were also used to determine which Educator Preparation Programs maintain state accreditation.

The researcher focused on one of the Missouri teacher certification assessments, the Elementary Education Multi-Content Assessment. This assessment was required for any Elementary Pre-Service Teacher seeking elementary education teacher certification in Missouri. The Multi-Content Assessment includes four subtests covering subject matter in: English; mathematics; science; and social studies.

This study concluded that there were significant differences in scores based on: race and ethnicity; gender; preparation program selectivity level; and preparation program status as a Minority-Serving Institution. Furthermore, the study found that modifying mandated cut scores could mitigate race/ethnicity-based differences for three of the four subtests. The study also indicated that Pre-Service Teachers who identified as African American or Hispanic were more likely to fail at least one subtest and therefore fail to be recommended for teacher certification. The researcher recommended these assessments, their cut scores and accompanying accountability policies be reviewed.
\end{abstract}


QUANTITATIVE ANALYSIS OF MCA

\section{SECTION ONE}

\section{INTRODUCTION TO THE BACKGROUND OF THE STUDY}

Various accountability constructs have existed to verify that Elementary PreService Teachers (PSTs) and their Educator Preparation Programs (EPPs) met standards set forth by state and federal agencies (Angrist \& Guryan, 2004; Berk, 1995; Blackford, Olmstead, \& Stegman, 2012; Chung, 2008; Darling-Hammond, Amrein-Beardsley, Haertel, \& Rothstein, 2012; Department of Elementary and Secondary Education, 2014a, 2014b, 2015b, September 23, 2016e; Duckworth, Peterson, Matthews, \& Kelly, 2007; Edmonds, 2014; Flippo \& Canniff, 2000; Henry, Kershaw, Zulli, \& Smith, 2012; Larsen \& Calfee, 2005; U.S. Department of Education, 2000). Standards for PSTs and EPPs typically included benchmarks based on PST standardized exam scores (Wakefield, 2003). This was the case in Missouri (Department of Elementary and Secondary Education, 2014b, 2015b, September 23; Gitomer, Latham, \& Ziomek, 1999; Honawar, 2007; Sawchuk, 2010; Wakefield, 2003).

To be recommended for teacher certification in Missouri PSTs must have passed a certification exam in a subject matter area required by the Missouri State Board of Education (MOSBOE) and enforced by the Department of Elementary and Secondary Education (DESE) (DESE, 2014b). The MOSBOE instituted the Missouri Content Assessments (MCA) for this purpose in September, 2014 (DESE, 2014b). These assessments were subcontracted for development by a national testing company, Evaluation Systems Pearson (Evaluation Systems Pearson, 2009).

The Missouri Content Assessments (MCA) were the final step in a line of accountability measures for PSTs. These other accountability measures included grade 


\section{QUANTITATIVE ANALYSIS OF MCA}

point averages, general education assessments, performance evaluations, observational assessments, and a work styles inventory (DESE, 2014b).

EPPs were accredited by state and federal entities to ensure a quality educator workforce (Council for the Accreditation of Educator Preparation, 2016; Department of Elementary and Secondary Education, 2014a). These accreditation methods sought to maintain accountability among EPPs. EPP accountability was based on a variety of formal and informal assessments (Ameter, Douglas, Ferris \& Goka, 2006; DESE, 2014a). These measures ranged from standardized tests to observation forms to performance assessments (Larsen \& Calfee, 2005). In many states, including Missouri, failure to meet prescribed accountability benchmarks began a process to remediate the issue or close the EPP (DESE, 2014a). DESE has used aggregate testing data for this purpose since 2014 (DESE, 2014a).

However, Wakefield (2003) indicated that there was never a strong relationship between standardized testing scores and teacher performance. Also, PSTs from historically marginalized populations, such as individuals of African American or Hispanic descent, performed more poorly than PSTs who were White on high-stakes standardized examinations (Edmonds, 2014; Horn, 2003; Nettles, Scatton, Steinberg \& Tyler, 2011; Taylor, 2013; Wakefield, 2003; Wall, 2008). Standardized assessments were therefore barriers to PSTs of color becoming teachers (Bennett, McWhorter, \& Kuykendall, 2006; Horn, 2003). In addition, since these scores were typically tied to EPP accountability measures, these assessments could have had a disproportionately negative impact on (EPPs) that cater to a more diverse PST population. 


\section{QUANTITATIVE ANALYSIS OF MCA}

\section{Statement of the Problem}

The problem under investigation was the lack in knowledge of whether differences existed in Missouri Content Assessment scores between PSTs from different racial and ethnic backgrounds and gender identities. In addition, there was a lack of knowledge of whether a difference existed in Missouri Content Assessment scores between PSTs who attended EPPs of different selectivity levels and EPPs with different statuses as Minority-Serving Institutions (MSI).

The Missouri Educator Gateway Assessments (MEGA) were a suite of assessments utilized for Missouri teacher preparation accountability purposes for both PSTs and EPPs (DESE, 2014b). These assessments included; two standardized exams, the Missouri General Education Assessment (MoGEA) and the Missouri Content Assessments (MCA); a work-style inventory known as the Missouri Educator Profile (MEP); an observation form completed during student teaching known as the Missouri Educator Evaluation System (MEES), and a performance assessment known as the Missouri Pre-Service Teacher Assessment (MoPTA). Of the two standardized exams, the MoGEA has been researched for significant differences in PST scores based on race, ethnicity and gender. College students were required to pass the MoGEA to enroll in any Missouri EPP (DESE, 2014b).

The MoGEA was a general education assessment developed by Pearson Education to act as a gatekeeper to teacher preparation. Pearson was a large, standardized test development company with assessments used by over 450 credentialing organizations worldwide (Evaluation Systems Pearson, 2009). Pearson assessments were used for accountability purposes in teacher preparation, the military, government hiring, 


\section{QUANTITATIVE ANALYSIS OF MCA}

healthcare, and other fields (Evaluation Systems Pearson, 2009). Edmonds (2014) analyzed the MoGEA and concluded that female PSTs and PSTs of color received scores that were statistically significantly lower than those of White or male PSTs, which precluded female PSTs and PSTs of color from enrolling in Missouri EPPs. The MoGEA, Edmonds (2014) concluded, decreased the diversity of the educator labor supply in Missouri.

While the MoGEA was the gateway assessment to enter educator preparation programs in Missouri, the Missouri Content Assessments was required for teacher certification and are taken near the conclusion of educator preparation programs. These assessments covered different content areas, one for each type of teacher certification in Missouri. A passing score was required in each content area test before PSTs were certified to teach in that area (Pearson, 2015). The Missouri Content Assessment was first implemented in September 2014 (DESE, 2014b). This study investigated the presence of statistically significant performance differences for PSTs in the Missouri Content Assessments based on PST race, ethnicity or gender and the selectivity level and MSI status of the EPP which the PST attended.

Following Edmonds' (2014) research about the MoGEA, this study sought to fill a similar gap in the literature regarding the Missouri Content Assessments. In particular, this research aimed to determine if these assessments disproportionately penalized EPPs with more diverse PST populations. The full effect of the MCA's on the diversity of Missouri teachers was not determined. But, if the effect of these assessments was similar to the MoGEA and other standardized exams, the MCA's may have had a winnowing effect on Missouri teacher racial, ethnic and gender diversity. Also, MSI status of each 


\section{QUANTITATIVE ANALYSIS OF MCA}

educator preparation program and the selectivity level of each institution were analyzed as well in regards to PST Missouri Content Assessment scores.

DESE used the Missouri Content Assessments as accountability measures both for PSTs and their EPPs. However, since assessments of this type historically shown significant differences in achievement between historically marginalized and nonmarginalized populations, these assessments may have had negative unintended consequences in two ways: reducing PST diversity; and reducing the likelihood that EPPs serving diverse PSTs had an equitable chance to score well on these accountability measures.

While the percentage of teachers of color increased since 1988, the percentage increase in K-12 students of color was larger (Villegas, Strom, \& Lucas, 2012). Recent research indicated that learners of color learned better from teachers of color (Goldhaber \& Hansen, 2010; Irvine, 1990, Wakefield, 2003). Therefore, the closure of this gap was vital to equitable education (Ravitch, 2013). In addition, state and federal accountable strategies judged EPPs by how well their program completers fared on standardized exams (U.S. Department of Education, 2000). The problematic issue was that PSTs of color generally fared less well on standardized exams than White counterparts (Edmonds, 2014; Flippo \& Canniff, 2000; Nettles et al., 2011; Wall, 2008).

\section{Purpose of the Study}

The purpose of this study was to fill the gap in the knowledge as to whether differences existed in PST scores on the Missouri Content Assessments (MCA) based on PST racial, ethnic and gender diversity or based on the selectivity level or MSI-status of the EPP the PST attended. The following research questions in Table 1 guided inquiry. 
QUANTITATIVE ANALYSIS OF MCA

\section{Research Questions}

Table 1

Research Questions and Null Hypotheses

Research Question Null Hypothesis

1. What are the descriptive summary statistics for the study participants when broken down by race, ethnicity, gender, institutional selectivity and MSI status?

2. Do statewide scores on the Elementary Education MCA subtests since September 2014 represent a normal distribution?

3. Is there a difference in Elementary Education MCA subtest scores for the following demographic variables?
a. Ethnic origin
b. Race
c. Gender

4. When composite ACT score is used as a covariate, is there a difference in Elementary Education MCA subtest scores for the following demographic variables?
a. Ethnic origin
b. Race
c. Gender

5. How will establishing cut scores at different preset Standard Error of Measurement (SEM) levels affect PSTs?
$\mathrm{H}_{0} 1$ : Statewide scores on the Elementary Education MCA since September 2014 represent a normal distribution.

$\mathrm{H}_{0}$ 2: There is no difference in Elementary Education MCA mean subtest scores between demographic variables.

$\mathrm{H}_{0} 3$ : There is no difference in Elementary Education MCA mean subtest scores between demographic variables when composite ACT is used as a covariate.

$\mathrm{H}_{0} 4$ : Establishing cut scores at different preset Standard Error of Measurement (SEM) levels will not affect the PST licensure results in populations that have been historically marginalized 
6. What is the likelihood of racially and ethnically diverse PSTs earning access to the profession because of MEGA?

7. Is there a difference in Elementary Education MCA subtest scores for the following institutionlevel variables?

a. Selectivity level

b. MSI status
$\mathrm{H}_{0} 5$ : There is no difference between PSTs of diverse backgrounds and White PSTs' abilities to access the teacher profession due to MEGA

$\mathrm{H}_{0} 6$ : There is no difference in Elementary Education MCA mean subtest scores between institutional variables

Note . MCA = Missouri Content Assessment; MSI = Minority-Serving Institution; MEGA $=$ Missouri Educator Gateway Assessment; PST $=$ Pre-Service Teacher.

\section{Conceptual Framework}

This study focused on the use of accountability strategies by accrediting bodies on PSTs seeking certification and Educator Preparation Programs (EPPs) seeking accreditation. These accountability measures were utilized by the MOSBOE and DESE to ensure that PSTs were prepared to teach and that EPPs prepared PSTs according to standards (DESE, 2014b). To better illustrate the construct of accountability, this section reviewed: accountability as a conceptual framework; how it operates; problems associated with current accountability strategies; and potential fixes.

\section{Accountability: Function and Issues}

Anderson (2009) stated that accountability is a relationship between the accounter and the accountable. In this relationship the accounter held the power. The accounter sought to reward or punish good or bad outcomes by the accountable. According to this theory, these rewards and punishments ensured the accountable follows due diligence to ensure work is considered good by the accounter. In the best case scenario, the accountable reached agreed-upon goals while the accounter was satisfied with the work. 


\section{QUANTITATIVE ANALYSIS OF MCA}

However, the use of the accountability construct has led to negative outcomes on both sides of the relationship. Accounters may have appeared to be blameless when accountees produced data that failed to meet goals (Anderson, 2009). This may have led accountees to unethical behavior, such as hiding results or obscuring unfavorable information. These unintended consequences may have decreased validity in the accountability process.

This accountability conceptual framework may have led to a perception of hopelessness among EPPs. DESE has indicated that EPPs were responsible both to recruit and retain PSTs from diverse backgrounds and ensure that these PSTs passed content assessments at a level deemed appropriate. Some EPPs may have considered both of these endeavors important but difficult to attain simultaneously. The following figure was influenced by research from Goldhaber and Hansen (2010). 


\section{QUANTITATIVE ANALYSIS OF MCA}

Figure 1. Preparation Program Foci and Potential Outcomes

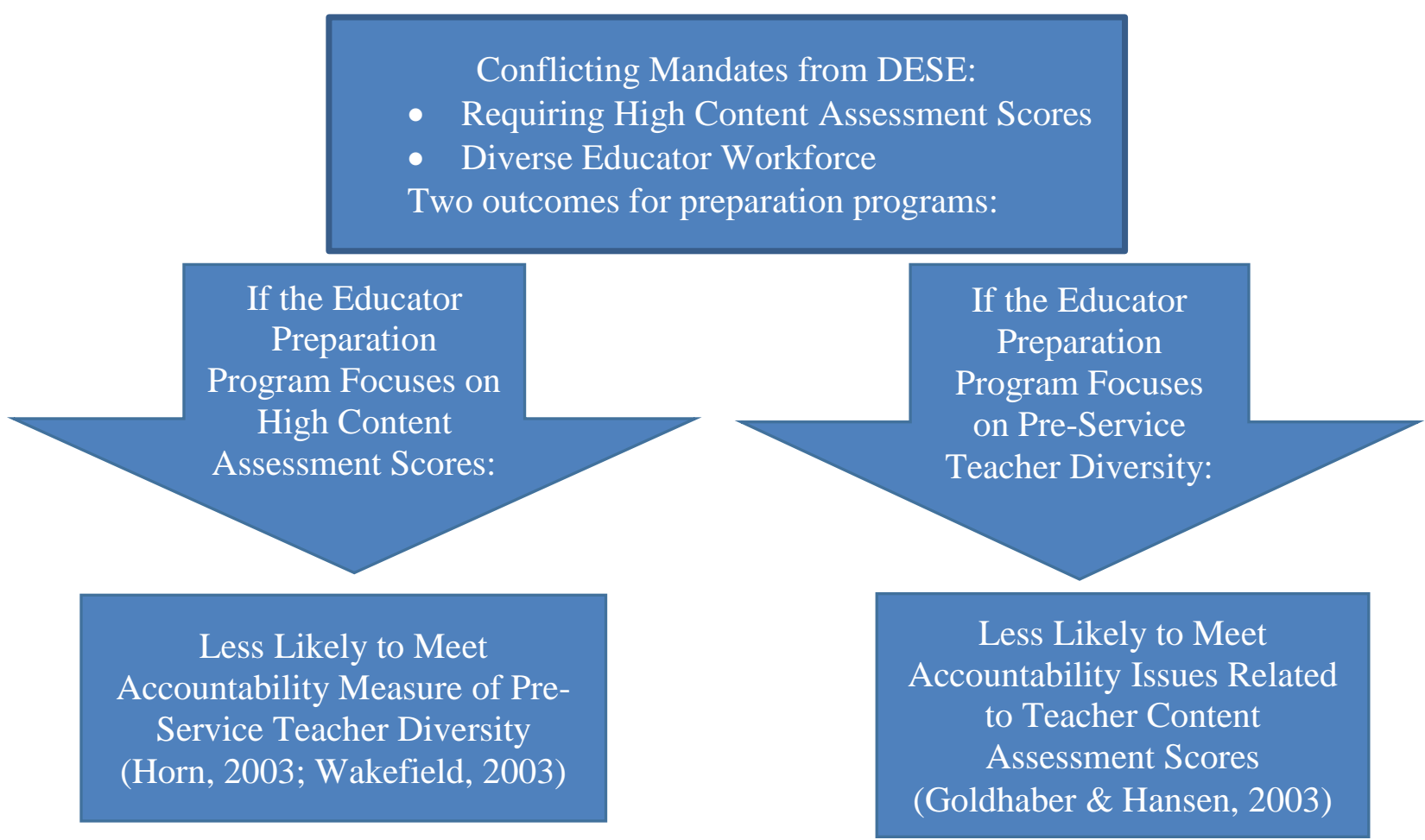

Figure 1. Accounters MOSBOE and DESE required that EPPs recruit and complete PSTs with high content assessment scores and diversity. Often, these goals were mutually exclusive and EPPS that focus on one were more likely to face accountability issues related to the other.

\section{Cultural Synchronicity and Accountability}

Cultural synchronicity referred to favorable academic outcomes of pairing students and teachers based on cultural similarity (Irvine, 1990). This was especially the case among students from historically marginalized populations (Allen, et al., 2011). African American teachers were more likely to set higher expectations for African American students and attribute racial achievement gaps to lower expectations (Uhlenberg and Brown, 2002). Pitts (2007) reported that high school seniors achieved higher graduation exam scores in districts with a similar race and ethnicity ratio between students and teachers. Goldhaber and Hansen (2010) indicated that, while subject matter 


\section{QUANTITATIVE ANALYSIS OF MCA}

assessments were more likely to remove diverse teachers from the workforce, student/teacher cultural matches were more important to student success than teacher licensure exam scores. These findings indicated that accountability measures focused solely on subject matter assessment scores were more likely to lower achievement among Pk-12 students from historically marginalized populations.

\section{Design of the Study}

This study employed a quasi-experimental design, as participants were selected by convenience and not randomly assigned to groups (Creswell, 2014). Randomly assigning PSTs to different EPPs, based on selectivity and Minority-Serving Institution (MSI) status would have resulted in an experiment with more valid data. However, this would have removed a great deal of personal choice on the part of the PSTs and was impossible. The researcher contacted assessment coordinators at educator preparation programs around Missouri and requested PST Missouri Content Assessment data, as well as test taker demographic data, with all identifying student data removed.

\section{Setting}

The setting of this study was a public, four-year EPP located within Missouri. This study included quantitative data since the test scores were reported on a range of 100-300 (DESE, 2014b). Even though the Missouri Content Assessments included a variety of exams that covered every possible certification a Missouri teacher could earn, the passing score for any of these exams was 220. This value was a Panel Based Cut Score (PBCS), meaning that Pearson suggested this score be the passing score for each test (DESE, 2014a). This score was on a scale of 100-300 (DESE, 2014a). The researcher analyzed these quantitative test score data along with categorical data of race, 


\section{QUANTITATIVE ANALYSIS OF MCA}

ethnicity, gender, selectivity of EPP attended and Minority-Serving Institution (MSI) status of EPP attended (Edmonds, 2014).

Pearson considered four other potential cut scores besides the PBCS for each MCA. Pearson set these potential cut scores at one and two standard errors of measure (SEM) above and below the PBCS. A Standard Error of Measurement is the standard deviation of test scores one hypothetical student would provide if they took a test many times. In other words, the Standard Error of Measurement is a way to estimate how reliable the test is towards estimating a concept known as a true score. This true score is what the student should receive on the test if all factors such as fatigue and sampling error were held as constants (Thorndike, 2005). The smaller a Standard Error of Measurement, the more accurate a test is at estimating a test taker's true score. The Standard Error of Measurement also acts like standard deviation. One Standard Error of Measurement below and above the PBCS should include $68 \%$ of all attempts if the same student took the test many times. Two standard errors of measure below and above the PBCS should capture $95 \%$ of attempted scores by that student. Even if a PST's hypothetical true score was above the PBCS, due to a variety of factors the PST may score lower on that day on that assessment and fail to pass the assessment. Lowering the cut score from the PBCS to a score one or two SEM below the PBCS would substantially increase the probability that the PST would receive a passing score regardless of their performance on an individual day.

The ACT was used as one of the covariates in this study. The ACT was a standardized multiple choice assessment commonly used as a college entrance requirement in the Midwest (ACT, 2016). Nearly all PSTs involved in this study would 


\section{QUANTITATIVE ANALYSIS OF MCA}

have taken the ACT. If a PST did not have an ACT score they would not have been used in this analysis. In addition, individuals with low socioeconomic status (SES), female and non-White test takers typically scored lower on the ACT (Wall, 2008). Using ACT as a covariate would have helped to remove the impact of Socioeconomic Status (SES) from the study.

\section{Participants}

These PSTs were of different races, ethnicities and genders at EPPs of different Minority-Serving Institution (MSI) status and selectivity levels, who took the Elementary Education Missouri Content Assessment beginning in fall 2014.

Participants were chosen from PSTs at EPPs in Missouri because these were the only PSTs affected by the Missouri Content Assessments. PSTs enrolled at MSI's or non-MSI's were chosen because MSI's were vital to the process of creating a racially and ethnically diverse teacher workforce (AACTE, 2013; Brooks et al., 2012). Also, MSI PSTs were less likely to pass standardized exams (Steinberg \& Weiner, 2015). These were the students most likely to be deleteriously affected by the Missouri Content Assessments. In addition, all standardized test scores were related to each other, including ACT (Wall, 2008). Educator preparation programs which had different levels of selectivity used different ACT scores for initial student acceptance (Wall, 2008). Therefore, EPP selectivity level of each PST was collected as well.

\section{Data Collection Tools}

For data collection tools, the researcher was dependent on educator preparation program assessment staff who reply to the request for data. These data included an excel sheet with lists of student data, including race, ethnicity and gender, along with Missouri 


\section{QUANTITATIVE ANALYSIS OF MCA}

Content Assessment scores. It excluded individual PST identifying information. Since no individual student data was viewed, the researcher applied for institutional review board exempt status. In the hopes of avoiding program embarrassment due to lack of PST diversity, or the inability to produce PSTs who successfully passed these exams, no program was identified by name. There were two Minority-Serving Institutions (MSI) in Missouri, and data from these programs were aggregated to avoid program identification.

\section{Data Analysis}

The researcher analyzed this data with the statistical analysis software Statistical Package for the Social Sciences (SPSS) to generate descriptive statistics and quantitative results via an ANOVA (Field, 2013). If differences in groups were found, the researcher conducted Tukey post hoc analyses to determine which specific groups had significant differences (Neter, Kutner, Nachtsheim \& Wasserman, 1996). Finally, the researcher used a $\mathrm{Z}$ test of proportions to determine if there was a statistically significant difference in the percent of PSTs able to pass each assessment based on race, ethnicity, gender, EPP selectivity or EPP MSI status (Milton \& Arnold, 2003).

Table 2

Summary of Analyses Used by Research Question

\begin{tabular}{|c|c|c|c|}
\hline Research Question & Analysis Strategy & $\begin{array}{l}\text { Independent and } \\
\text { Dependent } \\
\text { Variables and } \\
\text { Covariate }\end{array}$ & $\begin{array}{c}\text { Data Visualization } \\
\text { Strategy }\end{array}$ \\
\hline
\end{tabular}


QUANTITATIVE ANALYSIS OF MCA

1. Participant descriptive summary

statistics

2. Distribution

3. Demographic variable differences

4. Demographic variable differences

5. Cut score effect on demographic variables
Frequencies

Pie chart, by race, ethnicity, gender, selectivity and MSI status

Q-Q plots and data displays

Independent-samples ttest

IV: PST race, and ethnicity, gender DV: MCA subtest scores

IV: PST race, ethnicity, gender DV: MCA subtest scores

CV: ACT score

IV: Proportion of PSTs from each racial/ethnic/gender subgroup who passed MCA at each potential cut score DV: $\mathrm{Z}$ score giving probability that any difference between PST groups happened by chance $t$-test tables Histograms of mean score differences between groups

ANCOVA table

Z-score tables 
QUANTITATIVE ANALYSIS OF MCA

\begin{tabular}{|c|c|c|c|}
\hline $\begin{array}{l}\text { 6. Diverse PSTs' } \\
\text { abilities to pass the } \\
\text { MEGA exams }\end{array}$ & Chi-squared test & $\begin{array}{l}\text { IV: MCA passage } \\
\text { status, PST race, } \\
\text { ethnicity and gender } \\
\text { DV: Difference } \\
\text { between PSTs of } \\
\text { different } \\
\text { races/ethnicities/gen } \\
\text { ders to pass MCA }\end{array}$ & $\begin{array}{l}\text { Histogram } \\
\text { percentages of } \\
\text { diverse PSTs from } \\
\text { different } \\
\text { institutions as } \\
\text { education major } \\
\text { passing the MCA }\end{array}$ \\
\hline $\begin{array}{l}\text { 7. Institution variable } \\
\text { differences }\end{array}$ & $\begin{array}{l}\text { ANOVA, Post-Hoc } \\
\text { Tukey, independent- } \\
\text { samples } t \text {-test }\end{array}$ & $\begin{array}{l}\text { IV: Selectivity, MSI } \\
\text { status } \\
\text { DV: MCA subtest } \\
\text { scores }\end{array}$ & $\begin{array}{l}\text { ANOVA, Tukey } \\
\text { and } t \text {-test tables } \\
\text { Histograms of } \\
\text { mean score } \\
\text { differences } \\
\text { between groups }\end{array}$ \\
\hline
\end{tabular}

Note . MCA = Missouri Content Assessment; MSI = Minority-Serving Institution; MEGA = Missouri Educator Gateway Assessment; PST = Pre-Service Teacher.

\section{Limitations}

Limitations included in this study mainly focused on the EPPs participating. There were no financial or technical incentives for EPPs to participate. Assessment directors from each EPP sent data only if each director's supervisors approved the researcher's request, and if the assessment directors had time and inclination to reply.

Another limitation of the EPP-based analysis was that PSTs self-selected which program they attended. This analysis would have had higher validity if the PSTs were randomly assigned to each program. That would not be possible. Finally, while a major focus of this study had to do with PST assessment performance, this study also focused on the average performance of all PSTs from different EPPs. A related limitation was that there were only two Minority-Serving Institutions (MSI) in Missouri. Both had smaller PST pools than most EPPs in the state. 


\section{QUANTITATIVE ANALYSIS OF MCA}

One final limitation was the overlap of MSI and open-enrollment status. The only open-enrollment EPPs included in this study were also the only MSIs involved.

Therefore, conclusions may be difficult to interpret as to whether they were influenced by an EPPs status as an MSI or as an open enrollment EPP.

\section{Delimitations}

Only PSTs who attended Missouri EPPs between 2014 and 2016 and attempted the Elementary Education Multi-Content Assessment were included in this study. It was possible for PSTs who completed preparation programs in other states to take the MultiContent Assessments and seek certification to teach in Missouri. These data were not included in the study. There also was no opportunity to randomly assign PSTs to different EPPs (Creswell, 2014).

In addition, there were 56 Missouri Content Assessments (DESE, 2014). This study only focused on the four Elementary Education Multi-Content Assessments required of Elementary Education PSTs.

These PSTs must have been age 18 or older and must have sought certification since September 1, 2014. This is when the Missouri Content Assessments became required for Missouri teacher certification (DESE, 2014).

\section{Assumptions}

The assumptions related to this study were focused on the Missouri Content Assessment scores. The researcher assumed that these scores represented the PSTs' best efforts. Also, the researcher assumed that only PST data was submitted by EPPs. Some EPPs requested program faculty take this assessment in hopes of acquainting themselves with it to better prepare PSTs. EPPs were asked to remove this data before sending 


\section{QUANTITATIVE ANALYSIS OF MCA}

results to the researcher. Finally, the researcher assumed these scores were from PSTs who wanted to become teachers and attended each EPP as opposed to individuals who wished to become certified to teach and only claimed an EPP as a home program while never attending it. The researcher only wanted data from PSTs who had completed an EPP program since September 2014.

\section{Design Controls}

The researcher put some design controls into this study to maintain focus. This study analyzed data only from the Elementary Education Multi-Content Assessment. This assessment included four subtests that must be passed with a score of 220 on a scale of 100-300. These subtests included: English language arts; math; science; and social studies. The Missouri Content Assessments covered over 50 content areas, but targeting on the Elementary Education subtests maintained focus while providing a large enough sample size to be analyzed quantitatively. Only data from Missouri EPPs was collected. Theoretically, PSTs from outside of Missouri could have taken these content assessments to become certified to teach in Missouri. But, since this study focused on PSTs and EPPs from Missouri, only data from Missouri EPPs were collected. While data on all attempts from each PST were collected, only the first two attempts counted towards EPP accountability measures. The researcher only collected data from PSTs who completed an MCA since September 1, 2014. This is the date when the MCA policy went into effect. Before this date PSTs were required to complete a different assessment, the PRAXIS II (DESE, 2014b). 


\section{QUANTITATIVE ANALYSIS OF MCA}

\section{Definition of Key Terms}

Since this study utilized terminology specific to the setting of educator preparation and associated accountability efforts, the following terms are defined for clarification purposes.

Accountee. In accountability theory, an accountee is the entity which must provide proof that goals have been reached. These must be provided to the accounter in order to receive reward or punishment.

Accounter. In accountability theory, the accounter is in the position of power. The accounter reviews findings submitted by the accountee. The accounter then uses these findings to provide either reward or punishment to the accountee based upon prearranged guidelines agreed upon by all parties.

\section{C-BASE (College Basic Academic Subjects Examination). The CBASE is} precursor to the MoGEA, used before September 2014. The CBASE is a general education assessment required of college students to pass before gaining admittance to any Missouri EPP. Different from the MoGEA, an overall average score was needed in the CBASE before college students could become a Missouri PST. Current PSTs must pass all four MoGEA subtests.

Educator Preparation Program (EPP). An EPP is program developed to prepare college students to become a teacher or other type of educator. While these have typically been housed with Institutions of Higher Education (IHE), new programs have been developed by private companies. 
QUANTITATIVE ANALYSIS OF MCA

Evaluation Systems Pearson. Also known as "Pearson", this is a company which has developed most of the assessments included under the banner of MEGA. This includes the MoGEA, the MEP and the MCA.

Department of Elementary and Secondary Education (DESE). DESE is the Missouri office responsible for certification of teachers. DESE enforces assessment policy put forth by the state board of education, including the utilization of MEGA.

Institution of Higher Education (IHE). An IHE is either a college or university. In this study, all EPPs are housed within a larger IHE.

Missouri Content Assessments (MCA). The MCAs are the final assessments required for certification of Missouri PSTs. Each MCA is a multiple choice, standardized exam designed to test teacher content knowledge. There are over $50 \mathrm{MCAs}$, each covering a separate content area.

Missouri Multi-Content Assessments. The Multi-Content Assessments are the MCAs required of Missouri elementary education teachers before certification. Instead of one content exam, like most MCAs, these include four separate subtests for different content areas. These subtests include English/language arts, mathematics, science and social studies.

Missouri Educator Evaluation System (MEES). Part of MEGA, the MEES is currently an observational form used to assess a PST during their student teaching semester. This form is used formatively and summatively by a university supervisor and at least one cooperating teacher. The form is based entirely on Missouri teacher standards. 
QUANTITATIVE ANALYSIS OF MCA

Missouri Educator Profile (MEP). The MEP is a workstyles inventory.

Developed by Pearson, this assessment attempts to gather data from PSTs on their traits as a worker. It has been designed to work as an advisement tool at EPPs.

Missouri Educator Gateway Assessments (MEGA). MEGA is an umbrella term that includes all new Missouri educator assessments used since 2013. This includes the MoGEA, MEP, MEES, MCA and MoPTA.

Missouri General Education Assessment (MoGEA). The MoGEA is a general education assessment developed by Pearson. PSTs are required to pass the MoGEA before admittance to an EPP. The MoGEA was originally composed of five subtests prior to September, 2015. However, it has been revised to include only four. PSTs must pass each subtest separately.

Missouri Pre-Service Teacher Assessment (MoPTA). The MoPTA is a performance assessment developed by ETS. The MoPTA is completed by a PST during their student teaching experience and is scored off campus by scorers hired, prepared and paid by ETS. The 2015-2016 school year was the first full implementation of this assessment.

Minority-Serving Institution (MSI). An MSI is any IHE that have either historically or currently serve an ethnically or racially diverse population.

PRAXIS II. The PRAXIS II is a multiple choice, standardized exam developed by ETS and used in many states as a final assessment before PSTs become certified to teach. Like the MCA, a PRAXIS II exists for any possible teaching content area. The PRAXIS II was replaced by the MCA in Missouri beginning September 1, 2014. 


\section{QUANTITATIVE ANALYSIS OF MCA}

Standard Error of Measurement (SEM). In testing, the SEM is the standard deviation of an imaginary sample of scores created if an individual could take the same assessment many times. Once an assessment has a cut score, the SEM is used as a way to create higher or lower options for the cut score that may allow for the influence of outside factors on test taker performance. Since factors unrelated to test knowledge can impact test performance, such as personal issues, the SEM is used as a way to estimate a "true score" of the test-taker who has the knowledge to pass an assessment should receive if all other factors are nullified.

True score. Hypothetical score a test-taker should receive on the test if all factors such as fatigue and sampling error are held as constants (Thorndike, 2005). The smaller a Standard Error of Measurement, the more accurate a test is at estimating a test taker's true score.

\section{Significance of the Study}

\section{Practice}

Impact on educator preparation programs. In addition to individual PSTs, Missouri Content Assessment scores had an impact on Missouri educator preparation programs. The Department of Elementary and Secondary Education (DESE) was the accrediting body for Educator Preparation Programs (EPP) in Missouri. DESE began to use data benchmarks, including scores on the Missouri Content Assessment, to determine which EPPs stay open (DESE, 2014a). DESE's benchmark for a program's aggregate scores on the Missouri Content Assessments was an $80 \%$ passage rate within the PST's first two attempts (DESE, 2014a). In other words, at least $80 \%$ of program completers needed to pass a Missouri Content Assessment to meet DESE's benchmark. If an EPP 


\section{QUANTITATIVE ANALYSIS OF MCA}

did not meet this benchmark the EPP began a three year process of focused improvement (DESE, 2014a). If an EPP did not meet the $80 \%$ benchmark within three years, the Missouri State Board of Education began proceedings to close that program. So, aggregate passage rate for the Missouri Content Assessments were vital to EPPs in Missouri.

Minority-serving institution educator preparation programs. MinorityServing Institution (MSI) EPPs were vital to the development of competent multicultural pedagogy (AACTE, 2013; Brooks et al., 2012). However, PSTs at MSI's typically performed worse on educator preparation standardized exams than PSTs at non-MSI institutions (Steinberg \& Weiner, 2015). DESE was evaluating educator preparation programs on whether PSTs were able to pass the Missouri Content Assessments (DESE, 2014a). If EPPs did not meet state benchmarks for Missouri Content Assessment passage rates, DESE began proceedings to remediate the program or close the EPP within three years. Therefore, it was vital that assessment scores did not have significant differences based on MSI status. Otherwise, these MSI's may been more likely to close and the state would have lost resources vital to effective multicultural pedagogy among teachers.

\section{Scholarship}

Achievement gaps by race/ethnicity. The achievement of a high school diploma was a vital factor toward long-term economic independence. High school dropouts were $20 \%$ less likely to be employed than high school graduates (Sum, Khatiwada, McLaughlin, \& Palma, 2009). High school dropout rates fell overall in recent years but were still higher among African American and Hispanic students (Cataldi, Laird \& KewalRamani, 2009). 


\section{QUANTITATIVE ANALYSIS OF MCA}

There were many barriers to high school diplomas for students of color (Annie E. Casey Foundation, 2006; Boser, 2014a; Cataldi, Laird \& KewalRamani, 2009; National Center for Education Statistics, 2010). Racial stereotypes perpetuated an achievement gap between students of different races (Kellow \& Jones, 2008). Sometimes even counselors and school administrators acted as barriers to Hispanic males finishing high school (Clark, Ponjuan, Orrock, Wilson \& Flores, 2013).

Teachers of color had a positive impact on student success (Goldhaber \& Hansen, 2010; Steinberg \& Weiner, 2015). This phenomenon has been termed cultural synchronization (Steinberg, 2015). Through cultural synchronization, teachers of color were found to teach students of color more effectively than White teachers who scored higher on standardized teacher exams (Goldhaber \& Hansen, 2010).

Achievement gaps by gender. Edmonds (2014) found statistically significant differences between male and female PST scores in the MoGEA. Female PSTs scored lower on all MoGEA subtests except for the writing subtest. This was typical, based on research indicating that females did not perform as well in science and math standardized exams than male students, even if the female students received higher course grades in these areas (Halpern et al., 2007; Louis \& Mistele, 2012). The study sought to determine if there were similar significant differences in scores related to gender in the Pearsondeveloped Missouri Content Assessment as those found in the Pearson-developed MoGEA.

\section{Summary}

Previous research has shown that African American, Hispanic and female college students were less likely to score well on Pearson's standardized gateway exam to enter 


\section{QUANTITATIVE ANALYSIS OF MCA}

educator preparation programs in Missouri, the MoGEA (Edmonds, 2014). Pearson also developed the Missouri Content Assessments, which acted as teacher certification exams for new Missouri teachers. If there were significant differences based on whether or not the PST identified with a historically marginalized population, these content assessments may have also reduced teacher diversity in the state. This study endeavored to determine if there was a significant difference in PST scores on the Missouri Content Assessments based on PST race, ethnicity, gender, educator preparation program selectivity and whether the program was in a Minority Serving Institution.

The researcher requested anonymous PST data from Missouri educator preparation programs. This included Missouri Content Assessment scores, PST race, ethnicity and gender, all analyzed with a quantitative analysis. The significance of this study included potential influence on Missouri PST testing policy. This could have included modification of these tests or passing scores to improve validity. Finally, the hope was that K-12 students of color would be positively impacted by an influx of qualified teachers of color who were not invalidly and unnecessarily removed from the teaching pool. In a new era of increased national racial tensions, any improvement in the ability of students of color to complete high school should be seen as a valuable boon to increasing equity. 
QUANTITATIVE ANALYSIS OF MCA

\section{SECTION TWO}

\section{PRACTITIONER SETTING FOR THE STUDY}

The Department of Secondary Education (DESE) had a goal to become a top 10 program by 2020 . A goal of this "top 10 by 20 " initiative was to develop effective educators (DESE, 2016f). Ensuring this development within DESE falls under the purview of the Office of Educator Quality (DESE, 2016d). The Office of Educator Quality sought to:

- Set standards for the development of all pre-service educators

- Accredit educator preparation programs in Missouri

- Issue certificates to educators in the Missouri school system

- Assist with the review of certificate-holder misconduct

- Develop evaluation models for school personnel

- Deliver educator development programs for current educators at the state level

There were a variety of routes to prepare a pre-service educator to meet state standards and reach certification requirements (DESE, 2016e). These included the "traditional" route of a brick and mortar Institutions of Higher Education (IHE). This included completing all requirements for a degree that was created to prepare PSTs for the rigors of becoming an educator. Individuals could have also followed an alternative route. An individual who held a degree in a content area could have completed an abbreviated program meant to prepare them for the DESE teacher certification exam. Many of these alternative certification programs were also housed in brick and mortar IHE's. Once certified to teach, these completers were free to teach in Missouri. A more 


\section{QUANTITATIVE ANALYSIS OF MCA}

formalized version of the alternative route option was the nationally-used American Board of Certification for Teacher Excellence (ABCTE) (American Board, 2016). ABCTE was a for-profit organization. Educators could have also completed certification requirements for temporary authorization, as an out-of-state applicant and also after completing a doctoral program in a content area. However, the most common routes were traditional and alternative certification, whether through a Missouri IHE or a national for-profit organization.

\section{History of the Organization}

\section{Department of Elementary and Secondary Education}

The Missouri State Board of Education was added to the Missouri constitution in 1945 (DESE, 2016a). The board of education set policies for DESE (DESE, 2016c). Since 2010, the goal of DESE has been to develop a continuous improvement model that would bind together disparate centers of education: public schools, educator preparation programs and professional organizations (Hairston, 2014).

\section{Educator Preparation Program History}

In 1842, Missouri State Superintendent of Public Schools Minor reported on the need for "Encouragement of Teachers" (Phillips, 1911). The superintendent reported that Missouri needed to prepare individuals to be teachers through the use of "Normal Schools", which were used successfully to prepare teachers in Holland and Prussia. These pleas continued throughout the tenure of several more state superintendents until Superintendent Davis in 1855. Superintendent Davis outlined a plan for the state to cover the expense of selecting and educating prospective teachers. This was followed with a similar plea in 1857 from the state teachers' association. The association requested that 


\section{QUANTITATIVE ANALYSIS OF MCA}

Normal Schools, outside of other IHE's, be developed to help cultivate effective teachers. The Civil War promptly ended these aspirations and following 1865 the process of building public support and planning outside of the Missouri legislature had to begin again. Finally, after Superintendent Parker made a plea in 1870, and the establishment of a successful, privately-funded Normal School in Kirksville, Missouri, the state granted funds for the purpose of creating and sustaining Normal Schools. The schools ran year round using four 10-week semesters, including a week off for Christmas. The Normal Schools supplied teachers through five districts, including the Northeast area, the Northwest, Southeast, Southwest and Central Missouri. Lincoln Institute, specifically created to educate African Americans, was created in 1866 from donations of Black Civil War soldiers. Taken over by the state in 1870 , a program to create teachers was always part of its mission (Phillips, 1911).

In 1909, the consideration of a "certification" for teachers came into mind during a meeting of state education leaders in St. Louis (Phillips, 1911). If, among other steps, a student could complete an A.B. degree, the student could receive a three year teaching certificate. These teachers then received a lifetime certification upon completion of at least 16 months of successful teaching during that time.

Teacher requirements tended to loosen or become more stringent based on the number of individuals in the profession. For instance, while the American Council on Education first put forth a National Teacher's Examination covering content in the 1930's, following a teacher shortage at the beginning of World War II, many superintendents loosened teacher requirements in order to fill spots (Ravitch, 2003). 


\section{QUANTITATIVE ANALYSIS OF MCA}

These teacher requirements again tightened following the launch of Sputnik in 1957 (Williams, 2009). Teachers were blamed in part for American science falling behind that of the Soviet Union. With these condemnations, and also noting that traditional EPPs were not attracting enough PSTs of color to education, alternative certification routes were touted as a way to lure both PSTs of color and experts from other fields into teaching (Haberman, 1991). At the time of writing, there were 41 EPPs in Missouri and many included an alternative certification pathway (Hairston, 2014).

In order to track the success or failure of these new endeavors, a data strategy was devised (Hairston, 2014). This called for the creation of a "Missouri Comprehensive Data System.” Through this system, Educator Preparation Program (EPP) would be assessed using an Annual Performance Report. If program PSTs performed well on the assessments included in this report, programs would be allowed to continue functioning. However, if a program's assessment scores fell below accepted benchmarks that EPP would begin a three year period of review. If improvements were not made, these programs would face closure at the end of three years.

\section{Organizational Analysis}

Bolman and Deal (2008) intimated that organizations could be viewed using the following frames: symbolic; structural; human resources; and political. Following the conceptual framework of accountability, the two organizations reviewed in this study were an accounter and accountee. In this case, the accountee was Missouri EPPs. The accounter was DESE. 


\section{QUANTITATIVE ANALYSIS OF MCA}

\section{Symbolic Frame}

The symbolic frame consisted of the development of a culture, complete with symbols and ceremonies meant to pass on this culture (Bolman \&Deal, 2008). EPPs, especially those located in brick and mortar IHE's, utilized a variety of symbolic theatre. This included student organizations, classes, buildings, and graduations. These organizations had histories, formal and informal, passed on through different procedures. Awards were given for high achievement, such as high grades or certificates. Also, different campuses had different cultures. MSI's, for instance, typically had histories that differed quite a bit from large, land grant institutions.

DESE did not have as much culture as EPPs. DESE did have activities that would traditionally be considered "symbolic." This government office in the state of Missouri awarded accreditation to EPPs. This consisted of bestowing the ability of EPPs to recommend PSTs for certification. This included a website that certification officers at all EPPs were required use. In addition, DESE provided certification to PSTs, which gave PSTs the right to teach in Missouri. This could have been viewed as a symbolic stepping stone that all teachers must complete. Beyond this, DESE did not provide much in the way of culture to EPPs or teachers.

As an accounter, DESE did not generally utilize the symbolic frame to hold EPPs accountable. DESE did not take into account the type of culture on each EPP. This was an important part of an EPP's story. EPPs that typically enrolled PSTs with a lower SES could have been held accountable using different means than an EPP that generally enrolled suburban, higher SES PSTs. DESE provided accountability services to both 


\section{QUANTITATIVE ANALYSIS OF MCA}

EPPs and PSTs, but there was little culture passed on to either accountee. Perhaps the only culture that DESE may have passed on was one of accountability.

\section{Structural Frame}

EPPs followed a structured process to recruit, retain and produce teachers. These processes included instruction provided by faculty, and field experiences provided in a clinical setting where PSTs observed classrooms and practiced teaching. A final clinical experience, known commonly as student teaching, was typically completed. During student teaching PSTs completed twelve to sixteen weeks of supervised teaching practice. The PSTs partnered with and were supervised by a representative from the local EPP and an on-site cooperating teacher who worked at the school in question. Student teaching was a requirement for alternative certification programs as well as traditional programs. In the case of alternative certification EPPs, the PST was already teaching, typically with a temporary certification, and so completing this student teaching requirement would have been convenient for them. PSTs completed coursework, received grades and completed clinical experiences. If a PST was successful at all of this, the PST graduated and was recommended for certification.

Through the structural frame DESE acted as accounter for both PSTs and EPPs. DESE's structure did not affect PSTs until the PSTs were recommended for certification by EPPs. At that point, DESE either complied or denied the recommendation. The PST was contacted by DESE and could either begin to teach or was required to pass further assessments. Regarding EPPs, DESE's structure operated through the use of an Annual Performance Report (APR). DESE has mandated EPPs provide PST completer 


\section{QUANTITATIVE ANALYSIS OF MCA}

assessment data on an annual basis. These data were reviewed and if EPPs did not meet preset benchmarks DESE began a three year process of remediation or closure.

\section{Human Resources Frame}

The human resources frame was defined by the development of individuals. Since the main goal of EPPs is the development of teachers, these institutions were linked strongly with the human resources frame. This link was intrinsic whether the EPP was traditional, located in brick and mortar institutions of higher education, or an alternative program. Traditional EPPs, generally through course instructors, on-site supervisors and K-12 students with whom PSTs interacted, individually worked with PSTs to find weaknesses and develop these until the PSTs were effective educators. Different alternative certification EPPs may have offered differing levels of support. These alternative programs developed educators who were already employed as teachers but had not completed a preparation program. Alternative certification programs required that PSTs attended some classes and complete commensurate coursework. Then, like traditional programs, PSTs were required to pass any state-required assessments. The role of a cooperating or mentoring teacher or teacher was vital in this process regardless of how the EPP functioned.

Regarding DESE, the Office of Educator Quality ensured that PSTs were fully prepared to teach by reviewing assessment data. While acting as an accounter, DESE did little to develop these PSTs. DESE focused on making sure that PSTs passed all required assessments, but did not seek out these PSTs and provide means to improve themselves. Likewise, DESE did not provide resources to develop EPPs, but only acted as an accounter through the use of the Annual Performance Report (APR). 


\section{QUANTITATIVE ANALYSIS OF MCA}

The frame most closely associated with cultural synchronicity was human resources. The human resources frame focused on developing individuals to their utmost abilities (Bolman \& Deal, 2008). The use of cultural synchronicity in Pk-12 classrooms has led to more positive academic and disciplinary outcomes for students of diverse backgrounds (Goldhaber \& Hansen, 2010). So, strategies that improved the likelihood of cultural synchronicity in classrooms improved a school in the human resources frame. Additionally, ensuring that PSTs from diverse backgrounds finished their EPP programs and reached the teaching field was another implementation of the human resources frame. These PSTs were developed to their fullest potentials and then provided many positive impacts in the world at large.

\section{Political Frame}

The political frame focused on the use of power within an organization to determine who accessed finite resources (Bolman \& Deal, 2008). Within EPPs, there may have been power struggles between either IHE faculty or clinical supervisors and PSTs. Faculty and supervisors had legitimate, expert power over PSTs, and could potentially negatively influence PSTs. However, PSTs were not competing with faculty or supervisors for resources. These types of competition did exist between EPPs. EPPs competed for a finite number of PSTs and state funding. To that end, bigger EPPs with more funding sources could have done more through recruitment strategies to ensure large numbers of PSTs enroll. In addition, larger EPPs could have afforded to hire assessment professionals or purchase software to track data and ensure PSTs were prepared for any assessment. 


\section{QUANTITATIVE ANALYSIS OF MCA}

The political frame was most closely associated with accountability theory. The political frame was focused on the use of types of power to acquire and use limited resources (Bolman \& Deal, 2008). By using legitimate power, the MOSBOE has made policy initiating the use of the MEGA suite of assessments, including the MCA (DESE, 2014b). DESE has implemented this policy. The accounter, in this case DESE, monitored EPP and PST performance on the MCA and provided rewards or punishments based on results.

DESE wielded a great deal of political power over EPPs. As accounters, this was self-evident. However, if DESE enacted policies that award some EPPs and punish others based on the diversity of their PST student body this would have been a misuse of political power. An example would have been if EPPs were held accountable with PST assessment data, and PSTs from traditionally marginalized populations historically performed worse on these assessments. This would have been severely detrimental use of political power for EPPs that catered to these PSTs, especially MSI's.

\section{Leadership Analysis}

The relationship between DESE, EPPs and PSTs was viewed through different lenses of leadership theory. These different theories of leadership were known as the styles approach, path-goal theory and action-logic steps put forth in the Harvard Business Review. Below is a review of how DESE utilized these theories to act as a leader for both EPPs and PSTs.

\section{Leadership: Styles Approach}

The styles approach described behaviors related to leadership as either task behaviors or relationship behaviors (Northouse, 2013). Task behaviors focused on 


\section{QUANTITATIVE ANALYSIS OF MCA}

achieving the goals of the group while relationship behaviors centered on making team members feel comfortable and secure. The use of these types of behaviors led to the development of a "Leadership Grid" put forth by Blake and McCanse (1991). This grid acted on an axis of levels of task and job requirements, known as "Concern of Results" and people-centered requirements, known as "Concern for People." Low concern for results and concern for people was known as "impoverished leadership", whereby team members neither felt safe nor were developed, and where results were not reached. The opposite end of that spectrum was "team management" where high concern for people and high concern for results led to a high-functioning team where all members felt valued and developed.

Using the styles approach as a template, the leadership put forth by DESE could have best been described as high concern for results and low concern for people. DESE was focused on using an accountability structure to ensure that EPPs and PSTs completed required functions, in this case meeting requirements for accreditation and certification. DESE did offer a wide variety of webinars and supports, however these were all linked to ensuring EPP and PST accountability (DESE, 2015b). DESE, as an entity, did not offer supports for PSTs nor resources for EPPs to develop as institutions. In Northouse (2013), this was known as Authority-Compliance Management. Under this style, leaders saw followers solely as instruments to complete a task (Northouse, 2013). According to Northouse, DESE could have received better results while focusing on how to take more interest in relationships and developing both the EPPs and PSTs. 


\section{QUANTITATIVE ANALYSIS OF MCA}

\section{Leadership: Path-Goal Theory}

Another leadership theory DESE implemented was Path-Goal Theory (Northouse, 2013). Under this theory, leaders attempted to determine how to properly motivate followers in order to achieve goals (Northouse, 2013). Based on expectancy theory, Path-Goal Theory assumed subordinates will only be motivated enough to complete tasks if subordinates: felt qualified and prepared for the task; believed tasks would end with a specific outcome; and believed efforts would result in sufficient reward. As in the name of the theory, leaders led subordinates down a path on the way to a goal. However, obstacles appeared. It was up to the leader at that time to determine the best way to motivate subordinates to overcome this obstacle. The leader took into account the characteristics of subordinates and the task at hand, and then used them to determine which type of motivation would best inspire the subordinates to overcome the obstacle. The leader then defined goals, clarified the path, removed obstacles and provided support to get the subordinate to the goal.

While Path-Goal theory defined different leadership behaviors, DESE's behavior most closely resembled the behavior denoted as "Directive." Under directive behavior, leaders provided very clear standards of what needed to be done and how to do it. This type of behavior worked well for followers who are dogmatic and when tasks were confusing and complex. This leadership style may work best for DESE's situation.

What creates a good teacher is complex. A teacher cannot just be someone who is intelligent, but also someone who can communicate and relate to students. In turn, the work of an EPP is complex. Developing teachers is not just a matter of coursework. PSTs must be given opportunities for field experience and feedback from education 


\section{QUANTITATIVE ANALYSIS OF MCA}

experts on how to improve while maintaining motivation. Therefore, DESE has put forth well-defined standards for teachers (DESE, 2013), and clear expectations for EPPs through the APR process. Therefore, the use of a directive leadership approach in the Path-Goal theory of leadership by DESE is a good fit.

\section{Leadership and Action Logic}

The Harvard Business Review published an excellent article indicating that effective leadership should be developed over time (Rooke \& Torbert, 2011). The article outlined seven types of "action logic" that leaders used to make decisions and motivate subordinates. To become more effective, leaders moved down a continuum from less effective to more so. The lowest level of action logic put forth in this article was “opportunistic." This type of action logic was defined by mistrust and egocentrism. These leaders focused on wins for themselves and used any means necessary to reach goals. Followers were typically miserable over the long term. While this was the lowest point on the spectrum, six steps higher was the "alchemist" action logic. Leaders who used this kind of logic typically strove for system-wide or society-wide change, and altered organizations innovatively. Leaders could have used different types of logic depending on the situation and used methods outlined in the article to progress along the continuum.

The research defined DESE's managerial style in this paradigm as "achiever." Achievers focused on deliverables and created a positive work environment. While this type of logic was focused on achieving goals, it did not lend itself to innovation. Achiever was more of a managerial style than a leadership style. Achievers met goals, of which DESE certainly had many. 
QUANTITATIVE ANALYSIS OF MCA

\section{Implications for Research in the Practitioner Setting}

This study could lead to more research based on EPP and PST accountability measures and the impact these measures and their associated policies had on cultural synchronicity.

\section{Accountability}

The relationship between the accounter parties in Missouri educator preparation and those identified as the accountable should be studied. Accounters set policy, require data from accountable parties, and in return provided punishments or rewards (Anderson, 2009). In this case, MOSBOE and DESE qualified as the accounters. DESE collected data from both accountable parties in this case. These parties were the EPPs and PSTs. PSTs passed each subtest of the Multi-Content Assessment and once achieved, along with other requirements, DESE granted teacher certification (DESE, 2014b). EPPs were required to reach an $80 \%$ passage rate in the Multi-Content Assessment for their program completers, or DESE began a three year period to remediate the issue or potentially close the program. These relationships could be researched more following this study. For instance, if the Multi-Content Assessment was shown to disproportionately remove PSTs from historically marginalized populations or to disproportionately punish EPPs with a more diverse PST population, then these assessments or their impact should be studied more deeply. Changes to policies enforcing these accountability relationships may reduce the percentage of diverse PSTs removed from the workforce. Likewise, EPPs that cater to PSTs from traditionally marginalized racial, ethnic and gender groups would be less likely to face closure due to assessment results.

\section{Cultural Synchronicity}




\section{QUANTITATIVE ANALYSIS OF MCA}

In addition to accountability, findings from this study could lead to further research on cultural synchronicity in Missouri elementary schools. If this study indicated that the Multi-Content Assessment removed more teachers from the workforce from historically marginalized populations, future studies could track the impact of all MEGA assessments on cultural synchronicity in Missouri. Direct benefits of cultural synchronicity, like high school exam scores and teacher shortages in hard to teach areas could be studied ( Jonsson 2003; Pitts, 2007).

\section{Summary}

DESE utilizes a leadership style that was directive, focusing on explicit outcomes with little focus on individual people involved in the process. As a state leader in the teacher development process, DESE was described as an achiever. From this paradigm, DESE was again focused on goal achievement as opposed to follower development. Finally, another paradigm designated DESE's managerial style as authority-compliance. From this standpoint, DESE's goal as a leader was to ensure that followers complied with their requirements, as opposed to ensuring development or improvement on the part of the follower. 


\section{SECTION THREE \\ SCHOLARLY REVIEW \\ Introduction to the Problem}

The Department of Elementary and Secondary Education (DESE) required PSTs to pass the Missouri Content Assessments before receiving certification to teach in the state (DESE, 2014b). These assessments were developed by Pearson, a large testdevelopment company (Evaluation Systems Pearson, 2009). Pearson also developed the Missouri PST program entry exam, the Missouri General Education Assessment (MoGEA) (DESE, 2014b). Recent research by Edmonds (2014) indicated that African American, Hispanic and female PSTs were statistically less likely to score well on the MoGEA than male PSTs from other races and ethnicities. Therefore, PSTs from these populations were less likely to enter an educator preparation program, and were consequently less likely to become a teacher in Missouri. The required certification exam for PSTs at the end of Education Preparation Program (EPP) was the Missouri Content Assessment. If PSTs from historically under-represented groups were less likely to pass the Missouri Content Assessment, and these scores were not linked to teacher success, then these new certification exams were an unnecessary barrier to producing more diverse teachers in Missouri.

In addition, DESE tied Missouri Content Assessment results with EPP accreditation (DESE, 2014a). According to DESE benchmarks, if an EPP had fewer than $80 \%$ of its program completers pass Missouri Content Assessments within two attempts, proceedings began over a three year span to either remediate the situation or close the 


\section{QUANTITATIVE ANALYSIS OF MCA}

EPP. If the Missouri Content Assessments score achieved by PSTs from traditionally marginalized populations was significantly lower than those achieved by other PSTs, then EPPs with more diverse PST populations were more likely to be closed. This would have had the largest impact on Minority Serving Institutions (MSI) and Educator Preparation Programs with lower selectivity levels.

\section{Purpose of the Study}

The purpose of this study was to fill the gap in knowledge related to determining whether there were differences in Missouri Content Assessments scores based on:

-PST race, ethnicity, or gender

-PST preparation program selectivity or status as a Minority Serving Institution If differences were found in any of these areas, the researcher attempted to determine the impact of alternative exam cut scores on passage rates.

\section{Conceptual Framework}

\section{Accountability}

According to Anderson (2009), the conceptual framework of accountability rested on the premise that accountability is a relationship. This relationship was based on a belief that individuals must justify themselves to others (Scott \& Lyman, 1968; Semin \& Manstead, 1983; Tetlock, 1992). As part of this relationship, there was an implication that individuals who did not properly justify themselves should have received some sort of negative consequence. Depending on the situation and culture, these varied from social discomfort to loss of life (Stenning, 1995).

This may have caused EPPs to use what Anderson (2009) terms "avoidance strategies." For instance, an EPP facing closure due to low assessment scores may have 


\section{QUANTITATIVE ANALYSIS OF MCA}

felt the need to require that PSTs pass a Missouri Content Assessment before program completion. While this EPP would have a 100\% success rate, this result would not reflect the EPPs ability to create successful PSTs.

All accountability rested on the premise of causation (Anderson, 2009). Input A caused output B. This method of accountability assumed causation that was both linear and surface-level. An EPP provided such and such courses, all PSTs passed, and because of these courses all PSTs should now pass the Missouri Content Assessment. This type of accountability focused mainly on indicators that were easily measured and understood.

\section{Cultural Synchronicity Theory}

In addition to the lens of accountability, this study also focused on an emerging concept known as cultural synchronicity. According to Irvine (1990), this concept was the cause of many favorable academic and behavioral outcomes experienced by Pk-12 students when matched with teachers of similar cultural backgrounds (Goldhaber \& Hansen, 2010; Steinberg and Weiner, 2015, September; Villegas \& Irvine, 2010). This matching effect was more impactful for students from historically marginalized populations, such as African American or Hispanic (Pitts, 2007). Goldhaber and Hansen (2010) indicated that this matching effect was more powerful than teacher subject matter assessment scores when predicting Pk-12 student success.

\section{Elementary Education Pre-Service Teachers}

Elementary education teachers receive different preparation depending on the location of their EPP. This section will discuss the differences in preparation based on whether it was received outside of the United States or within, and also if it was received 


\section{QUANTITATIVE ANALYSIS OF MCA}

in Missouri. In addition, this section will review an ongoing discussion in Missouri as to whether there is a surplus of elementary teachers depending on environment.

\section{International Elementary Education Pre-Service Teachers}

A variety of studies offer different perspectives on what makes a successful elementary education teacher. In a study from Portugal, the quality of teacher student interaction is this most important factor (Cadima, Peixoto, \& Leal, 2014). This examination included classroom, teacher and school level variables in 115 classrooms. There was a small effect of teacher education on the quality of teacher-child interactions. Teachers with an advanced degree were more likely to be more emotionally sensitive and to have better instructional interactions in the classroom. For school-level characteristics, findings showed that the classrooms in private and smaller schools were likely to provide higher levels of emotional, organizational, and instructional quality. The results suggest that focusing on the interactions between teacher and children can provide valuable information to enhance elementary classroom quality.

An elementary PST must be properly motivated (Dundar, 2014). A study from Turkey indicated that women were more likely to be elementary PSTs than men. Female PSTs were more likely to be motivated by the chance of working with children and guiding their future development. Also, female PSTs had a more positive view of teaching than male PSTs. The study found that teaching was not a "fall back" career for these PSTs but a first choice, and that most were satisfied by their choice in career. So, elementary education PSTs were more likely to be female, and their views of teaching and motivations to teach were difference from male PSTs. 


\section{QUANTITATIVE ANALYSIS OF MCA}

Perceptions of self were also important to teacher success, according to studies. Cayci (2011) ran a study of 366 PSTs from the nation of Turkey to determine the impact of self-efficacy on teacher success. Self-efficacy was defined as a sub set of self-concept. It related to the positive and negative self-view someone has of their skills and other attributes. According to the results there is a positive and meaningful relationship between the elementary PSTs' teacher efficacy and their attitudes towards the profession of teaching.

\section{National Elementary Education Pre-Service Teachers}

The Council on the Accreditation of Educator Preparation (CAEP) is currently the only national, widely-used accrediting body for EPPs (Council on the Accreditation of Educator Preparation, 2013). CAEP requires that EPPs pass five standards related to: PST content and pedagogical knowledge; clinical partnerships and practices provided to PSTs; PST quality, recruitment, and selectivity; program impact on the learning of PK-12 students; and provider quality assurance and continuous improvement through assessment. Each standard includes quality indicators as well that more specifically outline the responsibilities of an accredited EPP. While CAEP accreditation is not mandatory these standards heavily impact the preparation of elementary education PSTs in the United States.

According to CAEP standards, PSTs must have a variety of knowledge and skills. This would include a working knowledge of the Interstate Teacher Assessment and Support Consortium (InTASC) standards, a set of standards that are separate from CAEP. InTASC is a consortium of state and national organizations and agencies with the goal of reforming the educator preparation process. The ten InTASC standards are split into the 


\section{QUANTITATIVE ANALYSIS OF MCA}

following four areas: the learner and learning; content knowledge; instructional practice; and professional responsibility. Other areas elementary PSTs must be knowledgeable in according to CAEP standards include: content and pedagogical knowledge; using technology in the classroom; and having appropriate dispositions for the teaching profession.

In addition, CAEP PSTs must be assessed at the recruitment, admission and completion level. CAEP standard 3.1 requires that each EPP develop a plan to recruit PSTs from diverse backgrounds. Standard 3.2 shifts from recruitment to admission and focuses more on academic achievement related to the ACT. This includes increasingly high expectations of PST achievement in comparison with nationwide performance on this assessment. Standard 3.2 requires that students admitted in $2016-2017$ be from the top 50\% of all ACT scores. In 2018-2019, this requirement rises to the top $40 \%$ and in 2020 rises to the top $33 \%$. According to ACT data provided earlier, this would certainly impact the likelihood of PSTs of color, even if they were heavily recruited, from gaining admission to an EPP.

A quick view of data from this study can illuminate the disparate impact of CAEP standards on PST diversity. As a comparison, 37 students who reported a race of African American or ethnicity of Hispanic/Latino in this study had cumulative ACT scores included in their data. According to recent ACT data, a cumulative score of 20 is at the $50^{\text {th }}$ percentile (ACT, 2016). If PSTs in this study with a score of 20 or below were removed from this dataset, 23 of the 37 would have not been able to meet minimum CAEP requirements for admission. That is a loss of $62 \%$ of the diverse PSTs included in this study. By comparison, of the 679 PSTs who did not identify as African American or 


\section{QUANTITATIVE ANALYSIS OF MCA}

Hispanic/Latino, 196 would have not have met minimum admission requirements. This is a loss of only $29 \%$ of PSTs who were not from a historically marginalized racial or ethnic group.

Selectivity levels in CAEP standards 3.4 and 3.5 remain high during PST preparation and completion. As in other standards, PSTs are assessed by content knowledge, pedagogical knowledge, skills and technology integration. However, in this case the PST's development throughout the program must be assessed. At completion the PST must be assessed for content knowledge, teaching effectiveness, and knowledge of laws, policies and ethics. This assessment of content knowledge would generally include a standardized exam like the Missouri Content Assessments.

CAEP standard 4 focuses on measures related to the success of the PST after EPP completion and once the PST is hired in a teaching position. Elementary education teachers must show that they have had an impact on student learning. In addition, elementary education teachers must show that they can apply professional knowledge and skills and dispositions. Finally, data must be collected from both the teacher and their employer on how satisfied they are with the elementary education teacher's preparation.

\section{Missouri and Elementary Education Pre-Service Teachers}

While CAEP accreditation is voluntary, all Missouri EPPs must be accredited by DESE in order to recommend elementary education PSTs for certification to teach in Missouri. DESE has also defined what makes a successful beginning elementary teacher. DESE indicates that, to become certified to teach in Missouri, an elementary education PST must complete and pass all assessments that fall under the umbrella of the Missouri Educator Gateway Assessments (MEGA) (Department of Elementary and Secondary 


\section{QUANTITATIVE ANALYSIS OF MCA}

Education, 2014b). This includes: a general education assessment (MoGEA); a workstyles inventory (MEP), a performance assessment (MoPTA), an observation form based directly on DESE standards (MEES) and a content knowledge assessment (Elementary Education Multi-Content Assessment). The cost of these assessments total $\$ 456$ at a minimum. If the PST decides to take any of the MoGEA subtests or Multi-Content Assessment subtests separately, or needs to retake any of these subtests after a failed score, these rates increase $\$ 97$ per subtest. In addition, if a PST needs to resubmit any of the four tasks included in the MoPTA, this includes an $\$ 85$ cost.

In addition to MEGA assessments, EPPs must meet standards, similar to CAEP, that are put forth by DESE (Department of Elementary and Secondary Education, 2013). These standards were created for the purpose of assessing Missouri teachers. However, they are also used to determine if elementary education PSTs are prepared to be certified to teach. DESE standards were developed in the form of a continuum. This gradation assumes that teachers will improve themselves as an educator according to all DESE standards throughout their careers, beginning as a PST ready to be certified. This continuum includes five levels: PST, or the level of standard proficiency that a PST should reach on a standard to be certified to teach; emerging teacher, or the level of proficiency in a standard of a new teacher; developing teacher; proficient teacher; and finally, distinguished teacher, or a teacher who has become a mentor and seeks to improve the field.

These standards cover a variety of teaching proficiencies, but in many respects are similar to CAEP standards. The main difference is that CAEP standards focus on the PST and the EPPs ability to train and assess the PST, while DESE standards focus solely 


\section{QUANTITATIVE ANALYSIS OF MCA}

on the PST's skills and abilities. The DESE standards cover: content knowledge; student learning, growth and development; curriculum implementation; critical thinking skills; how to develop and maintain a positive classroom environment; how to use effective communication; how to assess and analyze student data; professionalism; and how to collaborate as a professional. Again, PSTs must complete and pass all MEGA assessments in order to prove competency at the "PST" level of all DESE standards. This indicates to DESE that PSTs are prepared to be certified to teach in Missouri.

\section{Successful Preparation of Elementary Teachers}

There are some commonly-accepted strategies to prepare elementary teachers. For instance, elementary education PSTs in Missouri must pass all MEGA assessments (Department of Elementary and Secondary Education, 2014b). Assessments of these type are common to many states. The MEGA assessments as a whole cover general education, content knowledge, teaching performance, and observation data. Besides these factors, many other attributes are commonly included in the preparation of successful elementary education teachers.

A Nation at Risk has been used as a foundation when considering the requirements of an effective elementary education teacher (National Commission on Excellence in Education, 1983). This source included proper classroom management and content knowledge as vital to proper preparation. A Nation at Risk was less supportive of methods of teaching courses, citing these as time that could be better spent preparing PSTs with content knowledge.

Field experiences for PSTs are widely regarded as a valid preparation strategy. Ransdell and Maxwell, (2006) indicate that it is difficult to transition an undergraduate 


\section{QUANTITATIVE ANALYSIS OF MCA}

college student learner into a teacher. But, field experience is the key to this transformation. Ransdell and Maxwell (2006) further indicate that to maximize the effectiveness of these experiences, the PST should be assessed by EPP faculty and on-site cooperating teachers. In Missouri this function is completed using the MEES observation forms mandated by DESE (Department of Elementary and Secondary Education, 2014b). These experiences must be guided. These PSTs should be given the opportunity to struggle and improve in the field. Falk (2011) also indicates that formative assessments results during field experiences are tightly linked to pedagogical knowledge. So, while a Nation at Risk argues that less time needs to be spent on pedagogical training for PSTs, more recent research asserts that pedagogical knowledge is directly linked to success in field experiences, one of the most valid portions of PST preparation.

In addition to providing field experiences, preparation programs should also instruct PSTs on how to properly use technology in the classroom. Farnsworth, Shaha, Bahr, Lewis and Benson (2002), outline a study based on results from a Preparing Tomorrow's Teachers to Use Technology Grant. This study split up techniques to teach elementary students about levers in three categories: use of multimedia tools, specifically a system called HyperStudio; internet usage; or a control group with no technology. Groups who used the multimedia tool or the internet greatly outperformed those in the control group. However, a measure of positive attitude improvement for groups using technology, either internet or multimedia, was lower than groups of students who were instructed with traditional means. The researcher suggested this is because of added stress students may have in learning new technology. The researchers concluded that teachers must know how to weave technology in a lesson plan to increase student 


\section{QUANTITATIVE ANALYSIS OF MCA}

knowledge and also the teacher must help students understand new technology and address it with an appropriate attitude.

While field experience and technology are required of all elementary education PSTs, DESE's equity plan notes that the need for elementary teachers falls mainly in highly diverse, high poverty, and typically urban schools. So, practices used by EPPs to prepare PSTs for these populations and environments must be reviewed.

\section{Reported Surplus of Elementary Teachers}

Some sources have indicated that the supply of elementary education teachers has out grown the demand (Katnik, 2016). This would deem as unnecessary any efforts to increase the number of elementary education teachers. However, others note that elementary education teachers with specific backgrounds and skills are very much in demand in certain Missouri schools (DESE, 2015a).

Nationally, a higher education data collection systems known as the Integrated Post-Secondary Education Data System has stated that since 1987 the number of new teachers has nearly doubled from roughly 160,000 to 305,000 (Katnik, 2016, January).

But, teachers who are hired annually dropped since 1999 from 120,000 to 100,000. This indicates a supply that has outstripped demand on an annual basis. Current data also suggests that large class sizes are no longer a factor driving teacher production, as the current national student to teacher ratio is 16 to 1 , with a ratio in Missouri of 17 to 1 (America's Teaching force, 2015). Other research indicates that vacancies specifically for elementary teachers have decreased since 1999 (Goldhaber et al., 2015). This is the case in Missouri. 


\section{QUANTITATIVE ANALYSIS OF MCA}

Missouri labor market data indicates that while many teaching content areas need more educators annually, since 2005 there has not been a lack of elementary education teachers (Katnik, 2016, January). But, in 2014 and 2015, elementary education teachers accounted for $37 \%$ and $40 \%$ of new teacher certifications in the state respectively. This would indicate a supply surplus in Missouri. Most teaching content areas with shortages in Missouri were either Spanish or STEM teaching.

Since 2009-2014, 9,316 completers from Missouri EPPs have not found teaching jobs (Katnik, 2016, January). This, however, did not include PSTs who either found jobs in private schools or out of state. DESE has created an adjusted supply and demand table indicating which content areas were in the highest need which took into account recent completers who may be taking time off before searching for employment. The lowest supply and demand ratio was .37 for special education teachers. In that case, only $37 \%$ of open positions for special education teachers have a new program completer available for hire. The highest supply and demand ratio was 1.48 for elementary education positions. This would mean that $148 \%$ of potential elementary education teaching positions have a new completer available.

Evidence for the need for elementary education teachers. Other sources indicate a great need for qualified elementary education teachers. One recent national report indicates that while the creation of teachers has increased overall, the ratio of new elementary teachers has leveled off or decreased since 1990 (Calder Report, 2015). The DESE Labor Market Analysis does indicate that elementary education teachers comprise a higher proportion of teacher positions in Missouri than all others, at 48\% (Katnik, 2016, January). Of these, $25 \%$ of Missouri teachers are over the age of 50 (Department of 


\section{QUANTITATIVE ANALYSIS OF MCA}

Elementary and Secondary Education, 2015c). This could signal that an older generation of teachers is nearly at retirement age. A swell of open positions could soon be available. Also, Missouri data may not have taken into account that PSTs who complete an elementary education degree may have a double major or minor that is in demand, such as early childhood education or special education. The National Center for Education Statistics (2014) indicates that the need for all new teacher hires will increase from 352,000 in 2011 to 446,000 in 2022 . The definition of new teacher in this study includes those who have may have taught previously but in a different content area.

Other data would indicate a need localized to certain environments and populations. According to the DESE Equity Plan, $14.7 \%$ of elementary education teachers in high poverty schools were less than fully qualified compared to $4.3 \%$ in low poverty schools (Department of Elementary and Secondary Education, 2015a). In addition, $4.2 \%$ of elementary teachers were teaching outside of their field in high poverty and high minority schools, as opposed to only $1.4 \%$ of elementary teachers in low poverty schools. These inequalities are not recent developments.

Specific areas of need. Public school classrooms are becoming more diverse annually while the vast majority of teachers are White (Proctor, Rentz, \& Jackson, 2001). To address this, some EPPs are attempting to better prepare White PSTs for a more diverse classroom. At least one study reports that rural White PSTs have no trepidation about working with diverse students, and feel adequately prepared for the task (Kritzer \& Ziebarth-Bovill, 2012). New technology, such as video-chat systems, have been used successfully to "bring" White PSTs to diverse settings (Phillion, Miller \& Lehman, 


\section{QUANTITATIVE ANALYSIS OF MCA}

2005). However, something still seems to be missing when students of color are not taught by teachers of color.

Sleeter (2001) completed a meta-analysis of different methods EPPs use to prepare mostly White PSTs to teach in diverse schools. Sleeter noted that most multiculturalism efforts in teacher preparation focus on PST attitudes or the lack of knowledge of White PSTs about other cultures. Sleeter noted some specific strategies that had mixed success in preparing PSTs for a diverse classroom. These included community based immersion field experiences, coursework, and program-level interventions. However these strategies commonly miss one of the most key factors related to teacher success in a diverse, urban environment. That is the recruitment and retention of more diverse PSTs.

Community based immersion programs acted like large-scale field experiences. PSTs would teach and live in diverse areas. These are typically some of the most successful programs to prepare White PSTs to teach in diverse settings. This success is dependent on preparation programs offering effective supervision.

In regards to coursework, courses based on multiculturalism were either standalone knowledge-based courses, or included field experiences. Field experiences embedded in these courses typically included tutoring and ethnographic research knowledge. All of these course based interventions showed mixed results in developing culturally-responsive educators. In programs with negative results, students interpreted inner city surroundings with preconceptions they already held. Their courses did not engage them or ask them to challenge their preconceptions. Sleeter (2001) concluded that PSTs must have the opportunity to question their cultural assumptions. 


\section{QUANTITATIVE ANALYSIS OF MCA}

Sleeter (2001) noted that program-level interventions typically included restructuring a traditional program and adding more multiculturalism. This strategy also found limited impact in preparing educators for a diverse classroom. One study showed an increase of useful strategies for culturally diverse students, but the PSTs still had trouble with deep cultural beliefs. Some PSTs just put aside what they had learned in the program and learned on the job once they began teaching. While this strategy had limited impact, university and Pk-12 school collaborations were found to have a chance to have a more wide-spread successful impact.

Sleeter (2001) noted that all of these strategies to prepare White PSTs for multicultural students and environments were important. However, these strategies were not as important as recruiting and retaining more diverse and culturally responsive PSTs. The analysis touched on many efforts to recruit more diverse PSTs into pre service programs (Becket, 1998; Brennan \& Bliss, 1998; Dillard, 1994; Littleton, 1998; Love \& Greer, 1995; Shade, Boe, Garner, \& New, 1998; Torres-Karna \& Krustchinsky, 1998; Yopp, Yopp, \& Taylor, 1992).

Villegas and Irvine (2010) agree that culturally diverse teachers are a vital piece of any strategy to decrease the achievement gap between White students and students of color. Villegas and Irvine (2010) indicate three main factors related to why the phenomena of a diverse teaching workforce improves diverse student outcomes. These are: the effect of diverse teachers as role models for diverse students; the ability of diverse teachers to build "cultural bridges" to help diverse students learn new concepts; and the positive impact that more diverse employees have on any workforce. Goldhaber and Hansen (2010) indicate that matching teachers of color with students of color from 


\section{QUANTITATIVE ANALYSIS OF MCA}

similar backgrounds can improve student outcomes. This is known as cultural synchronization. In 2007, 41\% of American K-12 students were students of color, but only $16.5 \%$ of teachers were teachers of color (Ingersoll \& May, 2011). From 1988 to 2008, the percent of minority students in American K-12 schools increased by $73 \%$, while the White student population decreased by 2\% (Ingersoll \& May, 2011).

As noted in the DESE Equity Plan, preparing PSTs for a diverse classroom is important. But, most of the diverse classrooms and many high poverty schools are in urban school districts. Buddin and Zamarro (2009) completed a study of what teacher attributes were linked to success in urban schools. Of all attributes, teacher success was not linked to certification test scores or advanced teaching degrees. The study found that success was only linked, weakly, with teacher experience. The main outcome indicated poor outcomes for teachers in their first and second year of teaching. The question then becomes how to retain new teachers in urban, high poverty, high diversity schools until they have some experience and can have a positive impact.

DESE's Equity Plan organized causes for the lack of diverse teachers and teachers in diverse settings under several headings: environmental causes; lack of proper preparation; and workforce issues. All issues under the heading of "lack of proper preparation" were caused by EPPs. DESE noted that EPPs failed to prepare PSTs to teach in challenging conditions. PSTs were not prepared to teach in content areas and grade levels with the highest needs and EPPs did not include enough field experiences in content areas of highest need. DESE believes that all of these causes need to be addressed in order to achieve true equity of teachers in Missouri. 


\section{QUANTITATIVE ANALYSIS OF MCA}

Elementary teacher certification and race. While there is a great need for diverse teachers both nationally and especially in Missouri, there are many barriers to becoming a teacher of color and also to teaching in a high-minority school. Teachers at schools with $50 \%$ or more students of color in 2003 were more likely to have lower pay, more serious student discipline issues, inadequate support from leadership and inadequate school resources, than teachers at majority White schools (Ingersoll \& May, 2011). It is also difficult to retain current teachers of color. The percent of teachers of color who left a school position has increased over time. In 1988, $15.1 \%$ of teachers of color left a teaching position, compared to $14.4 \%$ of white teachers. However, by 2008 , that percentage of teachers of color who left a teaching position was $19.3 \%$, compared to $15.6 \%$ of White teachers (Ingersoll \& May, 2011). So, even if a PST of color becomes a teacher, it is difficult to retain that teacher of color.

People of color seeking adequate education in the United States have faced a variety of obstacles. The educational opportunities offered to African American slaves were sparse. The end of the Civil War saw the development of Freedman's Bureau, a group of policymakers focused on providing adequate education to African Americans in the former confederate states (Anderson, 1988). Also, reconstruction era legislation mandated an end to the segregation of schools in 1870 . But by 1875 nearly all of these laws had been overridden by state laws placing segregation back into effect. The "separate but equal" decision of the Supreme Court in the Plessy vs. Ferguson case of 1896 indicated that even someone who was 7/8 White, and 1/8 African American, had to ride in a different train car than fully White passengers. This "separate but equal" decision spread to education as well with separate schools for African American and 


\section{QUANTITATIVE ANALYSIS OF MCA}

White students that were considered equal by law. However, this scenario often left substandard schools for African American children and African American teachers were paid less than White teachers (Ravitch, 2013).

Jim Crow schools. During the early 1900's, separate but equal education took on the form of Jim Crow schools. In the 1930's, only 2\% of Southern African Americans were considered professionals (Irons, 2004). The other $98 \%$ were share croppers, house help or factory laborers. The education Southern African Americans received ensured training for these trades but not the requisite skills to rise above them (Irons, 2004). It was not until Brown vs. the Board of Education in 1954 overrode segregation that many of these barriers were confronted for the first time. Now, African American and White students were required to have the same educational experience. However, issues related to African American education would persist despite the importance of education.

Race and high school graduation. Current high school graduation rates are currently lower among African American students, despite how vital this achievement is to quality of life. Less than $46 \%$ of young high school drop outs were employed in 2008 , compared to $68 \%$ of those that completed high school and $87 \%$ of those that completed a four year degree (Sum, Khatiwada, McLaughlin \& Palma, 2009). These figures are more startling for young African American men who dropped out of high school. Less than 1/3 of African American dropouts (31\%) were employed in 2008 (Sum, Khatiwada, McLaughlin \& Palma, 2009). In addition, 23\% of African American male dropouts were institutionalized, compared to $7 \%$ of Asian, Hispanic and White dropouts.

Race and high school performance. Students of color who remain in high school still face unequal outcomes. African American (5.5\%) and Hispanic (6.3\%) high 


\section{QUANTITATIVE ANALYSIS OF MCA}

school students were much less likely to have taken a higher order math class, like Calculus, than White students (15.3\%) in 2008 (Aud, Fox \& KewalRamani, 2010). Perhaps more distressing is that these percentages have fallen since 1998 for African American students (from $6.6 \%$ to $5.5 \%$ ). Meanwhile, the percentage of White students taking a calculus course grew during the same decade (Aud, Fox \& KewalRamani, 2010).

Even when African American and Hispanic students took AP courses, both scored lower than White students (Aud, Fox \& KewalRamani, 2010). The percentage of African American (13.6\%) and Hispanic (8.7\%) students taking the ACT in order to gain entry to college was again far below the percent of White students (68.3\%) (Aud, Fox \& KewalRamani, 2010). Finally, the average ACT score in reading and math for African American (17.0) and Hispanic (19.0) test takers was lower than the White average (21.0) (Aud, Fox \& KewalRamani, 2010).

Achievement gaps and school environment. Some of these outcomes can be explained by the differences between school districts attended by students of different races and ethnicities. In a report by Boser (2014a) school districts were ranked according to financial efficiency and whether funds were spent in areas most likely to assist student development. In these districts, Hispanic students were twice as likely to be in the least productive districts as the most productive. African American students were 8 times more likely to be in the least productive districts than the most productive (Boser, 2014a). In addition, schools with majority White students were more than twice as likely to offer advanced placement courses than schools where African American or Hispanic students were the majority (Annie E. Casey Foundation, 2006). 


\section{QUANTITATIVE ANALYSIS OF MCA}

The National Center for Education Statistics (2015) took an in depth look at why these performance gaps persist between White students and students of color as a matter of school environment. When the study accounted for SES, and other student, teacher and school variables, African American students who were at largely African American schools did perform worse than African American students from largely White schools. The most interesting finding of this study would be that the White achievement gap is more strongly related to within-school factors, as opposed to between-school factors. That would indicate that schools vary accessibility to technology, newer textbooks and more experienced teachers in a way that benefits White students over African American students.

Further studies agree that students of color were more likely to have inexperienced or ineffectual teachers (Annie E. Casey Foundation, 2006). Aud, Fox and KewalRamami (2010) investigated the differences between teachers at majority White public schools vs. majority non-White public schools. In public schools with majority African American enrollment, $75 \%$ of math teachers had a college math major or certification to teach math. If a school was majority Hispanic, $85 \%$ of math teachers had a college math major or math certification. However, at majority White schools, $92 \%$ of math teachers had a math major or certification (Aud, Fox, \& KewalRamami, 2010).

The DESE Equity Plan notes that while part of the demand for better teachers in high poverty and high diversity schools comes from workforce issues, such as teacher preference and lack of incentives for teaching in difficult to staff areas, that EPPs have also been a factor (Department of Elementary and Secondary Education, 2015a). DESE indicates that EPPs have not prepared PSTs to teach in challenging conditions, and that 
QUANTITATIVE ANALYSIS OF MCA

too few of the PSTs are qualified to teach in particular content areas. The Equity Plan also asserts that EPP clinical placements do not emphasize teaching environments that are traditionally difficult to staff.

\section{Assessment of Educator Preparation Programs}

\section{Educator Preparation Program Types}

There are several varieties of EPPs that must meet these accreditation standards. Traditionally, EPPs have been part of a larger, brick and mortar Institution of Higher Education (IHE). These institutions may have a school, college, or department of education. These institutions can be publicly or privately-funded institutions of higher education. Some of these institutions are Historically Black Colleges and Universities, Hispanic Serving Institutions and Tribal Colleges. For the purpose of this study, these institutions was designated as Minority Serving Institutions (MSI).

Also, these institutions can be organized according to the Missouri Department of Higher Education Selectivity Category (Missouri Department of Higher Education, 2016). IHE's can be known as highly selective, selective, moderately selective or openenrollment. These selectivity levels are based on the number of college credits completed and percentile scores students receive on ACT or SAT tests. Given that EPPs are accredited according to standardized test scores, and research indicates a strong link between these scores and PST race, ethnicity, gender and SES, we infer that a privatelyfunded, highly selective non-MSI will have an easier time receiving accreditation than a publicly-funded, open-enrollment MSI.

\section{Educator Preparation Program Accountability Policy}




\section{QUANTITATIVE ANALYSIS OF MCA}

Outside of the policy arena experts agree using standardized tests to predict teacher success is weakly supported. Darling-Hammond, Amrein-Beardsley, Haertel, and Rothstein (2012) suggest the current state of educator preparation is awful. Others emphasize that educator preparation programs cannot be successfully evaluated with the score from only a single assessment (Henry, et al, 2013). However, other sources such as Levine (2006) state that only a high verbal score is required of teachers to improve student learning. But, Levine does state that other standardized forms of exams are nearly useless in predicting teacher success.

There are other forms of teacher and PST assessment currently used besides multiple-choice tests. Any of these could potentially be considered or developed into a replacement for high stakes multiple choice assessments. The Bill and Melinda Gates Foundation (2010) has invested millions into teaching reform, including assessment reform. The foundation has funded the use of the MET project, which uses surveys to collect school student perceptions about teachers. This data is undergoing rigorous analysis and may eventually lead to a widely-used, survey-based teacher assessment system. In addition, research done by Duckworth, Peterson, Matthews and Kelly (2007) recommend the use of GRIT analysis. GRIT is viewed as a personal characteristic linked to mental and emotional hardiness and overcoming obstacles toward goals. GRIT has been linked to business, military and athletic success. Researchers believe that GRIT can also be an effective predictor of teacher success. Meanwhile, international research by Rockoff, Jacob, Kane, and Staiger (2008) indicate that teacher cognitive skills, not content knowledge, is the most effective predictor of student success as seen through 


\section{QUANTITATIVE ANALYSIS OF MCA}

student test scores. However, currently the most widely-used alternative PST assessments are performance based assessments.

Performance based assessments focus on measuring a PST's ability to conduct all of the tasks necessary to being a teacher, including teaching students (Chung, 2008; Denner, Norman, Salzman \& Pankratz, 2003). The use of a Teacher Performance Assessment (TPA) began in California and has recently been revised and reapproved as a certification requirement (Honawar, 2007). As of 2010, performance-based assessments were being piloted in 19 states (Sawchuk, 2010). Today, the most widely used performance assessment, the EdTPA, is being used in over 40 states and the District of Columbia (American Association of Colleges for Teacher Education, 2016b).

Regardless of which tool is used to assess PSTs, the use of a single high stakes assessment as a gatekeeper to the program or certification is unsupported by research. Rockoff, Jacob, Kane and Staiger (2008) conducted a wide-ranging study to determine which teacher assessments predicted student outcomes. Rockoff et al. (2008) eventually organized all assessed attributes into either cognitive or non-cognitive factors. This set of factors did have a statistically significant relationship with student outcomes, especially student test scores. However, the researchers concluded that no one assessment could effectively predict teacher success. Therefore, many assessments should be used and weighed when predicting teacher outcomes instead of single, high stakes assessments.

\section{Educator Preparation Program Accrediting Organizations}

Institutions of higher education are accredited typically by a variety of organizations. Some of these focus on the institution as a whole, and others offer accreditation to smaller units within these institutions. An example of whole-institution 


\section{QUANTITATIVE ANALYSIS OF MCA}

accreditation is the Higher Learning Commission (HLC, 2016). This entity's accreditation provides status to over 1000 institutions of higher education.

Organizations that provide accreditation to EPPs include the Council on the Accreditation of Educator Preparation (CAEP). CAEP is an organization that originated from the joining of two similar entities, the National Council on the Accreditation of Teacher Education and the Teacher Education Accreditation Council. NCATE began providing accreditation services to EPPs since 1954 and TEAC since 2003 (CAEP, 2016). These entities merged in 2013. CAEP now provides non-mandatory accreditation to any EPP that wishes to attempt to meet its standards.

While CAEP provides national accreditation, states can require additional accreditation of EPPs. In Missouri, this falls under the purview of DESE (DESE, 2014a). DESE now collects data annually using its Annual Performance Report (APR). Programs that do not meet the benchmarks set forth in this report begin a three year process of either remediation or closure. These benchmarks include the following: $80 \%$ of completers must pass the Missouri Content Assessment in the appropriate content area within two attempts; $85 \%$ of completers must have a $3.0 \mathrm{GPA}$ in all content area courses and a 2.75 cumulative GPA; $90 \%$ of completers must report feeling at least fairly prepared during a first year completer survey; and $90 \%$ of the principals of these new teachers must report the teachers were at least fairly prepared in another first year teacher survey (DESE, 2014a). Both of the survey result benchmarks require a minimum response rate of $60 \%$. Only programs with 30 or more completers over a three year rolling period may be assessed.

\section{External Pressures}




\section{QUANTITATIVE ANALYSIS OF MCA}

Pressures to accredit teacher preparation programs typically come from outside the teaching profession in the form of policy makers. The launch of sputnik in 1957 was a milestone that increased scrutiny of how American teachers were prepared (Blackford, Olmstead, \& Stegman, 2012). The publication of a Nation in Crisis was another incarnation of reform of the 1980's (National Commission on Excellence in Education, 1983). Then, in the 2000's, No Child Left Behind brought its own requirements for teachers (Cibulka, 1990).

\section{Educator Preparation Program Detractors}

EPPs are constantly reforming partially due to detractors. The most recent example of an educator preparation retractor is the National Council on Teacher Quality (NCTQ). The NCTQ has an initial working mission statement focused on changing the current state of teacher preparation (NCTQ, 2013). NCTQ has developed a rating system based on input from syllabi collected from EPP coursework. Some of these have been collected without EPP cooperation. Legal action has even occurred between the EPP at the University of Missouri and NCTQ, in an attempt to block NCTQ from collecting syllabi (Columbia Daily Tribune, 2014).

\section{Missouri Educator Gateway Assessments}

MEGA was a suite of assessments mandated by DESE for PSTs to pass before receiving certification to teach in Missouri (DESE, 2014b). MEGA included a variety of assessments. The Missouri General Education Assessment (MoGEA) was a general education assessment that college students were required to pass before entering an EPP in Missouri. Research by Edmonds (2014) indicated that there was a statistically significant difference in scores achieved by PSTs who were African American, Hispanic 


\section{QUANTITATIVE ANALYSIS OF MCA}

and female as opposed to White male counterparts. The Missouri Content Assessments (MCA) were used as the certification content exam required of PSTs before earning certification to teach in Missouri.

While there was an MCA for any teaching content area, this study focused on the Elementary Education Multi-Content Assessment (DESE, 2014b). This is the multiple choice assessment required of all elementary education PSTs. This assessment is composed of four subtests, measuring PST content knowledge in English, mathematics, science and social studies. A passing score of 220 on a scale of 100-300 is needed on each of these assessments before the PST is considered "passed". These assessments are $\$ 77$ if taken at once or $\$ 39$ if taken as separate subtests. The PST can take these subtests as many times as necessary to pass. However, only the first two attempts count towards the Annual Performance Report accountability measure of each EPP.

DESE has approved a variety of Missouri Content Assessments to be used as certification exams in different content areas and teaching levels (DESE, 2014b). However, some sources question whether these assessments disproportionately remove PSTs of color from the teaching workforce (Bock \& Addo, 2015). These could be seen as an unnecessary barrier to the teaching field for PSTs of color.

The final goal of PST assessments is to determine which PSTs will provide the best services to K-12 students. The question is whether multiple choice, high stakes assessments can accomplish this task. Multiple sources indicate that certified teachers do tend to have a more positive impact on students (Cowan \& Goldhaber, 2015). However, Angrist and Guryan (2004) indicate that standardized tests are useless in predicting 


\section{QUANTITATIVE ANALYSIS OF MCA}

teacher impact on students and may also deter some excellent PSTs from becoming teachers.

One of the first instances of standardized teacher testing in the 1930's served as a proxy to ensure that African American teachers could be paid less than White counterparts (Kirk, 2009). Standardized testing at the time was seen as a more equitable way to ensure that all teachers had the same opportunity to receive equal pay. In that regard, the hope was actually to lower the possibility of teacher pay discrimination based on race. A precursor to the Praxis was used. African American teachers scored lower, and were therefore paid less.

Nettles et al. (2011) took an in-depth look at the ability of African American PSTs to pass the current Praxis. The Praxis II is the standardized test developed by ETS to act as a certification requirement (similar to the Missouri Content Assessments). The first time passage rate for African American PSTs completing the Math content knowledge assessment was $25.3 \%$, versus $72.6 \%$ of White PSTs. This was similar to the social studies (47.6\% vs. $83.9 \%$ ) and English (46.4\% vs. $88.7 \%)$ content exams.

Another recent study found African American PSTs in Atlanta felt EPPs did not prepare them properly to take the current teacher certification exams (Taylor, 2013). Large percentages of African American PSTs were failing the exam. Some of these PSTs were able to get the testing requirement waived based on experience. One of those teachers in 2009 was named Teacher of the year at her school. Another was named teacher of the year after failing the Praxis ten times. Obviously, these test results were totally unrelated to teacher success (Taylor, 2013). 


\section{QUANTITATIVE ANALYSIS OF MCA}

Berk (1995) states that there is no perfect way to set a standardized cut score. Once experts have a chance to determine a "fair" standard, these standards are always modified based on political, social or other pressures (Berk, 1995). This is particularly true with PST assessment. While standards have been set by DESE and testing companies, these assessments have a long history of scores with significant differences based on teacher diversity. Even current best practices fall short to improve this bias. However, perhaps an approach with a stronger quantitative basis could help remove significant differences in PST assessment.

In addition, the methods used to set passing scores on these assessments was reviewed. Pearson has literally written the book on ensuring fairness in standardized testing (Evaluation Systems Pearson, 2009). In this 2009 publication Pearson touts the use of Bias Review Committees (BRC) to minimize the language in any test item that is considered to be biased against any traditionally marginalized member of society. BRC's consist of recruited local education experts who are trained over a course of hours on how to review each assessment item in a specific section. BRC's act as a group to detect item language that is biased based on race, ethnicity, gender or other forms of biases. If bias is detected, the BRC suggests these items be revised or removed from the assessment. However, this process is not without detractors. The use of BRC's has already been proved to be ineffective in removing significant differences in standardized test scores based on racial and ethnic differences (Engelhard, Hansche \& Rutledge, 1990). But, partnering a BRC with a quantitative data review of assessment results could potentially improve the equity of standardized test passing scores on any assessment. If assessment 


\section{QUANTITATIVE ANALYSIS OF MCA}

items were scored on how likely a PST of color would correctly answer vs. a White PST, this may increase the validity of the BRC.

\section{Accountability Foundations}

At its core, the theory of accountability functions as a relationship (Anderson, 2009). In this relationship, there is an accounter and an accountable party. The accounter holds the power in this relationship. The accountable is required to provide some sort of input, typically proof of achievement of benchmarks. The accounter then provides feedback to the accountable. This can be either some sort of reward for reaching benchmarks or punishment for failure to reach benchmarks using some sort of measure of effectiveness. In the example of this study, the accounter is DESE or the MOSBOE. The accountable parties include PSTs and EPPs, since both must provide proof of effectiveness via MCA scores, and then both receive some sort of punishment or reward based on their ability to reach benchmarks.

\section{Accountability: Shortcomings}

But, fear of failure on the part of the accountable can lead to outcomes that may impede the original goals of the accounter. The end result of the accountability conceptual framework is that some accountable party will eventually suffer blame. This act of blaming creates a scapegoat and limits the accounter's ability to truly understand the accountable (Anderson, 2009). However, the act of blaming is desirable to accounters in that it implies that accounters do not share any blame with the accountable party (Harmon, 1995). The accountable was simply unable to meet agreed-upon terms. In this study, an example situation would be that DESE could, by using accountability driven by standardized examinations, which narrow diversity, indicate that several 


\section{QUANTITATIVE ANALYSIS OF MCA}

Missouri EPPs did not create enough successful teachers. Therefore, because of assessments screening PSTs from marginalized populations, these low-performing schools of education would face closure. DESE would not share in any blame felt by those EPPs for perceived low performance.

Anderson (2009) indicates that the use of the accountability conceptual framework can lead to "illusions of accountability." Along these lines, the use of strict accountability standards restricts open and honest discussions about important issues the accountable is dealing with of which the accounter may not even be aware. This may occur even though the accountability measures are accessible and easily understood. For example, one of the accountability measures currently used by DESE to accredit EPPs is that all program completers must pass a Missouri Content Assessment within two tries with an $80 \%$ passing rate. While this is easy to understand for policy makers, it ignores the fact that EPPs have not had sufficient time to modify curriculum to match the content of the Missouri Content Assessments, nor does it reflect the historically-rooted phenomena of lower performance by marginalized groups on standardized examinations.

Surface-level accountability has more negative impact besides the failure to tell a complete story. Anderson (2009) indicates that these accountability strategies: marginalize cooperation; lower transparency; discourage information sharing with peers; encourage secrecy; distort communication between the accountable and the accounter; exaggerate success; encourage blaming failure on others; increase the risk of upper management failing to receive vital information; and decrease effective democratic governance. Metzger (2006) states that errors like this are due to focusing on one point 


\section{QUANTITATIVE ANALYSIS OF MCA}

of interest and ignoring other important issues. Through this, accounters are able to construct a story about the accountable (Weick, 1995).

The accounter can split accountees into "heroes" and "villains". The heroes were accountees who completed all accountability measures on time and met benchmarks. The villains were accountees who failed to do either or both. Heroes were met with rewards while villains received punishments. In the example of this study, EPPs who failed to meet benchmarks could face closure, while EPPs who did meet benchmarks would continue producing PSTs. However, since EPPs that serve comparatively larger populations of PSTs from marginalized groups may be less likely to meet benchmarks based on content assessments, the accounter, DESE in this scenario, may not be assessing the accountable for factors within their control.

Often, surface level accountability plans use quantitative data. These quantitative analyses act as a buffer to legitimize the belief that $\mathrm{X} \%$ of outcome is due to $\mathrm{Y} \%$ of the accountable's work. However, in the complex world of creating effective educators, $\mathrm{X}$ alone seldom leads to Y alone. In the case of EPPs and PSTs, complex socio-historical factors, including systems of inequality, racism and different learning opportunities for diverse PSTs leading up to the moment they begin a high-stakes assessment provide a richer pictures than pass-fail data. This study attempts to look beyond the surface of the issue of pass rates and comparative institutional accountability structures.

The end result of this illusion of accountability is the illusion of easy decisionmaking (Harmon, 1995). An example from this study would be if $80 \%$ of an EPPs completers fail to pass Missouri Content Assessments. If the EPP cannot rectify this situation within three years, DESE may close the EPP. If DESE's goal as accounter is to 


\section{QUANTITATIVE ANALYSIS OF MCA}

ensure all PSTs attend effective preparation programs, this surface-level analysis and decision is sensible. However, important decisions, such as whether to close entire preparation programs, should rarely be based on individual decisions, but on a web of interactions (Harmon, 1995). Perhaps a teacher shortage in a difficulty discipline, like math or science, has caused more individuals to enroll in an EPP focused in those areas. But, if science and mathematical subject matter assessments are more difficult than other content area assessments, this EPP may face a problem since a higher percentage of its PSTs would fail the test. To close this EPP based on these assessment scores would be a surface level decision that would actually punish an EPP for attempting to create more teachers in a high needs content area.

\section{Accountability: Potential Solutions}

The aforementioned accountability conceptual framework has shortcomings. However, some strategies exist that could improve the effectiveness of accountability theory. Anderson (2009) strongly suggests that accountability must become more collaborative. This needs to come from rational discourse between the accountable and the accounter, not via a system of hard and fast rewards or punishments. This discourse would not focus on mandated answers to surface-level questions, but rather meaningful and iterative discussion of issues that would lead to mutually-accepted outcomes based on continuous quality improvement. Anderson (2009) indicates that accountability should not be viewed as an end destination, but rather the telling of a story free of distortion.

\section{Accountability and Pre-Service Teacher Certification}




\section{QUANTITATIVE ANALYSIS OF MCA}

Individual PSTs need certification from the state in order to legally teach. In this way, PSTs are accountable to the state to prove adequate preparation to teach. Anderson (2009) states that accountability mechanisms (like the Missouri Content Assessments) are utilized with the assumption that individuals will respond positively to incentives. In addition, this assumes that the accountable will not reach the goals of the mechanism without positive or negative reinforcement. Given the types of people who generally become teachers, this is an interesting supposition.

Since the 1960's policymakers have attempted to require PSTs to pass high stakes, multiple choice assessments (Angrist \& Guryan, 2004). Angrist and Guryan (2004) go on to state that the certification exam used in Missouri in 2004, the Praxis II, although a "weak screen", did favor PSTs who attended traditional educator preparation programs as opposed to PSTs who chose alternative routes to teacher education. Angrist and Guryan (2004) finish with noting that there is a connection between the use of these tests and an increase in teacher quality. Other studies disagree, stating that increased teacher testing does not improve teacher quality (Flippo, \& Canniff, 2000).

Test preparation strategies can increase the likelihood of PSTs passing certification assessments (Wall, 2008). The successful use of these strategies illustrate how these assessments measure factors outside of content knowledge and teaching quality.

Teachers and PSTs are currently evaluated using a myriad of techniques and strategies internally by EPPs and externally by accounters. Typically, educator preparation programs want to monitor PST development according to standards (Larsen \& Calfee, 2005). This is done through selected assessments given to PSTs at certain academic career 


\section{QUANTITATIVE ANALYSIS OF MCA}

milestones. This can be at program entry, student teaching entry, program completion and certification.

\section{Accountability and Educator Preparation Programs}

According to Lindkvist and Llewellyn (2003) organizations are methods societies use to reach goals. This is certainly the case in accreditation, where national and state accrediting entities, either mandated or suggested, are used to ensure EPPs prepare PSTs in a way that corresponds with set standards. Ameter et al. (2004) states that organizational accountability is centered around a higher-level organization exerting its will on smaller units or individuals. In this way, accrediting bodies exert standards on EPPs. Romzek, LeRoux and Blackmar (2012) state that accountability is a relationship with three "facets": a source of authority; expectations for the accountable; and mechanisms that hold an entity accountable, leading to either reward or punishment (Bardach \& Lesser, 1996; Behn, 2001; Romzek \& Dubnick, 1987; Schillemans, 2008).

According to Ameter et al. (2004), mechanisms to enforce accountability can be either formal, such as reports, or informal, such as social pressures. For the sake of EPP assessment this study will only focus on formal assessments. Romzek et al. (2012) states that recent shifts in governmental policies have increased roles for nongovernmental entities to perform accountability duties (Hodge \& Greve, 2005; U.S. Government Accountability Office, 2006). These come in the form of contractual collaborations between government offices and service providers. (Edelenbos \& Erik-Hans, 2007; Isett \& Provan 2005; Van Slyke, 2007). This is a reality in Missouri, where Pearson answered a Request for Proposals to provide the current Missouri Content Assessments. Pearson then reports scores to the student, the EPP and DESE, where the student can be awarded 


\section{QUANTITATIVE ANALYSIS OF MCA}

or withheld certification. Also, the EPP may face accreditation issues due to low passage rates. These EPPs must then balance institutional missions with priorities put forth by these accountability partners (Kenis \& Provan, 2007; Svennson, Trommel, \& Lantink 2008). This can lead to complex relationships and outcomes that are difficult to measure with surface-level analysis.

Finally, Race to the Top is the latest incarnation of attempted teacher preparation reforms. Announced in 2009, Race to the Top is the first of these major reforms attempting to tie EPP accountability to teacher effectiveness. However, teacher effectiveness in the context of Race to the Top is measured in student test scores (Henry, Kershaw, Zulli \& Smith, 2012; Lewis \& Young, 2013). Whether this is a valid measure of teacher effectiveness, in which factors such as SES, race, student capabilities, student level or content are not accounted for is another matter (Ravitch, 2013). Cultural Synchronicity: Possible Solutions

Racial gaps exist in regards to high school graduation, college preparatory high school classes, access to school technology and access to experienced teachers (Annie E. Casey Foundation, 2006; Aud, Fox \& KewalRamani, 2010; National Center for Education Statistics, 2015; Sum, Khatiwada, McLaughlin \& Palma, 2009). However, studies indicate that an increase in more diverse teachers could impact the success of all students, especially students of color (Goldhaber \& Hansen, 2010). Modification of testing accountability strategies could potentially alter the diversity of the teaching workforce (Wakefield, 2003).

\section{Summary}




\section{QUANTITATIVE ANALYSIS OF MCA}

The teaching field needs more teachers of color. Historically, assessments used to determine which PSTs are prepared to teach have been standardized tests. These have a strong history of showing significant differences between scores achieved by White test takers and test takers of color. The looming question is then how do EPPs develop and assess PSTs of color in a way that does not remove them from the field in an unnecessarily larger proportion than their White counterparts. The MoGEA, developed by Pearson, is not an effective gateway assessment in this effort, as it is more likely to disproportionately remove students of color and female PSTs from the field. Currently in Missouri the Missouri Content Assessment is used as a certification exam. However, other certification exams used historically for teacher licensures, such as the precursor to the PRAXIS, the PRAXIS I and the PRAXIS II have been found to show significant differences between PSTs of African American vs. other backgrounds. The question then becomes whether the Missouri Content Assessments are equitable to PSTs of all backgrounds. Missouri Content Assessments are the descendants of older assessments that demonstrated differences in scores between marginalized and non-marginalized populations. Also, the MCA are developed by Pearson, who developed the MoGEA. In addition, Pearson exams for teacher licensure have been removed from New York due to perceived "test bias" issues (Harris, 2015). Based on these concerns this research will seek to fill the gap in knowledge as to whether Missouri Content Assessments scores are significantly different based on PST race and ethnicity. 


\section{SECTION FOUR}

\section{CONTRIBUTION TO PRACTICE}

\section{Plan for Dissemination of Practitioner Contribution}

Who: Attendees of the Missouri Association for Colleges of Teacher Education (MACTE) conference in 2017 (policy makers, EPP faculty and staff).

When: 2017 MACTE Conference

How: Through a presentation at the MACTE conference. The presentation was a slide show.

\section{Type of Document}

Document type is a slide show presentation that will be presented at the MACTE Conference. The slide show will inform the audience on the study outcome, as to whether the Missouri Content Assessments should be considered a valid and equitable measure of teacher content knowledge. Upon request the full study will be available.

\section{Rationale for this Contribution Type}

MACTE is the state chapter of the American Association for Colleges of Teacher Education (AACTE). The AACTE strives to act as a resource for EPPs through advocacy and research and education strategies. MACTE conference attendees will include Missouri EPP deans, assessment directors and faculty. Presenting findings at this conference will allow other stakeholders an opportunity to consider using similar strategies to analyze findings from other Missouri Content Assessments.

\section{Outline of Proposed Contents}

Background of Missouri EPPs and PSTs

Research surrounding assessment and teachers of color Findings (quantitative results indicating impact of Missouri Content Assessment on Missouri teacher diversity. This would include impact on EPPs with highly diverse populations).

Implications for highly diverse EPPs and Missouri K-12 schools. 


\section{QUANTITATIVE ANALYSIS OF} MISSOURI TEACHER LICENSURE EXAMS THROUGH THE LENS OF SOCIAL JUSTICE

MIKE MCBRIDE

DR. TIM WALL

MISSOURI ASSOCIATION OF COLLEGES FOR TEACHER EDUCATION

SPRING 2017 CONFERENCE

MARCH 27, 2017

A presentation planned for the Spring 2017 MACTE conference. This presentation could be modified to present at either state or national venues.

\section{Purpose}

There is a gap in the research on whether differences exist in Missouri teacher licensure exam passage rates based on:

- Pre-Service Teacher (PST) race and ethnicity

- Potential use of alternative exam cut scores

- Preparation program selectivity level

- Preparation program status as a Minority-Serving Institution 
Since September, 2014, Pre-Service Teachers (PSTs) have been required to complete and pass a subject matter assessment based in their teaching area before they are certified to teach in Missouri. This is the Missouri Content Assessment, a multiple choice, standardized, online assessment (DESE, 2014). Different versions of this assessment are required based on teaching subject matter. No research has been done yet to determine if this assessment produce scores that are significantly different for PSTs from historically marginalized populations.

\section{Background}

The goal of this study is to search for differences in Missouri teacher licensure exam passage rates based on:

- Pre-Service Teacher (PST) race and ethnicity

- Potential use of alternative exam cut scores

- Preparation program selectivity level

- Preparation program status as a Minority-Serving Institution

Previous research by Edmonds (2014) indicated a significant difference in passage rates according to race and ethnicity in the Missouri General Education Assessment (MoGEA). The MoGEA is an assessment required for PSTs to enter any Missouri EPP. The MoGEA is developed by Evaluation Systems Pearson, the same testing company that developed the Missouri Content Assessment (DESE, 2014). 


\section{Theoretical Frameworks in Opposition}

Figure 1. Accountability and Cultural Synchronicity in Opposition
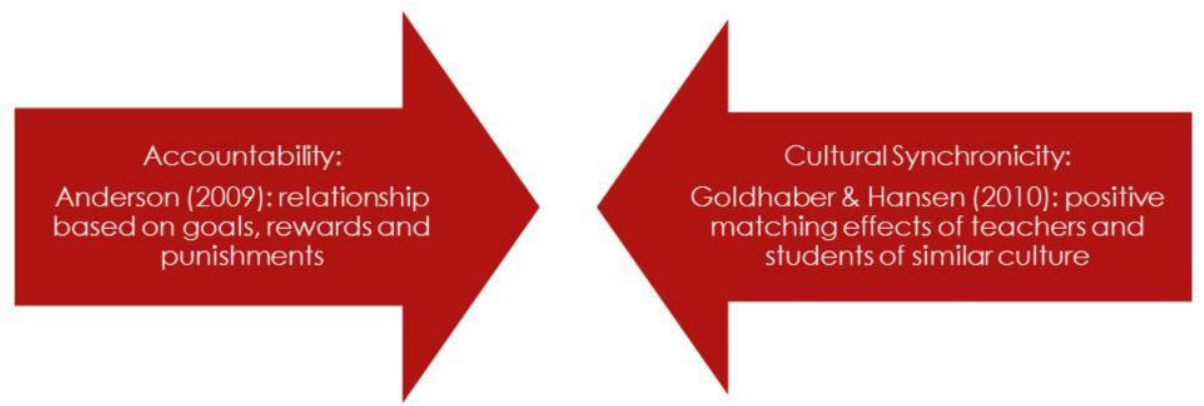

Accountability is a conceptual framework used to outline a type of relationship (Anderson, 2009). Accountability in this respect is a relationship that is designed to be mutually beneficial to all parties involved.

Cultural synchronicity is a social construct. Students in Pk-12 classrooms have better academic outcomes when they are matched with teachers from similar cultural backgrounds (Goldhaber \& Hansen, 2010: Steinberg and Weiner, 2015, February; Villegas \& Irvine, 2010).

However, when accountability is used in educator preparation it can infringe upon the benefits of cultural synchronicity. 


\section{Analogy:}

\section{Two Magnets in Opposition}

Figure 2. Accountability and Cultural Synchronicity as Opposing Magnets

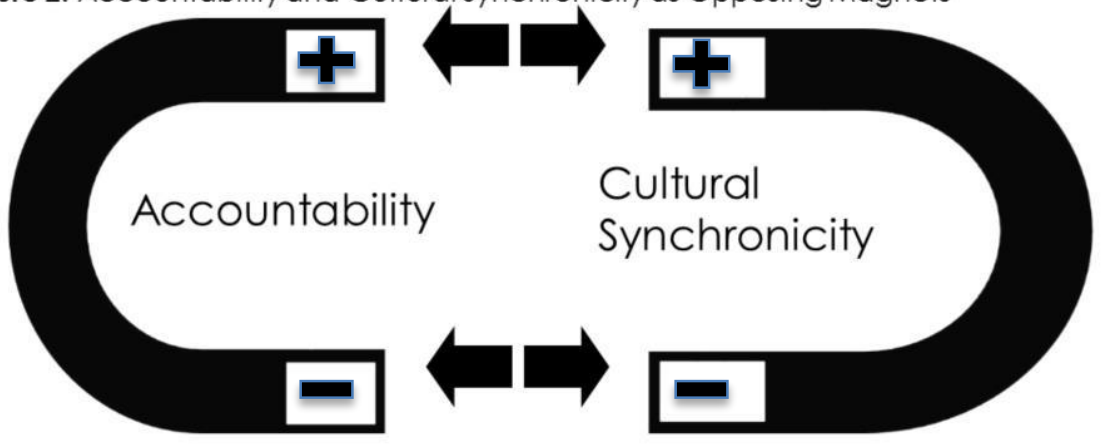

This analogy illustrates the relationship between both constructs in educator preparation. Both can be beneficial, but striking a balance between both has posed elusive.

\section{Perhaps a More Accurate Analogy}

Figure 3, Quality Assurance and Social Justice as a Continuum

Continuum of Educational Policy Choices

This analogy illustrates the relationship between the constructs of quality 
assurance and socially just practices in educational policy. Both constructs are beneficial, but striking a balance has been elusive.

\section{Theoretical Framework: Accountability}

- Accountability (Anderson, 2009)

- A relationship to accomplish goals

- Accounter, the responsible overseer

- Accountable, responsible to produce findings with favorable outcomes

- Accounter responds with rewards or punishment

In accountability theory, a relationship exists between two parties (Anderson, 2009). These are the:

Accounter: The party in power in this relationship, the accounter is responsible for collecting responses from the accountable. If the responses from the accountable meet predetermined goals, then the accounter provides rewards, in the forms of benefits. If the accounter does not receive agreed-upon responses from the accountable, then the accounter responds with punishments of some kind, or a negative outcome.

Accountable: This member of the accountability relationship must provide results of some kind to the accounter and then expect to receive either negative or positive reinforcement based on their results. 


\section{Theoretical Framework: Accountability Example}

\section{In this example}

Accounter: MOSBOE/DESE

Accountable

- EPPs, via MCA passage rates

-PSTs, via passing the subject area MCA

In this case, the accounter would be DESE or the Missouri State Board of Education. Also in this case, the accountable would be the EPPs and PSTs of Missouri providing MCA data.

\section{Theoretical Framework:}

Accountability Shortcomings

Accountability Shortcomings (Anderson, 2009)

Accounter does not share responsibility of good or bad results

- "Surface-level" assessment

- Unethical reporting practices

May fail to produce true

Anderson (2009) does suggest potential negative outcomes of the accountability relationship. 
The accounter does not share the responsibility whether the accountable produces good or bad results. Whether the accounter should be held responsible good or bad results may not be clearly indicated.

Many accountability measures, such as test scores, may represent only "surface- level" data. This data may not illustrate the state of the accountable in the most descriptive and valid manner possible.

The accountable may be tempted to follow unethical reporting practices that distort the situation that the accountability framework is attempting to measure.

\section{Theoretical Framework: Cultural Synchronicity}

\section{Cultural synchronicity}

- As defined (Goldhaber \& Hansen, 2010; Steinberg and Weiner, 2015, February; Villegas \& Irvine, 2010)

Students and teachers with matching race, ethnicity and culture experience more favorable academic outcomes, regardless of teacher licensure exam scores

Cultural synchronicity is a social construct. Students in Pk-12 classrooms have better academic outcomes when they are matched with teachers from similar cultural backgrounds (Goldhaber \& Hansen, 2010: Steinberg and Weiner, 2015, February; Villegas \& Irvine, 2010). 


\section{Pillars of Our Literature Review}

Pillars:

- Teacher licensure exams as accountability measures (Anderson, 2009)

- Impact of cultural synchronicity on Pk-12 outcomes (Irvine, 1990)

- Impact of accountability measures on cultural synchronicity (Goldhaber \& Hansen, 2010)

The three pillars of the literature review for this study are:

- Teacher licensure exams, of which the Missouri Content Assessment is one

- The impacts of cultural synchronicity on Pk-12 students

- The impacts of teacher licensure exams on cultural synchronicity, and by extension, on Pk-12 students.

\section{Teacher Licensure Exams as Accountability Measures}

Many times accountability in teacher preparation equates to testing (Darling-Hammond, 2004; Horn, 2003; Wakefield, 2003)

- Common responses to accountability pressure include raising test scores (Darling-Hammond, 2004; Horn, 2003; Wakefield, 2003; Wall, 2001; Wall, 2008) 
Accountability in regard to educator preparation is often equated with teacher testing (Darling-Hammond, 2004; Horn, 2003; Wakefield, 2003). This is an example of a surface-level assessment (Anderson, 2009). These test results are easy for policy makers to understand but perhaps not the most valid measure of EPP or PST performance.

In addition, policy makers typically attempt to set teacher test cut scores at a perceived high score in order to ensure that only the individuals with the highest content knowledge become teachers (Darling-Hammond, 2004; Horn, 2003; Wakefield, 2003, Wall, 2001; Wall, 2008). However, this may have unintended impact on cultural synchronicity.

\section{Teacher Licensure Exams as} Accountability Measures

Typically these exams are (Wakefield, 2003):

Multiple choice

Standardized

- Content-based

Most states require a content-based assessment of PSTs as a final requirement for licensure (Wakefield, 2003). These exams are typically taken at the end of a preparation program. 


\section{Teacher Licensure Exams as Accountability Measures}

\section{Act as gatekeepers to the teaching profession (Bennett, 2006; Kirk, 2009; Wakefield, 2003)}

These assessments are barriers that PSTs must pass in order to receive teacher licensure. In addition, policy makers often become involved in the process to set cut scores for these assessments. In the hopes of using these assessments as accountability measures and to improve the perceived ability of teachers, policymakers sometimes influence cut scores in order to make them more difficult to pass.

\section{Teacher Licensure Exams as Accountability Measures}

- Nationally the most commonly used teacher licensure assessment is the Praxis II, developed by ETS (Wakefield, 2003)

The Praxis II is very similar to the Missouri Content Assessment, in that it is a group of assessments for different content areas (Wakefield, 2003). Developed by ETS, the Praxis II is a multiple choice assessment used in many states as a teacher licensure requirement. 
The Missouri Content Assessment is developed by Evaluation Systems Pearson (DESE, 2014).

\section{Teacher Licensure Exams as Accountability Measures}

In Missouri, this is the Missouri Content Assessment

- Required for teacher licensure

- Since September 1, 2014

- Includes 56 different assessments

- Some content areas require multiple assessments

- Elementaryeducation

The Missouri Content Assessment, similar to the Praxis II, has been used since September 1, 2014 as a licensure requirement for Missouri PSTs (DESE, 2014). On a scale of 100-300, PSTs must reach a cut score of 220 on each subtest to pass this licensure requirement.

\section{Teacher Licensure Exams:} Elementary Education Multi-Content Assessment

- For elementary education PSTs, this is the Elementary Education Multi-Content Assessment

- Consists of four subtests (DESE, 2014)

- English/Language Arts

- Mathematics

- Science

- Social Studies

- All require a 220 on a scale of 100-300 
For PSTs in elementary education EPPs, the Missouri Content Assessment to complete is the Elementary Education Multi-Content Assessment. This assessment is composed of four subtests, each with its own content area.

The subtests and content areas of the Elementary Education Multi-Content Assessment are:

- English/Language Arts Subtest

- Mathematics Subtest

- Science Subtest

- Social Studies Subtest

\section{Teacher Licensure Exams as Accountability} Measures

Multi-Content Assessment as Accountability Measure:

- PSTS

- Teacher licensure requirement (DESE, 2014)

- EPPS

- Annual Performance Report Benchmark

- $80 \%$ passage rate required for all program completers of subject matter assessment (MCA)

- If $80 \%$ not maintained, programs begin three year period of remediation or face closure

Teacher licensure exams in Missouri are used as an accountability measure among two accountable parties

- PSTs, in that PSTs must pass the MCA in their subject matter to be recommended for certification (DESE, 2014).

- EPPs are partially assessed by DESE on an annual basis, and each program must reach a benchmark of an $80 \%$ passage rate for all completers, or begin a three year cycle of remediation or closure. 


\section{Teacher Licensure Exams as Accountability} Measures

In this case (Anderson, 2009)...

- The "accounter" is MOSBOE/DESE

- The "accountable" are:

$\rightarrow$ PSTS

$\rightarrow$ EPPS

- Are these measures too surface level?

Again, in this example, the accounter can be identified as the MOSBOE or DESE. In turn, both the PSTs and EPPs can be considered accountable parties (Anderson, 2009).

\section{Impact of Cultural Synchronicity on Pk-12 Outcomes}




\section{Impact of Cultural Synchronicity on Pk-12 Outcomes}

Gaps in academic opportunities and outcomes based on race and ethnicity (Aud, Fox \& KewalRamani, 2010)

- Pk-12 students who are African American, especially boys, are likely to face discipline more often and more harshly than students of other races and ethnicities (Skiba, Michael, Nardo, \& Peterson, 2000).

Gaps exist in academic opportunities and subsequent outcomes in Pk-12 schools based on race and ethnicity (Aud, Fox, \& KewalRamani, 2010). Teachers are the most vital ingredient to closing these gaps, especially among Pk-12 students of color (Mills $\&$ Ballantyne, 2016).

\section{Impact of Cultural Synchronicity on Pk-12 Outcomes}

Teachers are vital to closing achievement gaps for historically marginalized Pk-12 students (Mills and Ballantyne, 2016)

Teachers are a vital intervention in the lives of Pk-12 students from historically marginalized populations (Mills \& Ballantyne, 2016). 


\section{Impact of Cultural Synchronicity on $\mathrm{Pk}-12$ Outcomes}

Students who are African American or Hispanic especially require positive teacher-student relationships for academic success (Allen, et al., $2011)$

Pk-12 students who are African American or Hispanic can be successful in public schools and in higher education. However, members of historically marginalized populations require more teacher interaction to ensure academic success (Allen et al., 2011). This would indicate that, if more teachers of diverse backgrounds have a positive impact on students of diverse backgrounds, that more of these teachers would have a positive impact on specifically African American and Hispanic students.

\section{Impact of Cultural Synchronicity on Pk-12 Outcomes}

Cultural synchronicity case study by Monroe and Odidah, 2004

- "Ms. Simpson"

- Verbal and non-verbal communication similar to students' home experiences

- High academic expectations

- Quick thinking, quick responses

- Related to classroom management more than content delivery

- Actions that many white teacher educators would consider inappropriate or unprofessional build rapport and trust in an African American classroom

- Stricter discipline, but handled in class, informally, without suspensions

The case study of "Ms. Simpson" showed an example of how cultural synchronicity operates in an urban school (Monroe \& Odidah, 2004). Monroe and Odidah indicate that 
this African American teacher demonstrated behaviors that a White teacher might consider unprofessional. This teacher at an urban, majority African American school was the focus of in class flirtation from a male student in her high school class. The male student would cause interruptions focusing on his affections for Ms.

Simpson, typically in ways that would cause other students to laugh in class. Finally, Ms. Simpson asked this student during class if he was "a man" and if he "paid bills". Ms. Simpson indicated that she only dated men. The student said yes and that he had money. Ms. Simpson responded that she saw him every day in the lunchroom asking people for their extra juice boxes. How could he pay bills? The other students laughed and the interruptions stopped.

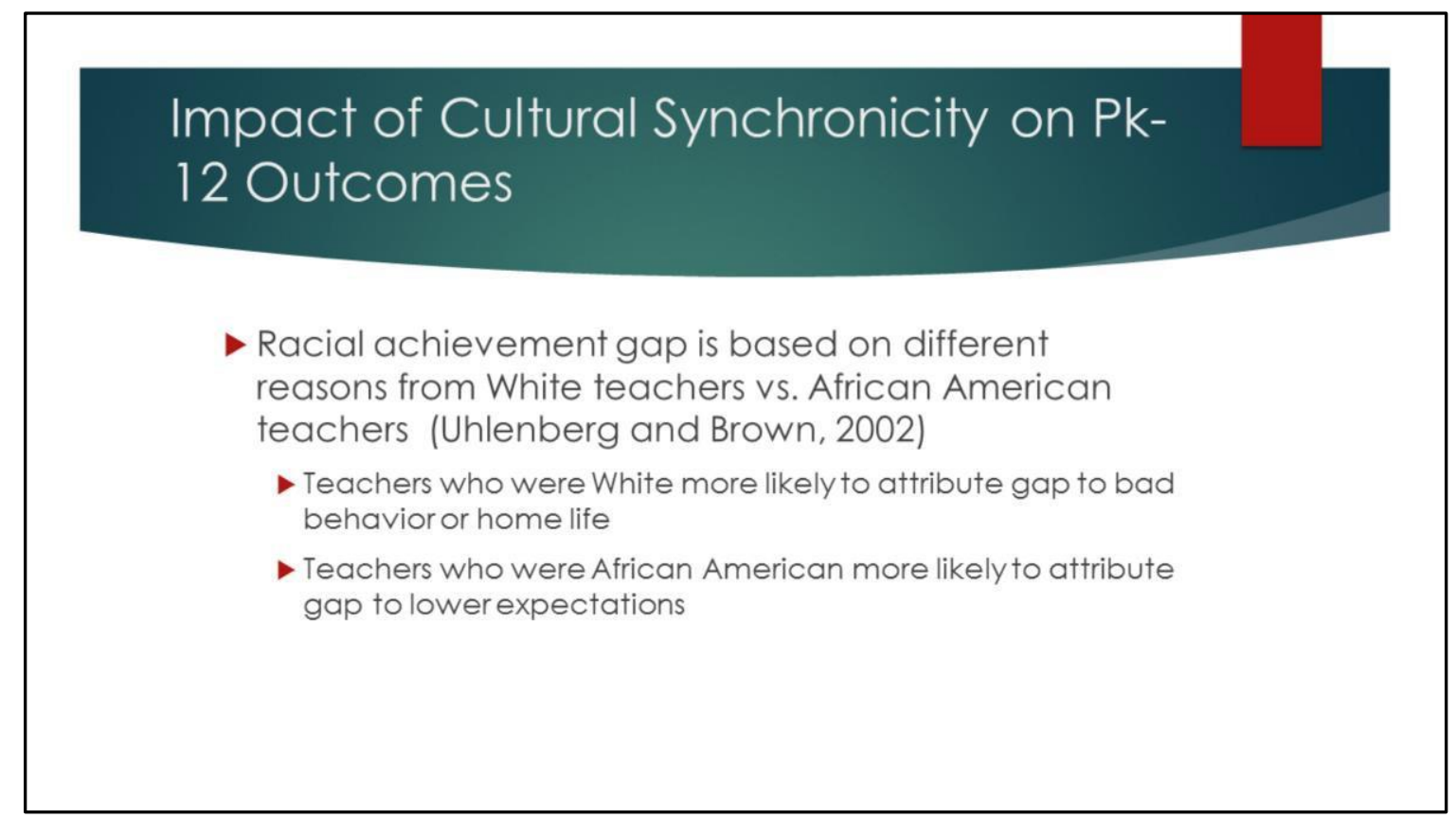

To understand why cultural synchronicity has its positive impact requires understanding the differences between White and African American teachers. Most specifically, Uhlenberg and Brown (2002), studied how teachers of different races viewed the racial achievement gap. This study noted that White teachers were more likely to believe African American students experienced negative academic outcomes because of their lack of good behavior in school and because of unsupportive parents. African American teachers, however, were more likely to believe that these gaps existed because African American students were given lower academic expectations. Previous research suggests that this gap exists because of ineffective classroom management (Monroe \& Odidah, 2004). 


\section{Impact of Cultural Synchronicity on Pk- 12 Outcomes}

Pitts (2007) reported higher graduation exam scores in districts with similar teacher/student race and ethnicity ratio

Cultural synchronicity, while it is mainly related to classroom management, does end in higher academic success for students of diverse backgrounds. Specifically, when teachers and students match culturally, graduation scores are higher among these students (Pitts, 2007).

\section{Cultural Synchronicity:}

Workforce Shortage (Villegas \& Irvine)

Teachers who are African American or Hispanic also more likely to reduce shortage of educators for highneed urban schools (Jonsson 2003)

Another positive impact of a diverse teaching workforce is that teachers from diverse backgrounds are more likely to work in areas where they are needed most (Jonsson, 2003). DESE (2015) indicates that schools with majority African American or Hispanic 
student populations were more likely to have fewer experienced or properly prepared teachers. So, when more individuals of diverse backgrounds become teachers, they are more likely to fill these gaps.

\section{Cultural Synchronicity: Bottom Line}

- "...teacher education institutions need to find ways not only to attract more teachers of color but also to motivate and educate all pre-service teachers to become culturally relevant educators" (Irvine, 2012)

The final note related to cultural synchronicity is that EPPs need to recruit, retain and complete more PSTs from diverse backgrounds (Irvine, 2012). However, the issue becomes, even if EPPs recruit and guide PSTs from diverse backgrounds to program completion, these individuals will never become teachers and make positive impacts in cultural synchronicity unless they are able to pass their licensure exams. For Missouri elementary education PSTs, this equates to the Elementary Education Multi- Content Assessment. 
Impact of Accountability Measures On Cultural Synchronicity

\section{Analogy: \\ Two Magnets in Opposition}

Figure 4. Accountability and Cultural Synchronicity as Opposing Magnets

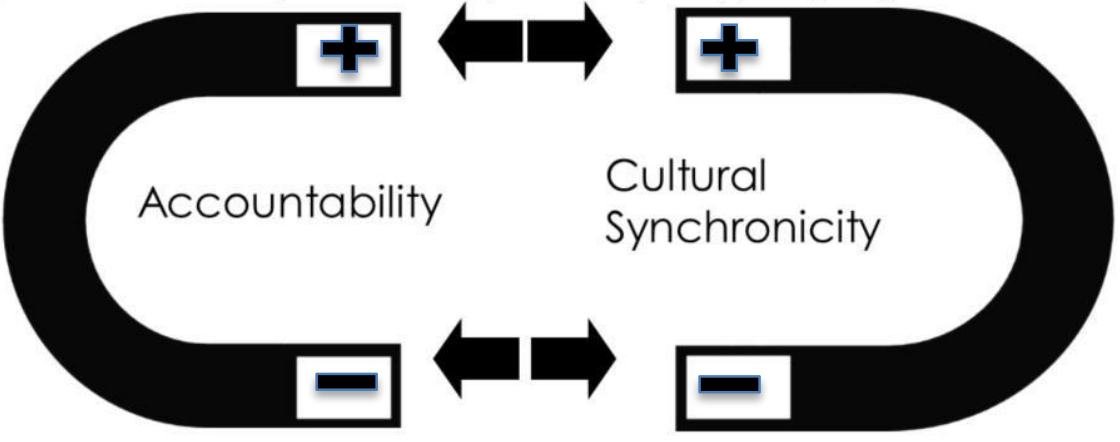

Again, the concepts of accountability and cultural synchronicity act as two magnets that are pushing against each other. When accountability measures increase in educator preparation fewer teachers from diverse backgrounds join the profession (Wakefield, 2003). 


\section{Impact of Accountability Measures On Cultural Synchronicity}

1950's: Increased use of teacher testing in South (Kirk, 2009)

- National Teacher Examination (NTE)

- Determined teacher pay

- Teachers who were African American scored lower on average

- Used specifically to legitimize lower salaries for African American teachers

One of the main goals of the NAACP in the 1930's was equality of teacher pay based on race (Kirk, 2009). Lawyers affiliated with the NAACP would sue individual districts that paid African American teachers less than White counterparts. The strategy worked. In the 1930's, African American teachers on average earned 50\% of what White teachers were paid. By 1950, African American teachers were paid $85 \%$ of what White teachers earned. However, districts began to use teacher testing as a way to prove that African American teachers were worth less than White teachers. African American teachers on average scored lower than White teachers, and so these scores were used as legal precedence to allow districts to pay them less. 


\section{Impact of Accountability Measures On Cultural Synchronicity}

- What does it mean for teacher candidates from diverse backgrounds when standardized test scores increase?

- Wakefield (2003) chronicles serious issues related to cultural synchronicity

Wakefield (2003) outlines several negative ramifications of test scores as accountability measures. This is especially the case for at-risk teacher candidates, particularly those from low SES and/or underrepresented minority populations when teacher education programs comply with state and federal accountability pressure by raising licensure exam requirements

\section{Impact of Accountability Measures On Cultural Synchronicity}

- Goldhaber \& Hansen (2010):

- "Minority teachers (Black teachers in particular) tend to perform substantially less well on licensure tests than do White teachers; thus these tests have a disparate impact on who is eligible to teach. This means that licensure policies, to at least some extent, conflict with the recruitment of minorities in teaching, a long standing policy goal, particularly in districts with large percentages of minority students." (p. 219). 


\section{Impact of Accountability Measures On} Cultural Synchronicity

Goldhaber \& Hansen (2010):

- "... state education leaders need to take the impact that these tests have on minority candidates seriously and offer evidence supporting a valid relationship between teacher testing and student outcomes". (p. 219).

\section{Impact of Accountability Measures On Cultural Synchronicity}

- "Insomuch as diversity in the public teacher workforce is socially desirable, test standards that disproportionately screen out minority teacher candidates conflict with efforts to diversify the workforce." (Goldhaber \& Hansen, page 4, 2010)

Students from historically marginalized populations, especially African American Pk-12 students, are more likely to face negative outcomes in public schools related to classroom management. These include disciplinary actions, especially among African American male students (Skiba, Michael, Nardo, \& Peterson, 2000).

Goldhaber and Hansen (2010) concluded that there are many benefits to matching students and teachers of similar cultural heritage and experiences. However, Goldhaber and Hansen (2010) also note that teacher testing disproportionately remove culturally and racially 
diverse teachers from the workforce than teachers who are White. This phenomena is noted as a negative unintended impact of teacher testing.

\section{Impact of Accountability Measures On Cultural} Synchronicity

"Enforcing strict cutoffs has the potential to both adversely affect minority student outcomes and decrease workforce diversity." (Goldhaber \& Hansen, p. 220).

Goldhaber and Hansen (2010) specifically indicate that teacher licensure testing policies with high cut scores will negatively teacher diversity. Through the concept of cultural synchronicity, this will negatively impact academic outcomes of diverse Pk-12 students.

\section{Impact of Accountability Measures On Cultural Synchronicity}

Passing rates for first-time test takers who were White on PRAXIS were approximately double in math and writing of students who were African American (Nettles, et al, 2011)

- Contemporary placement of licensure examinations as gatekeepers is a key source of inequality (Bennett, 2006)

- Memory, Coleman and Watkins (2003) calculated that raising the required scores on basic skills tests by one point would eliminate between $4 \%$ and $9 \%$ of Black students eligible for teacher licensure.

While research conducted by Kirk (2009) focused on the precursor to the Praxis II, the current Praxis II also exhibits statistically significant lower scores from PSTs from 
diverse backgrounds. Passing rates for the Praxis II among White first time test takers were nearly double than African American test takers in the areas of math and writing (Nettles, et al, 2011). Bennett (2006) indicates that these licensure exams are a definite source of teacher inequality, and Memory, Coleman and Watkins (2003) are even more specific with their findings. Memory, Coleman and Watkins (2003) concluded that even small increases in teacher test passing scores would lead to significant reductions in teacher diversity.

\section{Impact of Accountability Measures On Cultural Synchronicity: Edmonds (2014)}

\section{Missouri General Education exam (MoGEA)}

- Another standardized, multiple choice exam

Passing score required on all subtests before admission into an EPP

\section{Analyzed}

Differences in score based on race, ethnicity, gender ( $t$ tests and ANOVA)

The Missouri General Education Assessment (MoGEA) is a multiple choice, standardized assessment that college students must pass before admittance into any Missouri Educator Preparation Program (EPP) (DESE, 2014). However, research has indicated that the MoGEA produces significantly lower scores among test takers who are African American or Hispanic (Edmonds, 2014). 
Impact of Accountability Measures On Cultural Synchronicity: Edmonds (2014), cont.

- Results

- All differences found were significant

- No passing score would remove significant differences

- MOGEA not recommended as a valid entry exam into EPP

- Outcome

- MoGEA, completely revamped and relaunched fall 2015

Edmonds' (2014) research found significant differences in MoGEA scores between PSTs of different racial and ethnic backgrounds. This was the case across all five subtests of the MoGEA, which focused on:

- $\quad$ Reading

- Writing

- Mathematics

- Science

- $\quad$ Social studies

PSTs who identified as African American or Hispanic scored lower on these assessments than PSTs from any other racial or ethnic group. Edmonds concluded that the MoGEA should not be used as a gateway to educator preparation, because it removed so much diversity from the future teaching workforce. 


\section{Research Questions}

Research Questions: Is there a difference in Missouri teacher licensure exam passage rates based on:

- Pre-Service Teacher (PST) race and ethnicity?

- Potential use of alternative exam cut scores

- Preparation program selectivity level

- Preparation program status as a Minority-Serving Institution

Since the Elementary Education Multi-Content Assessment is composed of four subtests, and only PSTs who pass all four subtests are able to move forward towards teacher licensure, the main concern of this study is to review PSTs able to pass all four subtests (DESE, 2014).

\section{The Study}




\section{Context}

\section{Quantitative data}

- Scores are reported on a range of 100-300 (DESE, 2014)

- Passing score for any of these exams is 220

- Categorical data

- PST race, ethnicity (Edmonds, 2014)

- Combined data from PSTs who reported as African American and/or Hispanic, vs. PSTs from all other races or ethnicities

- Preparation program selectivity level and MSI status

The passing score for each subtest is 220 on a scale of 100-300 (DESE, 2014). These test scores were reported with PST self-reported data, indicating what race and ethnicity each PST identified themselves.

\section{Participants}

Quasi-experimental design, convenience sample and no random assignment (Creswell, 2014)

Pre-Service Teachers (PST) are of different races, ethnicities and genders

- Only elementary education PSTs

- Highest sample size of exam scores

- Limits analysis to four subtests of Elementary Multi-Content exam

- All have taken exams since September 1, 2014

A random sample was not possible, as it would be impossible to randomly assign PSTs to different races or ethnicities. Therefore, this study was considered a quasi- experiment (Creswell, 2014). Out of all 56 Missouri Content Assessments, only the Elementary Education Multi-Content Assessment was chosen, since this was the licensure assessment 
taken by the most PSTs in the state. All scores were completed since September 1, 2014, when this assessment debuted in Missouri.

\section{Participants, cont.}

- PSTs from 14 Educator Preparation Programs (EPP) of different Minority-Serving Institution (MSI) status and selectivity levels

- MSI's are vital to diverse teacher workforce (American Association of Colleges for Teacher Education, 2013; Brooks et al., 2012)

- MSI PSTs less likely to pass standardized exams (Steinberg \& Weiner, 2015, February)

- EPPs with different levels of selectivity use different ACT scores for initial student acceptance. All standardized test scores are related to each other, including ACT (Wall, 2008)

PST data was collected from 14 EPPs in Missouri. This included two Minority Serving Institutions (MSI). All institution-level results was kept anonymous, as will results from individual PSTs. These 14 institutions covered the range of selectivity, from openenrollment institutions to the highest level of selectivity in Missouri (Missouri Department of Higher Education, 2016). 


\section{Participants, cont.}

- Two groups of participants compared

- PSTs identified as African American or Hispanic

- PSTs who identified as any other race or ethnicity

- Similar to Edmonds (2014)

Based on Edmonds' (2014) methodology, the researcher split PSTs who took the Elementary Education Multi-Content Assessment into two groups.

- $\quad$ PSTs who identified as African American or Hispanic

- $\quad$ PSTs who identified as any other race or ethnicity

The researcher then compared whether these groups were able to pass all four subtests at the same rate.

\section{Data Collection and Analysis}

- Researcher contacted exam coordinators at MO EPPS

- Data collected by email by a proxy

- University of Missouri IRB: not constitute human subject research

- Confidential

- Student identifying data removed

- No EPP identified by name

- Two Minority-Serving Institutions (MSI) in Missouri: data aggregated 
The researcher contacted assessment coordinators at EPPs across Missouri. A proxy was used to officially request and collect data. The researcher sent a template spreadsheet to indicate the most effective way to upload data. No PST identifying information was requested. Because of this and the use of a proxy, the University of Missouri IRB office concluded that this study did not constitute human subject research. In addition, no EPP was identified by name and results from MSI's were aggregated to protect anonymity.

\section{Data Collection and Analysis}

- Comparing PSTs who took and passed all four Multi-Content Exams for elementary education teachers vs. those who took all and failed at least one

- Only best scores used, if PST had multiple attempts

- PST can take these subtests as many times as necessary to pass

- Data collected from 14 EPPs

Only the best scores of PSTs were used in this study, if the PST took multiple attempts. The comparison was between PSTs who passed all subtests of the Elementary Education Multi-Content Assessment, vs. those that failed at least one subtest. 


\section{Data Collection and Analysis}

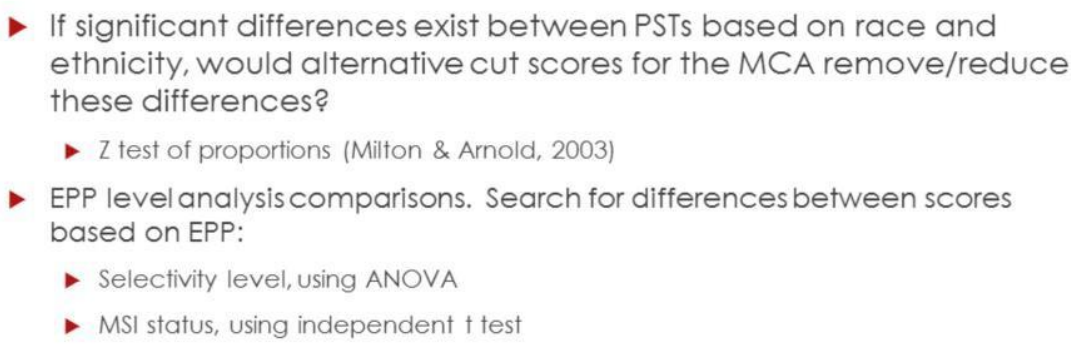

- EPP level analysis comparisons. Search for differences between scores based on EPP:

- Selectivity level, using ANOVA

- MSI status, using independent $\dagger$ test

Only the best scores of PSTs were used in this study, if the PST took multiple attempts. The comparison was between PSTs who passed all subtests of the Elementary Education Multi-Content Assessment, vs. those that failed at least one subtest.

\section{Data Analysis}

This collected data was compared using a Chi square test. This test compared the number of PSTs who passed all four subtests against PSTs who failed at least one, based on whether or not the PSTs were African American or Hispanic. 


\section{Research Question One: Participant Descriptive Statistics}

First, what were the descriptive summary statistics for the study participants when broken down by race, ethnicity, gender, institutional selectivity and MSI status?

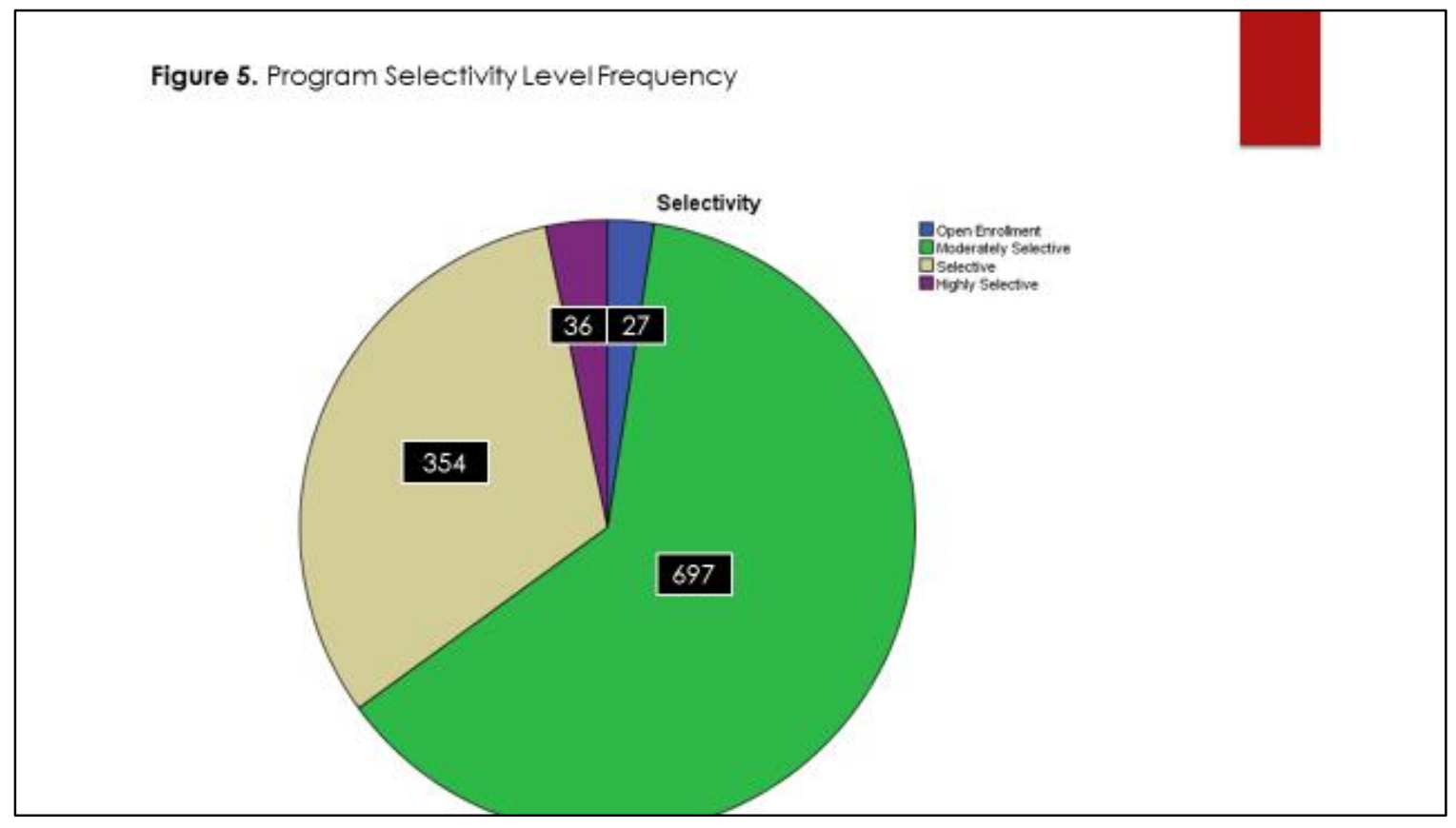

Frequency data related to selectivity level of EPP Indicates that nearly all PSTs attended moderately selective (green) or selective (gray) EPPs. 
Figure 5. Program Minority-Serving Institution Status Frequency

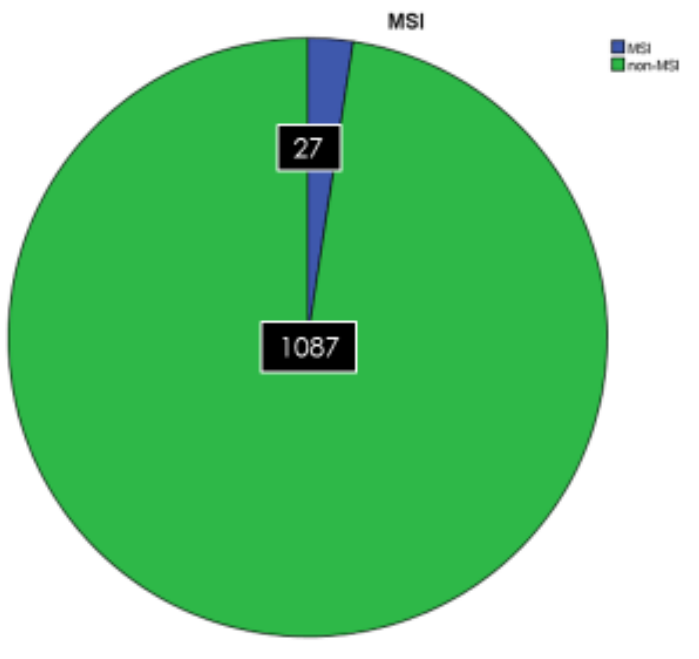

By a large margin, most PSTs in this study attended non-MSI EPPs.

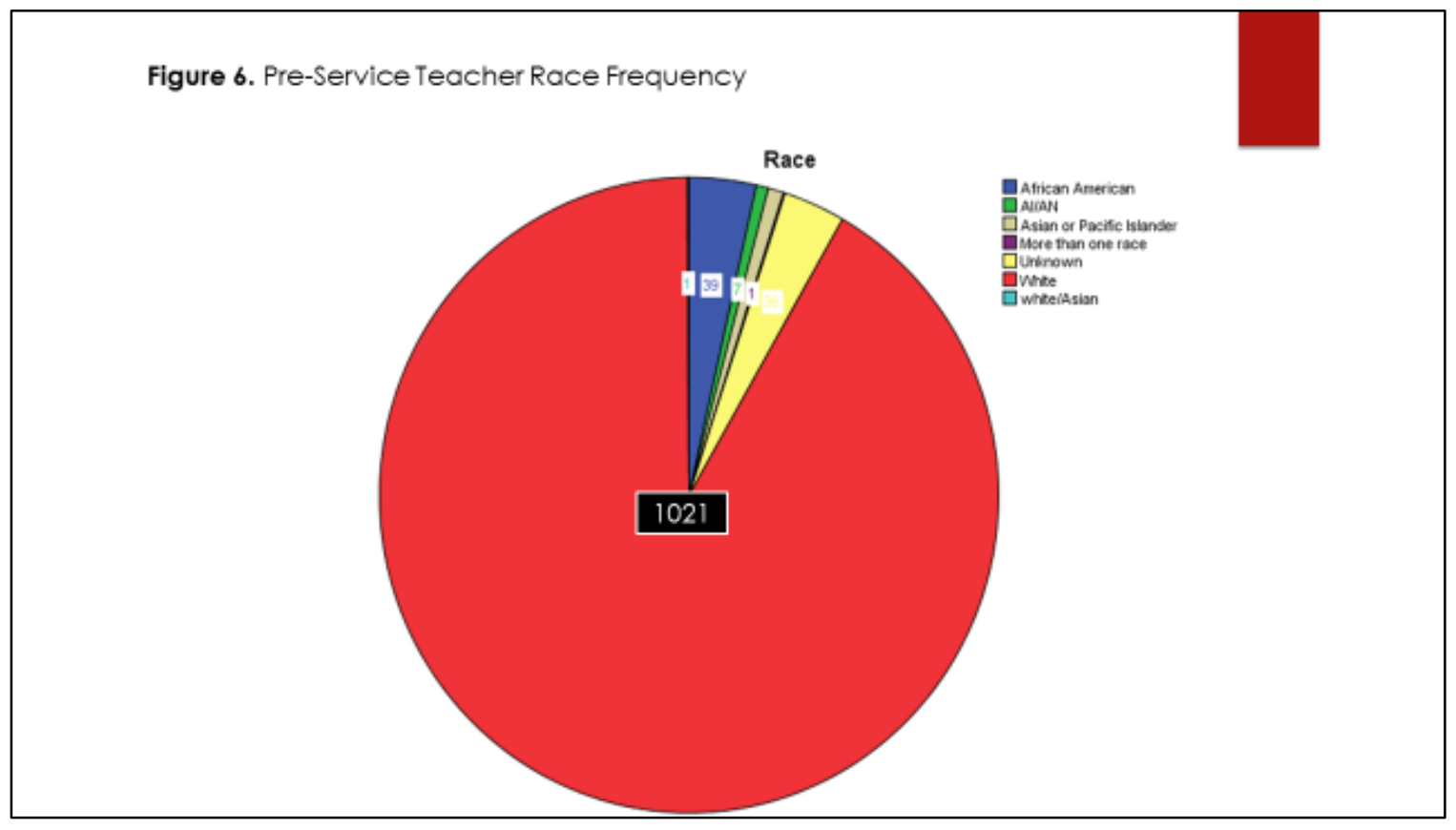

Again, a large margin of the PSTs reported their race as "White". 
Figure 7. Pre-Service Teacher Ethnicity Frequency

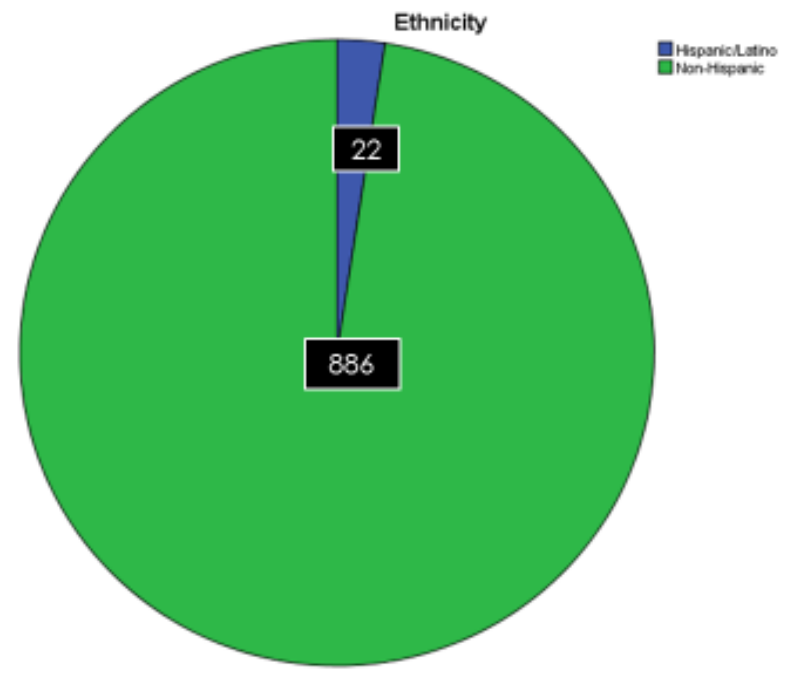

The large majority of PSTs reported being non-Hispanic.

Figure 8. Pre-Service Teacher Gender Frequency

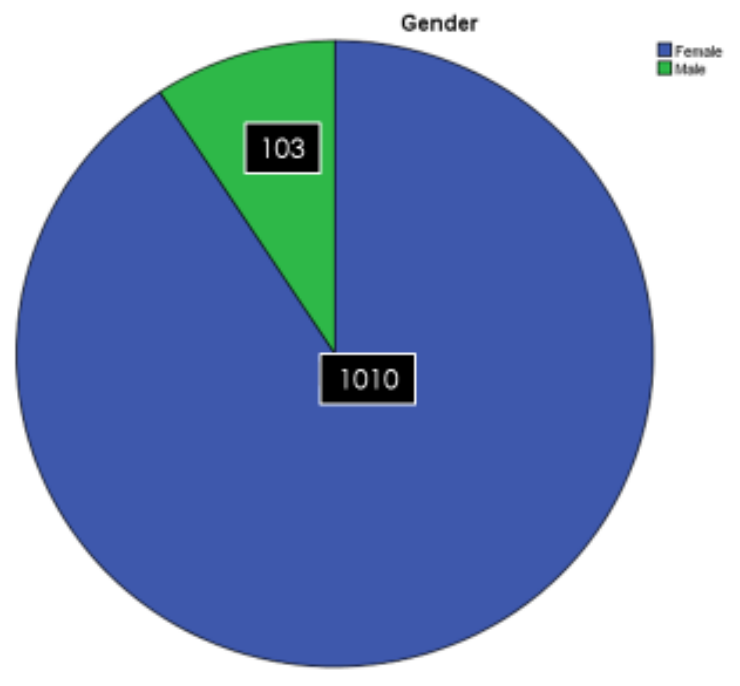

Nearly $90 \%$ of the respondents indicated their gender as "female". 


\section{Frequency Summary}

- Large sample $(n=1114)$

- But, not much representation from:

- Open enrollment or highly selective EPPs

- MSI EPPS

- PSTs from races other than White

- PSTs with ethnicities other than non-Hispanic

- PSTs who are male

While the sample was large $(\mathrm{n}=1114)$, most of the PSTs involved represented:

- Moderately selective or selective EPPs

- From non-MSI EPPs

- A self-reported race of White

- A self-reported ethnicity of non-Hispanic

- Female

\section{Data Analysis}

Quantitative PST data analyzed by Chi square test

(Field, 2013) 


\section{Research Question Six: Access to Profession by Race and Ethnicity}

This collected data was compared using a Chi square test. This test compared the number of PSTs who passed all four subtests against PSTs who failed at least one, based on whether or not the PSTs were African American or Hispanic.

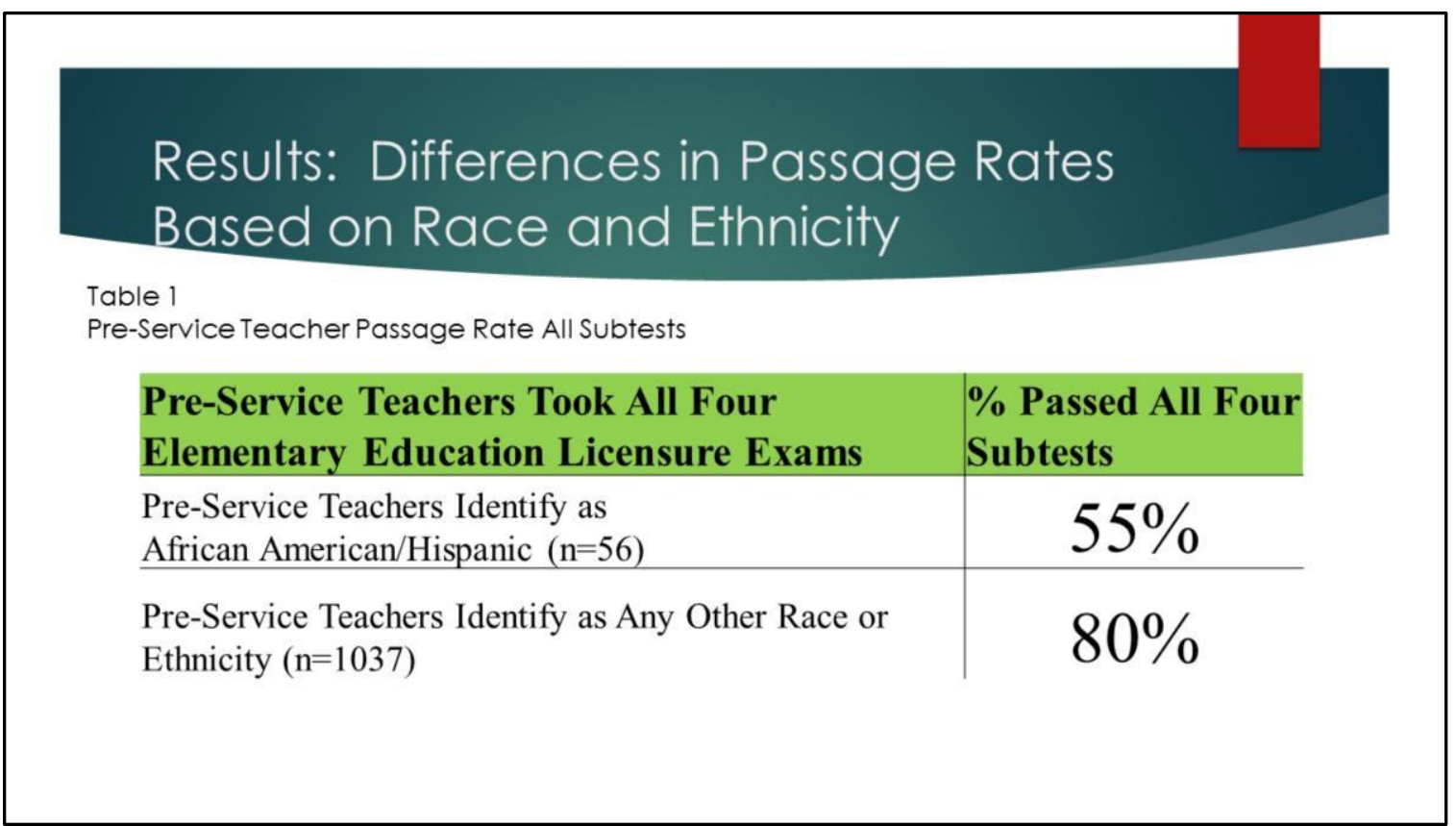

The final results indicate that only $55 \%$ of African American or Hispanic PSTs passed all four subtests of the Elementary Education MultiContent Assessment, compared to $80 \%$ of PSTs from any other race or ethnicity. 


\section{Results: All Between Group Differences Statistically Significant}

- Chi Square Test

- Alpha $=0.05$

- $P$ value $<0.000$

There is a significant difference in Missouri teacher licensure exam passage rates based on Pre-Service Teacher (PST) race and ethnicity

Using a Chi square test, this indicated a statistically significant difference in test performance between these populations. There was less than a $0.1 \%$ chance that these results occurred by random chance.

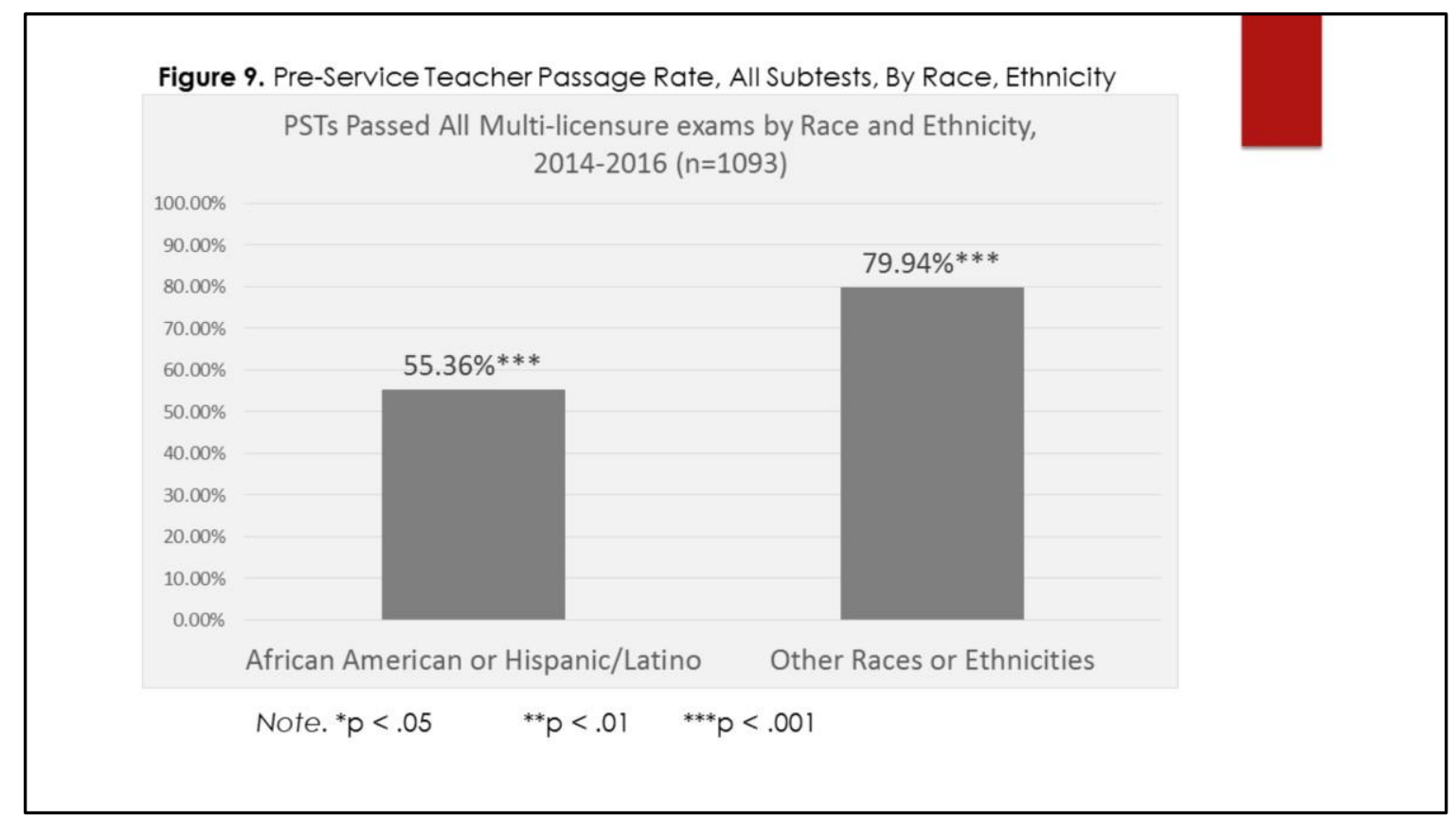

This graphical representation gives another view of these differences. 
Figure 10. Pre-Service Teacher Subtests Attempts and Passages, by Race/Ethnicity

PSTs Attempted and Passed all Multi-licensure exams, by Race and Ethnicity

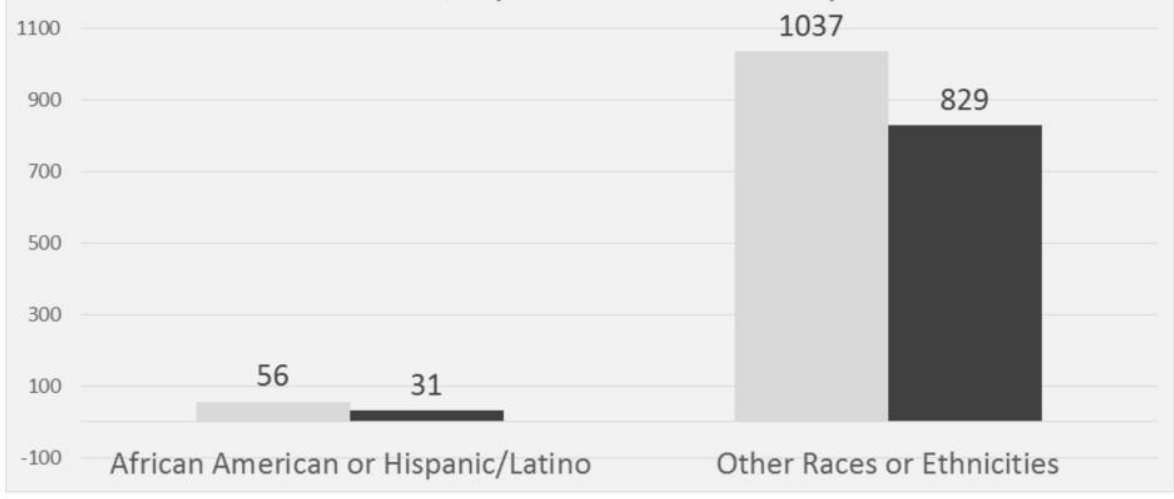

While considering the importance of cultural synchronicity and the impact of the Elementary Education Multi-Content Assessment on this construct, the researcher must note the difference in PSTs by race and ethnicity who even took this assessment. In the data gathered from 14 EPPs, only 56 African American or Hispanic PSTs took this assessment. This compared to 1037 PSTs of any other race or ethnicity. The impact of the Elementary Education Multi-Content Assessment is even more profound, as from this small sample only 31 African American or Hispanic PSTs pass all of these assessments, compared to 829 PSTs of any other race or ethnicity.

\section{Reducing Significant Differences: Alternative Cut Scores}

- Since significant differences did exist based on race and ethnicity, analysis was done on alternate cut scores

- Pearson postulated using different cut scores based on Standard Error of Measurement (SEM) (DESE, Evaluation Systems Pearson, 2015) 


\section{QUANTITATIVE ANALYSIS OF MCA}

Pearson considered the possibility of using different cut scores based on Standard Error of Measurement (SEM) around a cut score set by a panel of experts (Panel Based Cut Score), as noted in the Missouri Content Assessments Technical Manual Appendix (Department of Elementary and Secondary Education, Evaluation Systems Pearson. (2015). The SEM acts as a hypothetical standard deviation that would be calculated if one student took the test many times without any repeat effects. It is used as a way to account for error. For example, if a student is distracted by life events they could pass a cut score set a one SEM below the panel based cut score, but if the same student were not distracted they would easily reach the panel based cut score.

Every subtest of the Elementary Education Multi-Content Assessment has its own SEM (Department of Elementary and Secondary Education, Evaluation Systems Pearson. (2015).

- $\quad$ English: 16.0

- $\quad$ Math: 14.5

- $\quad$ Science: 15.4

- $\quad$ Social Studies: 15.2

\section{Reducing Significant Differences: Alternative Cut Scores}

Table 2

Subtest Cut Scores and Standard Errors of Measure

\begin{tabular}{|c|c|c|c|c|c|}
\hline $\begin{array}{l}\text { Elementary MCA } \\
\text { Alternate Cut Scores } \\
\text { Based on SEM }\end{array}$ & -2 SEM & -1 SEM & PBCS & +1 SEM & +2 SEM \\
\hline English LA & 188 & 204 & 220 & 236 & 252 \\
\hline Math & 191 & 205.5 & 220 & 234.5 & 249 \\
\hline Science & 189.2 & 204.6 & 220 & 235.4 & 250.8 \\
\hline Social Studies & 189.6 & 204.8 & 220 & 235.2 & 250.4 \\
\hline
\end{tabular}

Note: $\mathrm{MCA}=$ Missouri Content Assessment; $\mathrm{PBCS}=$ Panel Based Cut Score; SEM $=$ Standard Error of Measure

This is an illustration of what alternative passing scores were considered by Pearson. In the middle of this table is the Panel Based Cut Score (PBCS), and this is surrounded on either side by values at one and two SEMs from this PBCS. 


\section{What Cut Scores Would Remove Significant Differences?}

- Based on:

- Race/ethnicity?

- Gender?

- Analyzed each group's ability to reach alternate scores using:

- Z test of proportions

- Two tailed assessment

- Bonferroni adjustment (Field, 2013)

- Using alpha $=.05$

Research Question 5: Alternative Cut Scores

To determine which of these alternative cut scores would remove significant differences in group passage rates, each was analyzed using Z test of proportions (Milton \& Arnold, 2003). This analysis attempted to determine which cut scores had no statistically significant differences between groups based on race and ethnicity and gender.

\section{Race and Ethnicity: Alternative Cut Scores}

Table 3

Significant Differences in Subtest Subtest Passage Scores by Race/Ethnicity at Cut Scores and Standard Errors of Measure

\begin{tabular}{|c|c|c|c|c|c|}
\hline $\begin{array}{l}\text { Elementary MCA } \\
\text { Alternate Cut Scores } \\
\text { Based on SEM }\end{array}$ & -2 SEM & -1 SEM & PBCS & +1 SEM & +2 SEM \\
\hline English LA & 188 & 204 & 220 & 236 & 252 \\
\hline Math & 191 & 205.5 & 220 & 234.5 & 249 \\
\hline Science & 189.2 & 204.6 & 220 & 235.4 & 250.8 \\
\hline Social Studies & 189.6 & 204.8 & 220 & 235.2 & 250.4 \\
\hline
\end{tabular}

Note: $\mathrm{MCA}=$ Missouri Content Assessment; $\mathrm{PBCS}=$ Panel Based Cut Score;

SEM = Standard Error of Measure

This is an illustration of the results when comparing scores from PSTs who are African American and Hispanic vs. scores from PSTs who identify as any other race or ethnicity. All cells in red indicate that these cut scores have a significant difference, while cut 
scores in white indicate that there is no statistically significant difference. In this case, using the cut score of -2 SEM below the PBCS would remove all significant differences.

\section{Reducing Significant Differences: Alternative Cut Scores}

Table 4

Significant Differences in Subtest Subtest Passage Scores by Gender at Cut Scores and Standard Errors of Measure

\begin{tabular}{l|l|l|l|l|l|}
$\begin{array}{l}\text { Elementary MCA } \\
\begin{array}{l}\text { Alternate Cut Scores } \\
\text { Based on SEM }\end{array}\end{array}$ & -2 SEM & -1 SEM & PBCS & +1 SEM & +2 SEM \\
\hline $\begin{array}{l}\text { English LA } \\
\text { Math }\end{array}$ & 188 & 204 & 220 & 236 & 252 \\
\hline Science & 191 & 205.5 & 220 & 234.5 & 249 \\
\hline Social Studies & 189.2 & 204.6 & 220 & 235.4 & 250.8 \\
\hline
\end{tabular}

Note: $\mathrm{MCA}=$ Missouri Content Assessment; $\mathrm{PBCS}=$ Panel Based Cut Score;

SEM = Standard Error of Measure

Here is an illustration of the same analysis based on gender. All cells in red indicate a statistically significant difference in scores based on whether PSTs identified as male or female. As can be seen, these results are not as straight forward as those shown related to race and ethnicity. In this case, using the PBCS for all subtests would remove all statistically significant differences.

\section{Explanation}

- Z test analyses indicate significant differences among PSTs of different races and ethnicities for all but one subtest, mathematics

- Lowering cut scores one or two SEM would remove these differences

- Similar Z test analyses based on gender indicated that the current PBCS for all subtests may show the least differences between groups 
As a summary, statistically significant differences disappear across all subtests when a cut score -2 SEM below the PBCS is used. However the PBCS appears to be the option that would remove all statistically significant differences based on gender.

\section{Results Based on EPP Attributes}

Comparing PST results based on:

- Selectivity level of EPP attended

- Open-enrollment

- Moderately selective

- Selective

- Highly selective

- Minority-Serving Institution (MSI) Status (MSI or non-MSI)

\section{Research Question Seven B.}

Further analyses focused on the status of the EPP that the PST attended. This study searched for differences in PST scores based on EPP selectivity level and MSI status.

\section{Results Based on EPP Attributes} Selectivity Level

- ANOVA

- There was a significant difference across all four subtests at $p<.001$

- English/LA, $F(3,1045)=17.720, p<.001, \omega^{2}=0.05$

- Math, $F(3,1045)=17.169, p<.001, \omega^{2}=0.04$

- Science, $F(3,1043)=20.864, p<.001, \omega^{2}=0.05$

- Social studies, $F(3,1040)=26.933, p<.001, \omega^{2}=0.07$

- However, effect sizes were quite small 


\section{Research Question Seven A.}

The following is in response to research question 7. Is there a difference in Elementary Education MCA subtest scores for the following institutionlevel variables: selectivity level?

An ANOVA was used to seek for differences in Elementary Education Multi-Content Assessment scores based on EPP selectivity level (Field, 2013). All four subtests indicated statistically significant differences based on selectivity level, and that EPPs with higher selectivity levels scores significantly higher than lower levels. However, the effect sizes for each of these analyses were quite low.

\section{Results Based on EPP Attributes} Selectivity Level

- Tukey HSD (Honestly Significant Difference)

- PSTs from all selectivity levels showed significant differences in scores $(p<.05)$ except for:

- Mathematics, Selective vs. Highly Selective

- Social studies, Open Enrollment vs. Moderately Selective

While using a post hoc analysis was conducted to investigate differences between EPPs based on selectivity level. This was the Tukey Honest Significant Difference (HSD) test (Field, 2013). Again, PSTs from different selectivity levels showed significantly different results across all four subtests except in two cases. 


\section{Results Based on EPP Attributes MSI Status}

Using t-test, PSTs from MSIs scored significant lower on all subtests

- English: PSTs from MSIs scored lower $(M=224.27, S E=5.512)$ than nonMSI PSTS $(M=239.74, S E=.722)$. This difference, $-15.472, \mathrm{BCa} 95 \% \mathrm{Cl}[-$ $24.742,-6.201]$, was significant $t(1101)=-3.275, p=.001$; Effect size was quite large with a Cohen's $d=.65$.

Next, PST scores on each subtest were compared based on the MSI status of the EPP the PST attended. The MSI analysis showed statistically significant results with a quite large effect size in the English subtest. In this case, PSTs who attended an MSI scored significantly lower than PSTs who attended a non-MSI EPP.

\section{Results Based on EPP Attributes} MSI Status

- Using t-test, PSTs from MSIs scored significant lower on all subtests

- Math: PSTs from MSIs scored lower $(M=230.08, S E=4.192)$ than nonMSI PSTS $(M=249.36, S E=.750)$. This difference, $-19.285, \mathrm{BCa} 95 \% \mathrm{Cl}[-$ 28.841, -9.729], was significant $t(1101)=-3.960, p<.000$; Effect size was quite large with a Cohen's $d=.78$.

The MSI analysis showed statistically significant results with a quite large effect size in the Math subtest. In this case, PSTs who attended an MSI scored significantly lower than PSTs who attended a non-MSI EPP. 


\section{Results Based on EPP Attributes MSI Status}

- Using t-test, PSTs from MSIs scored significant lower on all subtests

- Science:PSTs from MSIs scored lower $(M=223.73, S E=5.691)$ than nonMSI PSTS (M $=239.70, S E=.698)$. This difference, $-15.972, \mathrm{BCa} 95 \% \mathrm{Cl}[-$ 24.940, -7.003], was significant $t(1099)=-3.494, p<.000$; Effect size was quite large with a Cohen's $d=.70$.

The MSI analysis showed statistically significant results with a quite large effect size in the Science subtest. In this case, PSTs who attended an MSI scored significantly lower than PSTs who attended a non-MSI EPP.

\section{Results Based on EPP Attributes}

\section{MSI Status}

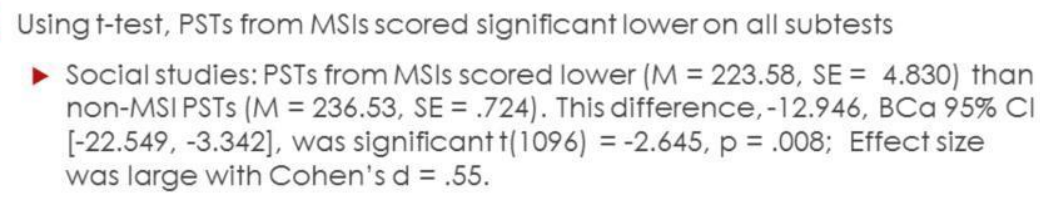

The MSI analysis showed statistically significant results with a quite large effect size in the Social Studies subtest. In this case, PSTs who attended an MSI scored significantly lower than PSTs who attended a non-MSI EPP. 


\section{Results: Final}

There was a statistically significant difference in Missouri teacher licensure exam passage rates based on Pre-Service Teacher (PST) race and ethnicity

PSTs who were African American or Hispanic were less likely to pass all licensure exams than PSTs from all other races or ethnicities

Final results indicate a statistically significant difference in the passage rates of the Elementary Education Multi-Content Assessment when comparing PSTs of different race or ethnicity. Specifically, PSTs who identified as African American or Hispanic had lower passage rates than PSTs from all other races or ethnicities.

\section{Results: Final}

Using alternate cut scores based on SEM would remove significant differences based on race and ethnicity, but not necessarily related to gender.

- There were significant differences in most subtests related to selectivity level, but with small effect sizes

- There were significant differences with large effect sizes related to MSI status, but selectivity could have been a confounding variable

Final results indicate a statistically significant difference in the passage rates of the Elementary Education Multi-Content Assessment when comparing PSTs of different race or ethnicity when using alternative cut scores. Moving the cut scores to -2 SEM in all subtests would remove all statistically significant differences based on race and ethnicity. 
However, moving the cut scores would not have the same effect on differences based on gender.

Selectivity showed significant differences as well, in that EPPs with higher selectivity levels had EPPs who received higher subtest scores. However, these effect sizes using Omega squared were quite small (Field, 2013).

The largest effect size and statistically significant difference came when reviewing PST scores who attended EPPs recognized as MSIs vs. EPPs that were not MSIs. However, there might have been a confounding variable. The two MSIs who supplied data were also the only open enrollment selectivity level EPPs that offered data as well.

\section{Discussion and Implications:} By Research Question

- The goal of this study is to search for differences in Missouri teacher licensure exam passage rates based on:

- Pre-Service Teacher (PST) race and ethnicity

- Potential use of alternative exam cut scores

- Preparation program selectivity level

Preparation program status as a Minority-Serving Institution

We should discuss what these results mean to Missouri EPPs, PSTs, educator preparation accountability and cultural synchronicity in state public schools. 


\section{Discussion and Implications: By Pillars}

\section{- Pillars:}

- Teacher licensure exams as accountability measures

- Impact of cultural synchronicity on Pk-12 outcomes

- Impact of accountability measures on cultural synchronicity

These results was viewed through lens of our three previous literature review pillars. These include: teacher licensure exams; the impact of cultural synchronicity; and the intersection of both.

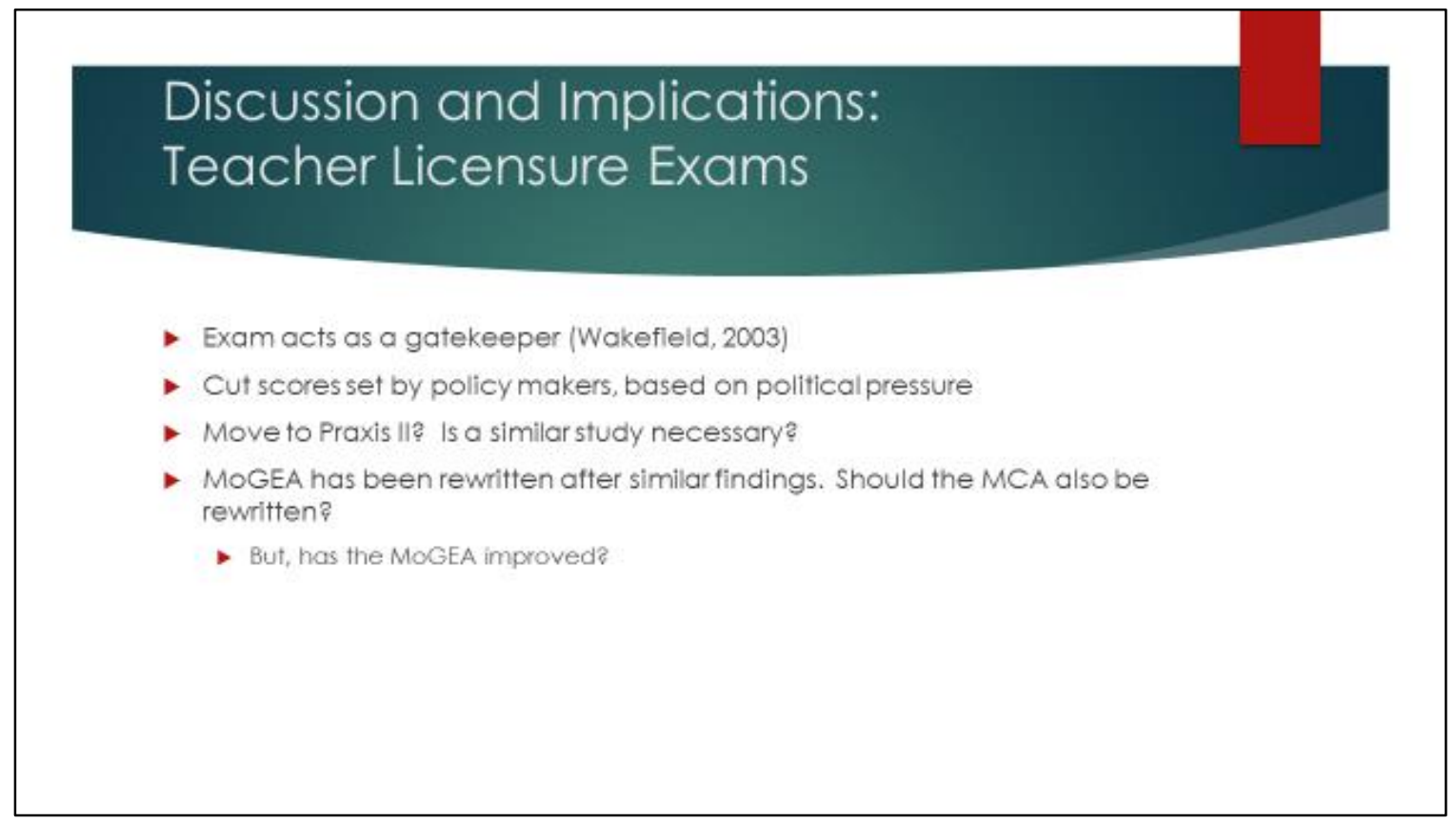

These licensure exams do act as gatekeepers to the teaching profession (Bennett, 2009). In addition, the final decision for which cut scores are set for these licensure exams are set by policy makers based on pressure to enact accountability measures (Wakefield, 2003). Both of these impact the final percentage of already few African American and Hispanic PSTs who become teachers. 
Some potential changes that may impact how the Elementary Education Multi- Content Assessment removed diverse teachers from the workforce could be to:

- $\quad$ Change from the current teacher licensure exam used in Missouri to the more widely used PRAXIS II. However, similar research should be conducted on this assessment to determine if similar differences in group outcomes exist based on race, ethnicity and gender.

- DESE could consider an entire content rewrite of this assessment, similar to the strategy they took following Edmonds' (2014) study.

\section{Discussion and Implications: Impact of Cultural Synchronicity on Pk-12}

- Positive matching effects of teachers of color on students of color, regardless of teacher test score

- Current Missouri teacher licensure exam will remove more teachers of color from workforce

- This will negatively impactPk-12 students of color

- Research should be conducted to record this expected decline in achievement among Missouristudents of color

Through a series of steps, the use of the Elementary Education Multi-Content Assessment will negatively impact Pk-12 students of color. If policy makers will not modify this assessment or how it is used, research should be conducted to chronicle the expected decrease in academic performance among Missouri Pk-12 students of color. This is especially the case if similar differences in scores can be found in all 56 of the Missouri Content Assessments as was found in the elementary education version. 


\section{Discussion and Implications: Impact of Teacher} Licensure Exams on Cultural Synchronicity

Licensure exams will reduce teachers of color in Missouri

- Would modification of cut scores impact ability of PSTs of color to pass these licensure exams?

If the licensure exams in Missouri remain unchanged, perhaps a modification in cut score could result in the removal of significant differences based on race and ethnicity. Research should be conducted on this to determine if the possibility of a cut score with no differences in passage rates based on race or ethnicity would even exist. If so, advocacy measures should be taken to move the cut score to a level that removes these differences.

\section{MEGA'S Three Objectives}

Recruit the Right People

Assess Content Knowledge

aAssess Performance

(DESE, 2016, August 3) 
As indicated in a DESE webinar from 2016, the three objectives of all assessments included under the banner of the Missouri Educator Gateway Assessments (MEGA) should be to recruit the right people as PSTs and assess PST content knowledge and teacher performance. While teacher performance is assessed with the Missouri PreService Teacher Assessment, many questions arise as to whether the first two objectives are at odds with each other.

\section{MEGA Objectives}

- Are the right people being recruited?

- Is content knowledge more important than teacher diversity?

- Are these licensure exams effective measures of teacher performance?

Should DESE define the "right people" recruited as diverse? According to the Equity Plan developed by DESE, this office does endeavor to recruit a diverse workforce (DESE, 2015). However, as the results above indicate, across 14 Missouri EPPs, only 56 African American or Hispanic PSTs in elementary education programs reached the final gateway to teacher licensure, the Elementary Education Multi-Content Assessment. Of these, only 31 passed these assessments. If only 31 new elementary teachers from diverse backgrounds were licensed to teach from these EPPs since 2014, this would represent a significant negative impact of these assessments on Missouri education. 


\section{Conclusions}

Diverse teachers on average receive lower standardized teacher test scores

- BUT this does not equate to teaching ability or Pk-12 learning outcomes

- Teachers from under represented groups have positive impacts on academic success of PK-12 students with similar backgrounds (Goldhaber \& Hansen, 2010; Steinberg \& Weiner, 2015, February)

- Increasing the number of racially and ethnically diverse teachers while not settling for lower ability to teach should be promoted

The final conclusion would be that a change needs to take place in how PSTs are assessed according to content knowledge.

\section{Conclusions}

Limiting use of some of these exams or reevaluating each exam's ability to predict successful teachers could reduce or remove differences based on race, ethnicity, gender and EPP status if they are deemed ineffective screens

If "recruiting the right people" as teachers is truly the most important objective of MEGA, then steps should be taken to modify either the assessment used or its cut score to positively impact the diversity of the Missouri teacher workforce. 


\section{Back to Our Analogy: Two Magnets in Opposition}
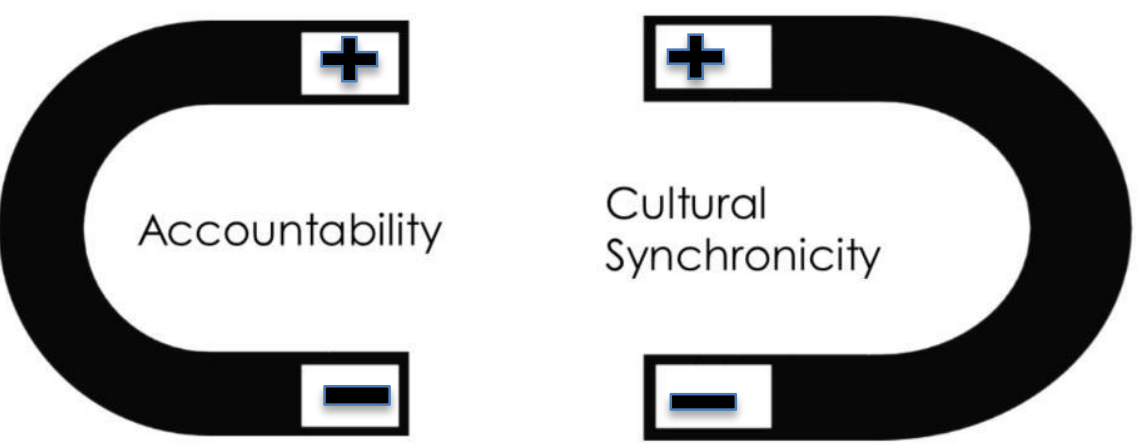

This analogy still appears accurate. The construct of cultural synchronicity cannot be changed. Teacher from diverse backgrounds have positive impacts on students from diverse backgrounds.

\section{Flip the Polarity}

- Cultural synchronicity is a fixed attribute

- Changes must happen according to accountability how Missouri Content Assessment is used among PSTs and EPPs in Missouri

- Final points

- Research shows that cultural synchronicity has positive impact on Pk-12 leamers

- Research shows only weak relationship between content knowledge and Pk-12 learning

- Accountability policies should be modified to lower content knowledge requirement to ensure more cultural synchronicity

Since this construct of cultural synchronicity is set, perhaps the MOSBOE should consider modifying accountability policies to ensure more cultural synchronicity within Missouri classrooms. 


\section{Contact Information}

\section{Mike McBride}

- mam77 anwmissouriedu

(660) 562-1089

Dr. Tim Wall

- TIMWALLanwmissouri.edu

- (660) 853-9039

\section{References}

- Allen, J.P., Pianta, R. C., Gregory, A., Mikami, A. Y., \& Lun, J., (2011). An interaction-based approach to enhancing secondary school instruction and stúdent achievement. Science, 333, 1034-1037. Retrieved from hittp://files.eric.ed.gov/fulltext/ED556046.pdf

- American Association of Colleges for Teacher Education. (2013). Minority-Serving Institutions Vital to Preparing

Minority Educators. Retrieved from hittps://secure.aacte.org/apps/r/resource.php? resid=3348.ref=rl

Anderson, J. (2009). Illusions of accountability: Credit and blame sensemaking in public administration.
Administrative Theory and Praxis, 31(3) 322-339. doi: 10.2753/ATP1084-1806310302

- Aud, S., Fox, M. A., KewalRamami, A. (2010). Status and trends in the education of racial and ethnic groups. (NCES Report 2010-015). Retrieved from National Center for Education Statistics website http://nces.ed.gov/pubs2010/2010015.pdf

- Bennett, C. I., McWhorter, L. M., \& Kuykendall, J. A. (2006). Will I ever teach? Hispanic and African American students' perspectives on Praxis I. American Educational Research Journal, 43(3), 531-575, doi: 10.3102/00028312043003531

- Brooks, M., West-Olatunij, C., Blackmon, A. T., Froelich, K., De La Torre, W., Montano, T., \& Smith, R. J. (2012). Minority-serving institutions and their contribution to advancing multicultural teacher education pedagogy. Education, 133(2), 349-360. Retrieved from PChecking.asp?http://ezproxy. nwmissouri.edu:2057/login.aspx? direct

Creswell, J. W. (2014). Research design: Qualitative, quantitative and mixed methods approaches. (4 $4^{\text {th }}$ ed.). Los Angeles, CA: Sage. 


\section{References}

- Darling-Hammond, L. (2004). Inequality and the right to learn: Access to qualified teacher in California's public schools. Teachers College

- Department of Elementary and Secondary Education. (2014). Missouri educator gateway exams. Retrieved from

- Department of Elementary and Secondary Education. (2015). Ensure equitable access to excellent educators. Retrieved from

- Department of Elementary and Secondary Education. (2016. August 3). MoPTA webinar.

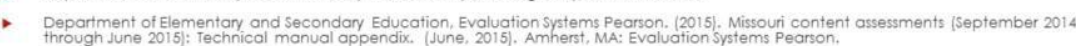

- Edmonds, J. M. (2014). Missouri General Education exam: Examination of teacher PST scores and predictor variables (Unpublished

- Field. A. (2013). Discovering statistics using IBM SPSS Statistics (4thed.). Thousand Oaks, CA: Sage.

- Goldhaber, D., \& Hansen, M., (2010). Race, gender, and teacher testing: How informative a tool is teacher licensure testing? American

- Hom, C. L. (2003). High-stakes testing and students: Stopping or perpetuating a cycle of failure? Theory into Practice, 42(1), 30-41.

- Invine, J. J. (2012). Complex relationships between multicultural education and special education: An African American

- Jonsson, $P$, (2003). White teachers flee Black schools: Some see exodus in South as a new form of segregation. Christian Science Monitor.

\section{References}

- Kirk, J. A. (2009). The NAACP campaign for teachers' salary equalization: African American women
educators and the early civil rights struggle. The Journal of African American History, 94 (4), 529-552

- Memory, D. M., Coleman, C. L., \& Watkins, S. D. (2003). Possible tradeoffs in raising basic skills cutoff scores for teacher licensure: A study with implications for participation of African Americans in teaching. Journal of Teacher Education, 54(3), 217-227. doi 10.117/0022487103251746. Retrieved from

- Mills, C. \& Ballantyne, J. (2016). Social justice and teacher education: A systematic review of empirical work in the field. Journal of Teacher Education, 67(4), 263-276, doi: 10.117/0022487116660152

- Milton, J. S., \& Arnold, J. C. (2003). Introduction to probability and statistics: Principles and applications for engineering and computing sciences. (4th ed.). Crawfordsville, IN:McGraw-Hill.

- Missouri Department of Higher Education. (2016). Admissions selectivity categories. Retrieved from ns-selectivity.php

- Monroe, C. R., \& Odidah, J. E. (2004). The influence of cultural synchronization on a teacher's perceptions Education, 55(3), 256-268. Retrieved from http://ite. sagepub.com/content/55/3/256.full.pdf

- Nettles, M. T., Scatton, L. H., Steinberg, J. H., \& Tyler, L. L. (2011). Performance and passing rate differences of African American and White prospective teachers on Praxis examinations, (Research report ETS RR-1108). Retrieved from http://files.eric.ed.gov/fulltext/ED523733.pdf 
QUANTITATIVE ANALYSIS OF MCA

\section{References}

- Pitts, D. W. (2007). Representative bureaucracy, ethnicity, and public schools. Administration \& Society, 39(4), 497-526.

- Popham. W.J. (2000). Big change questions: "Should large-scale assessment be used for accountability?" - Answer. Depends
on the assessment. silly! Gournal of Educational Change, 1. 283-289. dol:10.1023/A:1010054525759

- Skiba, R. J., Michael, R. S., \& Nardo, A. C. (2000). The color of discipline: Sources of racial and gender disproportionality in school punishment. (Policy Research Report \#SRSI). Retrieved from

- Steinberg, J.\& \& Weiner. S. (2015, February). The imperative of educational preparation programs to improve teacher diversity.

- Uhlenberg, J. \& Brown, K. M. (2002). Racial gap in teachers' perceptions of the achievement gap. Education and Urban

- Villegas, A.M. M. \& Irvine, J. J. (2010). Diversitying the teaching force: An examination of major arguments. The Urban Review.

- Wakefield, D. (2003). Screening teacher candidates: Problems with high-stakes testing. Educational Forum, 76(4), 380-388.

- Wall, T. J. (2001). Correlative study between student scores on the A.C.T. and C-BASE examinations at Northwest Missouri State

- Wall. T. J. (2008). Evaluation of the impact of the participation in the T.E.S.T. examination preparation program on elementary (toral Dissertation. University of Missouri). Retrieved from 


\section{SECTION FIVE}

\section{CONTRIBUTION TO SCHOLARSHIP}

\section{Target Journal}

The target journal for publication is the Journal of Teacher Education. The Journal of Research on Technology in Education is the official journal of the American Association of Colleges for Teacher of Education.

\section{Rationale for this Target}

The Journal of Teacher Education publishes studies from original research in the field of educator preparation. Since 1950, the Journal of Teacher Education has acted as a quarterly research forum that has helped guide the field of education. While the issues of concern have shifted in 65 years, current areas of interest include: educator effectiveness; impacting the education needs of marginalized populations; EPP design; teacher selection; recruitment and retention from underrepresented populations; accountability policy; and differing paths to certification (American Association of Colleges for Teacher Education, 2016a).

\section{Outline for Proposed Contents}

Title Page

Abstract (approximately 100 words)

Introduction of the Problem

Review of the literature

Theoretical framework

Research questions

Methods

Results

Discussion

References

Tables and Figures

\section{Plan for Submission}

Who: Journal of Teacher Education

When: Fall of 2016

How: ScholarOne portal located at https://mc.manuscriptcentral.com/jteachered 


\section{ELEMENTARY PRE-SERVICE TEACHER AND EDUCATOR PREPARATION PROGRAM PERFORMANCE ON THE MISSOURI CONTENT ASSESSMENTS BY RACE, ETHNICITY, GENDER, PROGRAM SELECTIVITY AND MINORITY- SERVING INSTITUTION STATUS}

Submitted to

The Journal of Teacher Education

by

Dr. MICHAEL A. MCBRIDE

DR. TIMOTHY J. WALL

\& DR. MATTHEW SYMONDS 


\begin{abstract}
The Missouri Content Assessment is a standardized exam that is required for teacher certification in Missouri. This study analyzed differences between Pre-Service Teacher (PST) scores on the Missouri Content Assessments disaggregated by PST race, ethnicity and gender. Results indicated several statistically significant differences for Missouri Content Assessment (MCA) scores among underrepresented groups. The researcher concluded the MCA should be reviewed for content changes which may enhance the ability of all PSTs to earn licensure. The author recommends that future researchers investigate policies and practices related to Educator Preparation Programs (EPPs) and their use of state tests as accountable measures. Additionally, the researcher suggests a holistic analysis of the use of standardized examinations and potentially disproportionate negative impact on educational workforce diversity.
\end{abstract}

\title{
Introduction of the Problem
}

\section{Review of the Literature}

This section will review extant literature concerning the pillars of this study. These include: the Missouri Educator Gateway Assessments as accountability instruments for EPPs and PSTs; access to equitable education in American schools; and standardized exams and race in America. These pillars were reviewed through the dual theoretical frameworks of accountability and cultural synchronicity.

\section{Missouri Educator Gateway Assessments}

The Missouri Educator Gateway Assessment (MEGA) is a suite of assessments mandated by the Department of Elementary and Secondary Education (DESE) for PreService Teachers to pass before receiving certification to teach in Missouri (DESE, 


\section{QUANTITATIVE ANALYSIS OF MCA}

2014). MEGA utilizes a variety of assessment tools, including: a general education assessment; a work-styles inventory; a field experience observation form; a performance assessment; and a content assessment.

The Missouri General Education Assessment (MoGEA) is the general education assessment that college students must pass before entering an EPP in Missouri. Research by Edmonds (2014) indicates that there is a statistically significant difference in scores achieved by African American, Hispanic and female teacher Pre-Service Teachers and White male counterparts. While Edmonds' research covered the admission assessment into EPPs, no research has yet been completed on the Missouri Content Assessments, which are the subject-matter assessment PSTs must pass before receiving Missouri teacher certification.

The Missouri Content Assessments (MCA) are used as the certification content exam Pre-Service Teachers must pass before earning certification to teach in Missouri. DESE has approved a variety of Missouri Content Assessments to be used as certification exams in different subject matter areas and teaching levels (DESE, 2014). There is an MCA for any teaching content area, a total of 56 different assessments. A score of 220 on a scale of 100-300 is the current cut score for each MCA. The Pre-Service Teacher can take these subtests as many times as necessary to pass.

This study will focus on the Elementary Education Multi-Content Assessment (DESE, 2014). This is the multiple choice assessment required of all elementary education PSTs. This assessment is composed of four subtests, measuring Pre-Service Teacher content knowledge in English, mathematics, science and social studies. These assessments are $\$ 110$ if taken at once or $\$ 39$ if taken as separate subtests. 


\section{QUANTITATIVE ANALYSIS OF MCA}

As noted, previous research on the MoGEA has indicated differences in passage rates based on race and ethnicity, restricting the number of diverse PSTs. While this study will investigate differences in MCA passage rates along these same lines, education in America has been restricted based on racial differences since its inception.

\section{Review of Access to Equitable Education and Race in American Schools}

From the Civil War to Brown vs. Board of Education. People of color seeking adequate education in the United States have faced a variety of obstacles. The educational opportunities offered to African American slaves were sparse (Irons, 2004). The end of the Civil War saw the development of Freedman's Bureau, a group of policymakers focused on providing adequate education to African Americans in the former confederate states (Anderson, 1988). Also, reconstruction era legislation mandated an end to the segregation of schools in 1870 . But, by 1875 nearly all of these laws had been overridden by state laws placing segregation back into effect. This scenario often lead to substandard schools for African American children. African American teachers were also paid less than White teachers (Ravitch, 2013). The cultural racial inequity was part of systematic barriers to public services, including education.

In the 1930 's, only $2 \%$ of Southern African Americans were considered professionals (Irons, 2004). The other $98 \%$ were share croppers, house help or factory laborers. The education Southern African Americans received ensured training for these trades but not the requisite skills to rise above them (Irons, 2004). It was not until Brown vs. the Board of Education in 1954 overrode segregation that many of these barriers were confronted for the first time. Now, African American and White students were required 


\section{QUANTITATIVE ANALYSIS OF MCA}

to have the same educational experience. However, issues related to African American education would persist despite policy changes.

Current issues in race and education. Life outcomes are less favorable for high school dropouts than high school graduates in general. But, high school dropouts who are African American are less likely to be employed and more likely to be institutionalized than dropouts from any other race or ethnicity, as seen in Table 1. Even when African American or Hispanic students remain in high school, they often face less favorable opportunities and outcomes than students of other races and ethnicities.

Issues related to environment. Some of these outcomes can be explained by differences between school districts. In a report by Boser (2014) school districts were ranked according to financial efficiency and whether funds were spent in areas most likely to assist student development. Hispanic students were twice as likely to be in the least productive districts as the most productive. African American students were 8 times more likely to be in the least productive districts than the most productive (Boser, 2014). In addition, schools with majority White students were more than twice as likely to offer advanced placement courses than schools where African American or Hispanic students were the majority (Annie E. Casey Foundation, 2006).

The National Center for Education Statistics (2015) took an in-depth look at why these performance gaps persist between White students and students of color as a matter of school environment. When the study accounted for SES and other student, teacher and school variables, African American students who attended majority African American schools did perform worse than African American students from majority White schools. The most interesting finding of this study indicated the White achievement gap is more 


\section{QUANTITATIVE ANALYSIS OF MCA}

strongly related to within-school factors, as opposed to between-school factors. That would indicate that within schools accessibility to technology, newer textbooks and more experienced teachers was inequitable in a way that benefited White students over African American students.

Issues related to teacher ability. Further studies agree that students of color were more likely to have inexperienced or ineffectual teachers (Annie E. Casey Foundation, 2006). Aud, Fox and KewalRamami (2010) studied differences between teachers at majority White public schools vs. majority non-White public schools. In public schools with majority African American enrollment, $75 \%$ of math teachers had a college math major or certification to teach math. If a school was majority Hispanic, $85 \%$ of math teachers had a college math major or math certification. However, at majority White schools, $92 \%$ of math teachers had a math major or certification (Aud, Fox, \& KewalRamami, 2010).

Addressing educational inequities. The DESE Equity Plan notes that while part of the demand for better teachers in high poverty and high diversity schools comes from workforce issues, such as teacher preference and lack of incentives for teaching in difficult to staff areas, that Educator Preparation Programs (EPPs) have also been a factor (Department of Elementary and Secondary Education, 2015). DESE indicates that EPPs have not prepared PSTs to teach in challenging conditions, and that too few of the PSTs are qualified to teach in particular content areas.

\section{Standardized Exams and Race in American Educator Preparation}

Overview. The final goal of PST assessments is to determine which PSTs will provide the best teaching services to Pk-12 students. The question is whether multiple 


\section{QUANTITATIVE ANALYSIS OF MCA}

choice, high stakes assessments can accomplish this task. Sources indicate that certified teachers do tend to have a more positive impact on students (Cowan \& Goldhaber, 2015). Since a standardized exam is usually included in teacher certification requirements, this finding would suggest that PSTs who pass a standardized exam are better teachers than those that cannot. However, Angrist and Guryan (2004) indicate that standardized tests are useless in predicting teacher impact on students and may also deter some potentially successful PSTs from becoming teachers.

Historical perspective of teacher testing and race. One of the first instances of standardized teacher testing in the 1930's served as a proxy to ensure that African American teachers would be paid less than White counterparts (Kirk, 2009).

Standardized testing at the time was seen as a "fairer" way to ensure that all teachers had the same opportunity to receive equal pay. In that regard, equality activists hoped to use standardized exam scores to lower the possibility of pay discrimination based on race. A precursor to the Praxis was used. African American teachers scored lower, and were therefore paid less.

Current status of teacher testing and race. Nettles, Scatton, Steinberg and Tyler (2011) took an in-depth look at the ability of African American PSTs to pass the current Praxis II. The Praxis II is a standardized teacher content assessment developed by ETS to act as a certification requirement (similar to the Missouri Content Assessments). The first time passage rate for African American PSTs completing the Math content knowledge assessment was $25.3 \%$, versus $72.6 \%$ of White PSTs. This was similar to the social studies ( $47.6 \%$ vs. $83.9 \%$ ) and English (46.4\% vs. $88.7 \%$ ) content exams. 


\section{QUANTITATIVE ANALYSIS OF MCA}

African American teachers in Atlanta reported their EPPs did not prepare them properly to pass current teacher certification exams (Taylor, 2013). Large percentages of African American PSTs failed their certification exam. Some of these PSTs were able to get the testing requirement waived based on experience. One of those teachers was named Teacher of the year at her school in 2009. Another was named teacher of the year after failing the Praxis II ten times. This would indicate that standardized exam scores were unrelated to teacher success (Taylor, 2013).

\section{Theoretical Frameworks}

Accountability. This study focuses on the use of teacher certification exams as accountability measures by the Missouri accrediting body, the Department of Elementary and Secondary Education (DESE). The Missouri Content Assessments are used as accountability measures for PSTs. These accountability measures attempt to ensure that PSTs are prepared to teach (DESE, 2014).

Anderson (2009) suggests that accountability exists as a relationship between an accounter and the accountable. Anderson (2009) states that the accounter seeks to reward or punish good or bad outcomes by the accountable. According to theory, these rewards and punishments ensure the accountable follows due diligence to complete work at standards agreed upon by both parties. The end relationship would be one of the accountable reaching upon goals while the accounter rewards the completed work. In this case, if a PST passes their Missouri Content Assessment, they have completed one hurdle of several towards gaining teacher certification. If a PST fails, they cannot be certified. 
QUANTITATIVE ANALYSIS OF MCA

Cultural synchronicity. Cultural synchronicity is the second theoretical framework that was considered during this study. Cultural synchronicity is the positive matching effect when students and teachers share cultural background (Irvine, 1990). Goldhaber and Hansen (2010) indicate that this matching effect is more vital towards student success than teacher assessment scores.

Accountability in teacher preparation and cultural synchronicity are two frameworks that are at odds in regards to educator preparation. While accountability seeks to ensure that the accountable (PSTs) provide effective proof of their content knowledge to the accounter (DESE), cultural synchronicity indicates that the positive matching effects of teacher and student cultural background outweighs the importance of content knowledge.

\section{Research Question Three: MCA Scores and Race, Ethnicity and Gender}

The research question that guided this study is:

Research Question: Is there a difference in Elementary Education MCA subtest scores when considering race, ethnicity and gender?

\section{Methods}

\section{Data Collection}

As Anderson (2009) puts forth, EPPs are currently the accountable party to provide data related to PST passage rates in the MCA. So, researchers contacted professionals at EPPs with access to this data. To enhance study participation the researcher wrote an introductory email message requesting data from Missouri Educator Preparation Program (EPP) assessment directors. This message included an overview of 


\section{QUANTITATIVE ANALYSIS OF MCA}

how the data would be used. This message was sent by a proxy and included an attached excel data template, as done in previous research conducted by Edmonds (2014).

This data template was an excel sheet with three rows of example data and included twelve data points. This file was first sent to an experienced EPP assessment director for review and feedback before being shared with Missouri EPP assessment directors for data collection.

The first data point was an optional example of a PST identifier. This consisted of the word of "Example" followed by a digit. No PST identifying information was requested, such as student name or number. The next data point was the name of the EPP.

In addition, the researcher was able to determine whether the PST attended a Minority-Serving Institution (MSI) or not. Only two Missouri EPPs are identified as MSIs. After data were collected, the institution names were removed and replaced with numeric codes indicating their selectivity and MSI status. This was done to maintain EPP anonymity (Field, 2013).

PST major was an additional data point. Nearly all PSTs in this study are likely to be Elementary Education majors, since the Elementary Multi-Content Assessments are the only content assessments included in the study. However, it is possible that PSTs with other majors took these assessments as well.

The template included column headings for PST scores on all four of the Elementary Education Multi-Content Assessments. Pearson designates these Missouri Content Assessments as: 007, the English/Language Arts Subtest; 008, the Mathematics 


\section{QUANTITATIVE ANALYSIS OF MCA}

Subtest; 009, the Science Subtest; and 010, the Social Studies Subtest (DESE, 2014). PST scores fall on a scale of 100 to 300 .

Irvine (1990) indicates that racial matching of students and teachers, known again as cultural synchronicity, is a valuable attribute related to student success. So, the template also requested PST race, ethnicity and gender. The potential race options were listed in a column heading. The options for PST race included: Black or African American; Asian/Pacific Islander; Native American/Alaskan Native; and White. The options for PST ethnicity included Hispanic/Latino and Non-Hispanic/Latino. PST gender was coded as "M" for male and "F" for female.

PST maximum ACT composite score was the final data point. Wall (2008) found significant relationships between and among standardized test scores used to certify Elementary Education teachers in Missouri EPP's. So, the ACT may be strongly related to Multi-Content Assessments as well.

\section{Data Sources}

The researcher presented on this proposed study with Dr. Tim Wall at the spring 2016 Missouri Association of Colleges of Teacher Education (MACTE) conference (Wall \& McBride, 2016, March). The presentation catered to EPP assessment directors, deans and program directors. As a by-product, the community was engaged and exhibited a willingness to partner in data collection and analysis. The researcher passed a sign-up sheet for programs that voiced interest in participating in this study. Missouri EPP assessment directors were the most appropriate data sources for this study, but all parties who signed the sheet were contacted with a request for data. 


\section{QUANTITATIVE ANALYSIS OF MCA}

EPP assessment directors were specifically targeted as they maintain databases of PST data needed for this study. In addition, if some sort of supervisor approval was required before their data were shared, these individuals were well versed on the topics of this study and could provide explanations about its goals and importance.

The 42 Missouri EPP's (as of 2016) represented a variety of enrollment sizes, campus cultures and campus philosophies (DESE, 2016). Some smaller EPPs did not have the resources to employ a full-time assessment director. In those cases assessment system development and data warehousing, including Elementary Education certification exam data, were typically done by a faculty member or other campus administrator.

The EPPs located in the two Missouri Minority Serving Institutions were specifically included in this study. MSIs are necessary to create a diverse teacher workforce (AACTE, 2013; Brooks et al., 2012). MSI PSTs are also less likely than PSTs from other EPPs to pass standardized exams (Steinberg \& Weiner, 2015).

\section{Data Analysis}

The goal of this study was to determine if there was a difference in Elementary Education MCA subtest scores when considering race and ethnicity. To this end, descriptive statistics and independent sample t-tests were calculated.

Descriptive statistics were compiled for each data template item. Similar to Edmonds (2014), independent samples t-tests were performed to determine the existence of differences in content assessment scores between PSTs from different demographic backgrounds. These analyses were conducted to search for statistically significant test score differences between PSTs who were African American or Hispanic compared with 


\section{QUANTITATIVE ANALYSIS OF MCA}

PSTs of any other race or ethnicity, as found in the Missouri General Education Assessment by Edmonds (2014).

\section{Delimitations}

Only PSTs who attended Missouri EPPs were included in this study. It was possible for PSTs who completed preparation programs in other states to take the MultiContent Assessments and seek certification to teach in Missouri. These data were not included in the study. There also was no opportunity to randomly assign PSTs to different EPPs (Creswell, 2014).

In addition, there were 56 Missouri Content Assessments (DESE, 2014). This study only focused on the four Elementary Education Multi-Content Assessments required of Elementary Education PSTs.

These PSTs must have been age 18 or older and must have sought certification since September 1, 2014. This is when the Missouri Content Assessments became required for Missouri teacher certification (DESE, 2014).

\section{Limitations}

All PSTs included in this study have taken and passed the MoGEA. This general education assessment was required of all college students before admittance into a Missouri EPP (DESE, 2014). This would remove a measure of test score variability in the study, since all participating PSTs have proven an ability to score well on a previous standardized assessment. In addition, this may lower the diversity of PSTs involved with the study, since PSTs who passed the MoGEA less likely to be African American or Hispanic (Edmonds, 2014). 
QUANTITATIVE ANALYSIS OF MCA

In addition, available data were dependent on participation from EPP assessment directors and approval by their supervisors. While assessment directors had an opportunity to sign up for participation in this study during the 2016 spring MACTE conference, this does not account for vacation schedules, unexpected workload changes, changes of employment and potentially uncooperative supervisors. The researcher offered to answer any questions about the study that supervisors may have had via an email message.

\section{Results}

\section{Population of the Study Group}

The sample size for this study was $n=1114$.

\section{Demographic Characteristics of the Study Group}

This sample was large at $n=1114$, but the proportion of PSTs who identified as White was high as shown in Tables 3, 4 and 5. Less than 10\% of PSTs identified as having a race other than White. Only $2 \%$ of PSTs who included ethnic data identified as Hispanic or Latino. By using the methods previously put forth by Edmonds (2014), the researcher combined PSTs who identified as African American and Hispanic or Latino. As shown in Table 5, this gives a small but significant group of PSTs, with a sample size of 63. Table 6 indicates that the sample was overwhelmingly female.

\section{Research Question Two: Normality}

The researcher used a Kolmogorov-Smirnov test to determine normality of the score data for each Multi-Content Assessment subtest. All four differed significantly from normality. The English/Language Arts subtest received a score on the K-S test of $\mathrm{D}(1103)=.091, \mathrm{p}<.000$. Likewise, the Math subtest differed significantly from normal 


\section{QUANTITATIVE ANALYSIS OF MCA}

with $\mathrm{D}(1103)=.058, \mathrm{p}<.000$ and the Science subtest received a K-S score of $\mathrm{D}(1101)=$ $.096, \mathrm{p}<.000$. Finally, the Social Studies subtest received a K-S score of $\mathrm{D}(1089)=$ $.105, \mathrm{p}<.000$.

However, since the sample sizes were large for each subtest, the researcher also produced Q-Q plots to determine if the K-S scores could be considered valid. Viewing the Q-Q plots for each subtest, the researcher determined the scores for each subtest of the Multi-Content Assessment to be normal, as can be seen in Figures 2, 3, 4 and 5.

\section{Comparing Scores by Race and Ethnicity}

In the English Language Arts subtest, on average, PSTs who reported their race as African American or ethnicity as Hispanic or Latino received lower scores $(M=227.55$, $S E=3.04)$, than PSTs who did not report as being part of this race or ethnicity $(M=$ $240.06, S E=.74)$. This difference, -12.514 , BCa $95 \%$ CI [-18.611, -6.418], was significant $t(1098)=-4.028, p=.000$; it also represented a medium effect size of $d=$ 0.52. Results are provided in Table 7.

In the Mathematics subtest, on average, PSTs who reported their race as African American or ethnicity as Hispanic or Latino received lower scores $(M=231.71, S E=$ 2.86), than PSTs who did not report as being part of this race or ethnicity $(M=249.92$, $S E=.76)$. This difference, -18.213 , BCa 95\% CI [-24.459, -11.967], was significant $t(1098)=-5.721, p=.000 ;$ in addition this represented a large effect size of $d=0.74$. Results are provided in Table 8.

In the Science subtest, on average, PSTs who reported their race as African American or ethnicity as Hispanic or Latino received lower scores $(M=224.48, S E=$ 3.13), than PSTs who did not report as being part of this race or ethnicity $(M=240.16$, 


\section{QUANTITATIVE ANALYSIS OF MCA}

$S E=0.71)$. This difference, -15.679, BCa 95\% CI [-21.540, -9.818], was significant $t(1096)=-5.249, p=.000 ;$ in addition this represented a large effect size of $d=0.69$. Results are provided in Table 9.

In the Social Studies subtest, on average, PSTs who reported their race as African American or ethnicity as Hispanic or Latino received lower scores $(M=224.07, S E=$ 3.45), than PSTs who did not report as being part of this race or ethnicity $(M=236.86$, $S E=0.73)$. This difference, -12.789, BCa $95 \%$ CI [-18.925, -6.653], was significant $t(1093)=-4.090, p=.000$; in addition this represented a medium effect size of $d=0.55$. Results are shown in Table 10.

There is a difference in Elementary Education MCA subtest scores when considering race and ethnicity. On average, PSTs who identified as African American or Hispanic/Latino scored lower than PSTs from other races or ethnicities in all four subtests. These results can be viewed in Table 11. Figure 1 provides a graphical representation of the differences in average Elementary Multi-Content scores between PSTs who identified as African American and Hispanic and PSTs who identified as being of any other race or ethnicity.

\section{Comparing Scores Based on Gender}

In the English Language Arts subtest, on average, PSTs who reported their gender as female received scores $(M=239.53, S E=.76)$, that were not statistically different from PSTs who reported their gender as male $(M=238.31, S E=2.11)$. This difference, 1.224, BCa 95\% CI [-3.626, 6.074], was not significant $t(1100)=.495, p=.621$; it also represented a very small effect size with a Cohen's $d=0.05$. 


\section{QUANTITATIVE ANALYSIS OF MCA}

In the Mathematics subtest, on average, PSTs who reported their gender as female received scores $(M=248.30, S E=.79)$, that were lower than PSTs who reported their gender as male $(M=254.88, S E=2.24)$. This difference, -6.581 , BCa 95\% CI [-11.586, -1.576], was significant $t(1100)=-2.58, p=.010$; it represented only a small effect size with a Cohen's $d=0.26$.

In the Science subtest, on average, PSTs who reported their gender as female received scores $(M=238.18, S E=.718)$, that were lower than PSTs who reported their gender as male $(M=251.14, S E=2.37)$. This difference, -12.957 , BCa 95\% CI [-17.631, -8.284], was significant $t(1098)=-5.44, p<.000$; it represented a medium to large effect size with a Cohen's $d=0.57$.

In the Social Studies subtest, on average, PSTs who reported their gender as female received scores $(M=235.35, S E=.738)$, that were lower than PSTs who reported their gender as male $(M=245.43, S E=2.64)$. This difference, -10.076 , BCa 95\% CI [$15.501,-4.652]$, was significant $t(1095)=-3.679, p<.000$; it represented a medium effect size with a Cohen's $d=0.43$.

There is a difference in Elementary Education MCA subtest scores when considering gender in all Multi-Content Assessment subtests except for English. On average, PSTs who identified as female scored lower than PSTs who identified as males in all subtests except English.

\section{Research Question Four: Considering ACT Scores}

The researcher hoped to complete an analysis of covariance (ANCOVA) to study differences in Multi-Content Assessment scores when controlling for ACT. However, one of the assumptions of ANCOVA is that the covariate be independent from the 


\section{QUANTITATIVE ANALYSIS OF MCA}

independent variable(s) (Field, 2013). When calculating a Pearson correlation coefficient between PST maximum ACT score and each Multi-Content Assessment subtest, the resulting correlations were all significant at $\mathrm{p}<.000$. The ACT had significant correlations with each subtest, and large effect size with: English, $\mathrm{r}=.612$; Math, $\mathrm{r}=$ $.644 ;$ Science, $r=.586$; and Social Studies, $r=.588$. Because the ACT was not independent from the independent variables, the ANCOVA was not calculated.

\section{Discussion}

\section{Results and Cultural Synchronicity}

Results indicated that on average Pre-Service Teachers (PSTs) who identified as African American or Hispanic scored significantly lower in all four content subtests of the Elementary Education Multi-Content Assessment (MCA) on average than PSTs from other races or ethnicities. Since the MCAs are typically taken near the end of a PSTs academic career, these results indicate that PSTs who were African American or Hispanic were more likely to be accepted into an educator preparation program, complete most or all requisite coursework and field experiences with assessments, and then fail to pass one of the final steps in Missouri teacher certification. Edmonds (2014) indicated that PSTs from a diverse background were less likely to be admitted into educator preparation programs due to significant differences in scores on the Missouri General Education Assessment (MoGEA). These findings show that PSTs with diverse backgrounds are being removed at a disproportionate rate from the pool of potential teachers at multiple points in their preparation.

PSTs from diverse backgrounds could also be encouraged to seek preparation for these assessments. If more of PSTs from diverse backgrounds were informed of how 


\section{QUANTITATIVE ANALYSIS OF MCA}

they may not perform as well on these assessments, these PSTs could take steps to better prepare themselves for these assessments. While PSTs from diverse backgrounds do score significantly lower in all four subtests of the MCA, more than half do pass each subtests.

DESE indicates there is not a lack in the teacher workforce of female teachers (DESE, 2015). But, PSTs who are female were more likely to score lower on the MCA. Perhaps steps could be taken to better specifically prepare PSTs who are female for the MCA.

Whichever strategy is undertaken to better prepare historically marginalized populations for the MCA, clear research indicates that these may be the most important future teachers in terms of Pk-12 student success (Goldhaber \& Hansen, 2010; Irvine, 1990). These sources would indicate that fewer teachers of diverse background equates to poorer academic outcomes for students from historically marginalized populations. While cultural synchronicity is a concept that cannot be modified in its scope or effect except more diverse teachers enter the field, perhaps changes to accountability strategies could be made to ensure that a more diverse teaching workforce is produced in Missouri.

\section{Accountability and Cultural Synchronicity Intersect}

A diverse teacher pool is a priority of the Department of Elementary and Secondary Education (DESE, 2015). To alleviate the issues of inequity, several possible solutions could be attempted. These solutions appear at the program level, at the PST level, and at the assessment level. Strategies focused on one or all of these lenses could potentially ensure that more diverse PSTs in Missouri become teachers. 


\section{QUANTITATIVE ANALYSIS OF MCA}

Educator preparation programs (EPP) could do more to recruit and effectively prepare PSTs from diverse backgrounds. DESE (2015) states that the lack of teacher diversity in Missouri should partly be attributed to EPPs and their lack of an effective strategy to recruit, retain and complete PSTs from diverse backgrounds. If more diverse PSTs were to enter the pool, more would pass these assessments and become teachers. Also, perhaps EPPs could initiate programs to screen PSTs based on race and ethnicity and ensure that they are prepared to pass the MCA. Test preparation strategies could be implemented at EPPs specifically focused on PSTs from diverse backgrounds to ensure test readiness.

However, as indicated in Anderson (2009), this may be an example of a negative outcome related to the accountability relationship. In this example, the accounter DESE is not sharing any of the blame for the negative outcome of fewer teachers from diverse backgrounds. The EPPs have not put forth accountability policies related to assessment passage rates, but DESE and the MOSBOE have. DESE and the MOSBOE also are requiring that EPPs recruit, retain and complete more PSTs from diverse backgrounds. It seems as if the accountable, the EPPs and PSTs, was unable to both reach these assessment benchmarks and complete the diverse PSTs that DESE is requiring. Since these goals put forth by accounters are apparently mutually exclusive, the accountable have no choice but to face negative reinforcement, while the accounters receive no reinforcement either positive or negative.

\section{Potential Alternate Accountability Strategies}

Finally, perhaps changes to the content of the MCA could be considered by DESE. After Edmonds (2014) analyzed the MoGEA, DESE commissioned an overhaul 


\section{QUANTITATIVE ANALYSIS OF MCA}

of the assessment's content. The MoGEA was shortened from five subtests to four and test questions were overhauled. The results was a brand new assessment that has not yet by analyzed as thoroughly as Edmonds (2014) completed on the original version.

Perhaps the MCA could be overhauled as well in an effort to reduce racial and ethnic score differences

While standardized exams show little to now relationship with effective teaching (Wakefield, 2003), perhaps a performance assessment could be used to predict teacher performance. Missouri already uses a state-wide final performance assessment for PSTs, the Missouri Pre-Service Teacher Assessment (MoPTA) (DESE, 2014). This assessment was developed by ETS and has been used as a PST certification requirement during the final semester of EPPs since September, 2015. Use of the MoPTA as the sole final assessment could potentially reduce differences in the ability of PSTs from different racial and ethnic backgrounds to complete certification requirements. However, more research needs to be completed on the MoPTA to measure whether similar differences in scores from PSTs of different backgrounds exists in that assessment as well. 
QUANTITATIVE ANALYSIS OF MCA

\section{References}

American Association of Colleges for Teacher Education. (2013). Minority-Serving Institutions Vital to Preparing Minority Educators. Retrieved from https://secure.aacte.org/apps/rl/resource.php?resid=334\&ref=rl

Anderson, J. (2009). Illusions of accountability: Credit and blame sensemaking in public administration. Administrative Theory and Praxis, 31(3) 322-339. doi:

10.2753/ATP1084-1806310302

Angrist, J. D., \& Guryan, J. (2004). Teacher testing, teacher education and teacher characteristics. Teacher Quality, 94(2), 241-246. Retrieved from http://economics.mit.edu/files/2209

Annie E. Casey Foundation. (2006). Race matters: Unequal opportunities for school readiness. Retrieved from http://www.aecf.org/resources/race-matters-unequalopportunities-for-school-readiness-1/

Aud, S., Fox, M. A., KewalRamami, A. (2010). Status and trends in the education of racial and ethnic groups. (NCES Report 2010-015). Retrieved from National Center for Education Statistics website http://nces.ed.gov/pubs2010/2010015.pdf

Berk, R. A. (1995). Something old, something new, something borrowed, a lot to do! Applied Measurement in Education, 8(1), 99-109.

Boser, U. (2014). Return on educational investment: 2014: A district-by-district evaluation of U.S. Educational Productivity. Retrieved from Center for American Progress website: https://cdn.americanprogress.org/wpcontent/uploads/2014/07/ROI-report.pdf 


\section{QUANTITATIVE ANALYSIS OF MCA}

Brooks, M., West-Olatunji, C., African Blackmon, A. T., Froelich, K., De La Torre, W., Montano, T., \& Smith, R. J. (2012). Minority-serving institutions and their contribution to advancing multicultural teacher education pedagogy. Education, 133(2), 349-360. Retrieved from http://ezproxy.nwmissouri.edu:2067/Library/IPChecking.asp?http://ezproxy.nwmi ssouri.edu:2057/login.aspx?direct=true \&AuthType=cookie,ip,uid \&db=afh\&AN= $\underline{84303947 \& \text { site }=\text { ehost-live }}$

Cowan, J., \& Goldhaber, D. (2015). National board certification and teacher effectiveness: evidence from Washington. (CEDR Working Paper 2015-3). Retrieved from Center for Data \& Research website: http://www.cedr.us/papers/working/CEDR\%20WP\%202015-

\section{3_NBPTS\%20Cert.pdf}

Creswell, J. W. (2014). Research design: Qualitative, quantitative and mixed methods approaches. ( $4^{\text {th }}$ ed.). Los Angeles, CA: Sage.

Department of Elementary and Secondary Education. (2014). Missouri Educator

Gateway Assessments. Retrieved from https://dese.mo.gov/sites/default/files/Educator-Preparation-Memo-10-202014.pdf

Department of Elementary and Secondary Education. (2015). Ensure equitable access to excellent educators. Retrieved from https://dese.mo.gov/sites/default/files/Educator-Equity-Plan-Missouri.pdf 


\section{QUANTITATIVE ANALYSIS OF MCA}

Department of Elementary and Secondary Education. (2016). Educator Preparation Programs. Retrieved from https://dese.mo.gov/educator-quality/educatorpreparation/programs

Edmonds, J. M. (2014). Missouri General Education Assessment: examination of PST scores and predictor variables (Unpublished doctoral dissertation). University of Missouri, Columbia.

Engelhard, G. Jr., Hansche, L., \& Rutledge, K. E. (1990). Accuracy in bias review judges in identifying differential item functioning on teacher certification tests. Applied Measurement in Education, 3(4), 347-360.

Evaluation Systems Pearson. (2009). Fairness and diversity in testing. Amherst, MA: Pearson Education.

Field, A. (2013). Discovering statistics using IBM SPSS Statistics (4th ed.). Thousand Oaks, CA: Sage.

Irons, P. (2004). Jim Crow's Schools. Retrieved from American Federation of Teachers website: http://www.aft.org/periodical/american-educator/summer-2004/jimcrows-schools

Kirk, J. A. (2009). The NAACP campaign for teachers' salary equalization: African American women educators and the early civil rights struggle. The Journal of African American History, 94(4), 529-552

National Center for Education Statistics. (2014). Projection of Education Statistics to 2022. Retrieved from https://nces.ed.gov/pubs2014/2014051.pdf 


\section{QUANTITATIVE ANALYSIS OF MCA}

National Center for Education Statistics. (2015). School composition and the Black-White achievement gap. Retrieved from https://nces.ed.gov/pubsearch/pubsinfo.asp?pubid=2015018

Nettles, M. T., Scatton, L. H., Steinberg, J. H., \& Tyler, L. L. (2011). Performance and passing rate differences of African American and White prospective teachers on Praxis examinations. (Research report ETS RR-11-08). Retrieved from http://files.eric.ed.gov/fulltext/ED523733.pdf

Ravitch, D. (2013). Reign of error: The hoax of the privatization movement and the danger to America's public schools. New York, NY: Knopf.

Sum, A., Khatiwada, I., McLaughlin, J., \& Palma, S. (2009). The consequences of dropping out of high school: Joblessness and jailing for high school dropouts and the high cost for taxpayers. Center for Labor Market Studies Northeastern University. Retrieved from: http://www.northeastern.edu/clms/wpcontent/uploads/The_Consequences_of_Dropping_Out_of_High_School.pdf

Taylor, M. L. (2013). African American teachers and state licensing examination in metropolitan Atlanta: A Case study. (Doctoral dissertation, University of Nevada, Las Vegas). Retrieved from http://digitalscholarship.unlv.edu/cgi/viewcontent.cgi?article=2898\&context=thes esdissertations

Wakefield, D. (2003). Screening PSTs: Problems with high-stakes testing. Educational Forum, 76(4), 380-388

Wall, T. J. (2008). Evaluation of the impact of the participation in the T.E.S.T. examination preparation program on elementary education PST C-Base and Praxis II 
QUANTITATIVE ANALYSIS OF MCA

performance. (Doctoral Dissertation, University of Missouri). Retrieved from https://mospace.umsystem.edu/xmlui/bitstream/handle/10355/5609/research.pdf?seq $\underline{\text { uence }=3 \mathrm{e}}$

Wall, T. J., \& McBride, M. A. (2016, March). MO Assessments MO Problems. Presented at the Spring 2016 MACTE Conference, Lake Ozark, MO. 
Tables

Table 1

Youth Employment and Institutional Outcomes

\begin{tabular}{lll}
\hline American Youth, 16-24 year olds & \% Employed & \% Institutionalized \\
\hline High School Dropouts, African American & 31 & 23 \\
High School Dropouts, Asian & 43 & 7.2 \\
High School Dropouts, Whites & 46 & 6.6 \\
High School Dropouts, Hispanic & 53 & 6.1 \\
High School Dropouts, All Races and Genders & 46 & 6.3 \\
High School Graduates & 68 & 1 \\
College Graduates & 87 & 0.1 \\
\hline
\end{tabular}

Note. Adapted from "The consequences of dropping out of high school: Joblessness and jailing for high school dropouts and the high cost for taxpayers", by A. Sum, I. Khatiwada, J. McLaughlin \& S. Palma, 2009, Center for Labor Market Studies Northeastern University.

Table 2

High School Outcomes and Opportunities by Race and Ethnicity

\begin{tabular}{llllll}
\hline \% Outcomes of HS Students & White & Black & Hispanic & Asian/PI & AI/Alaskan \\
\hline Taken Calculus & 32 & 17.9 & 20.5 & 48.8 & 15.9 \\
Taken ACT & 68.3 & 13.6 & 8.7 & 3.9 & 1.1 \\
Average ACT, English & 21.7 & 16.1 & 17.7 & 22.1 & 18.1 \\
Average ACT, Math & 21.8 & 17 & 19 & 24.1 & 18.8 \\
\hline
\end{tabular}

Note. $\mathrm{HS}=$ High School; PI = Pacific Islander; AI = Alaskan/Indian. Adapted from "The consequences of dropping out of high school: Joblessness and jailing for high school dropouts and the high cost for taxpayers", by A. Sum, I. Khatiwada, J. McLaughlin \& S. Palma, 2009, Center for Labor Market Studies Northeastern University.

Table 3

Pre-Service Teacher Race

\begin{tabular}{lcc}
\hline Self-Reported Race & Frequency & Percent of Total \\
\hline American Indian & 7 & $0.6 \%$ \\
Asian or Pacific Islander & 9 & $0.8 \%$ \\
African American & 39 & $3.5 \%$
\end{tabular}


QUANTITATIVE ANALYSIS OF MCA

\begin{tabular}{lcc} 
Multi-Racial & 47 & $4.2 \%$ \\
White & 1021 & $91.7 \%$ \\
Unknown/Not Reported & 29 & $2.6 \%$ \\
\hline
\end{tabular}

Note. $\mathrm{N}=1114$.

Table 4

Pre-Service Teacher Ethnicity

\begin{tabular}{lcc}
\hline Self-Reported Ethnicity & Frequency & Percent of Total \\
\hline Hispanic/Latino & 22 & $2.0 \%$ \\
Non-Hispanic/Latino & 886 & $79.5 \%$ \\
Unknown/Not Reported & 206 & $18.5 \%$ \\
\hline
\end{tabular}

Note. $\mathrm{N}=1114$.

Table 5

Pre-Service Teacher Race and Ethnicity

\begin{tabular}{ccc}
\hline Self-Reported Race, Ethnicity & Frequency & Percent of Total \\
\hline African American or Hispanic & 63 & $5.7 \%$ \\
Other Race or Ethnicity & 1048 & $94.1 \%$ \\
\hline
\end{tabular}

Note. $\mathrm{N}=1114$.

Table 6

Pre-Service Teacher Gender

\begin{tabular}{ccc}
\hline Gender & Frequency & Percent of Total \\
\hline Female & 1010 & $91 \%$ \\
Male & 103 & $9 \%$ \\
\hline
\end{tabular}

Note. $\mathrm{N}=1114$.

Table 7

English/Language Arts Subtest Average Scores by Race and Ethnicity 


\begin{tabular}{cccc}
\hline Self-Reported Race, Ethnicity & N & Mean & Std. Deviation \\
\hline African American or Hispanic & 62 & 227.55 & 23.940 \\
Other Race or Ethnicity & 1038 & 240.06 & 23.756 \\
\hline
\end{tabular}

Table 8

Mathematics Subtest Average Scores by Race and Ethnicity

\begin{tabular}{cllc}
\hline Self-Reported Race, Ethnicity & N & Mean & Std. Deviation \\
\hline African American or Hispanic & 62 & 231.71 & 22.516 \\
Other Race or Ethnicity & 1038 & 249.92 & 24.453 \\
\hline
\end{tabular}

Table 9

Science Subtest Average Scores by Race and Ethnicity

\begin{tabular}{cccc}
\hline Self-Reported Race, Ethnicity & N & Mean & Std. Deviation \\
\hline African American or Hispanic & 62 & 224.48 & 24.606 \\
Other Race or Ethnicity & 1036 & 240.16 & 22.738 \\
\hline
\end{tabular}

Table 10

Social Studies Subtest Average Scores by Race and Ethnicity

\begin{tabular}{cllc}
\hline Self-Reported Race, Ethnicity & N & Mean & Std. Deviation \\
\hline African American or Hispanic & 60 & 224.07 & 26.717 \\
Other Race or Ethnicity & 1035 & 236.86 & 23.357 \\
\hline
\end{tabular}


QUANTITATIVE ANALYSIS OF MCA

Table 11

Independent-Samples $\mathrm{t}$-Test - Race and Ethnicity

\begin{tabular}{lcccccccc}
\hline & Group & $n$ & Mean & $S D$ & $S E$ & $T$ & df & Sig. \\
\hline English \& LA & 1 & 1038 & 240 & 23.76 & .74 & & & \\
& 2 & 62 & 228 & 23.94 & 3.04 & & & \\
& Paired & & 12.51 & & 3.11 & 4.03 & 1098 & $.000^{* * *}$ \\
\hline Math & 1 & 1038 & 250 & 24.45 & .76 & & & \\
& 2 & 62 & 231 & 22.52 & 2.86 & & & \\
& Paired & & 18.21 & & 3.18 & 5.72 & 1098 & $.000^{* * *}$ \\
\hline Science & 1 & 1036 & 240 & 22.74 & .71 & & & \\
& 2 & 62 & 224 & 24.61 & 3.13 & & & \\
& Paired & & 15.68 & & 2.99 & 5.25 & 1096 & $.000^{* * *}$ \\
\hline Social Studies & 1 & 1035 & 237 & 23.36 & .73 & & & \\
& 2 & 60 & 224 & 26.72 & 3.45 & & & \\
& Paired & & 12.79 & & 3.13 & 4.09 & 1093 & $.000^{* * *}$ \\
\hline
\end{tabular}

Note. Group $1=$ Pre-Service Teacher of any race or ethnicity besides African American or Hispanic; Group $2=$ Pre-Service Teacher of African American or Hispanic heritage $* \mathrm{p}<.05 . * * \mathrm{p}<.01 . * * * \mathrm{p}<.001$. 
Figure 1. Average Elementary Multi-Content Assessment Subtests by Race and Ethnicity

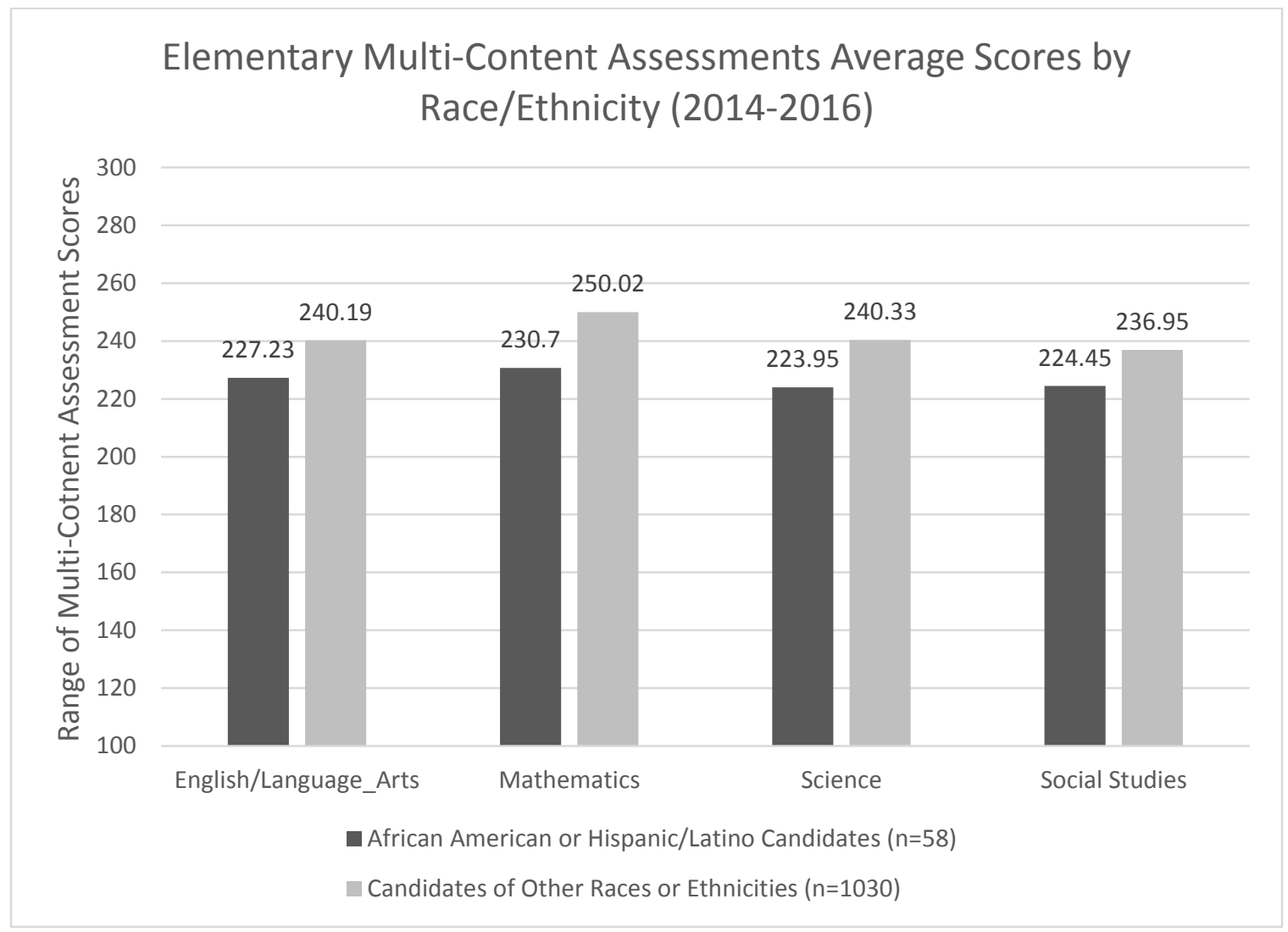

Figure 1. On the scale of possible Elementary Multi-Content test scores ranging from 100-300, PSTs from other races or ethnicities scored on average higher than PSTs who identified as African American or Hispanic. 
Figure 2. Normal Q-Q plot of English Subtest

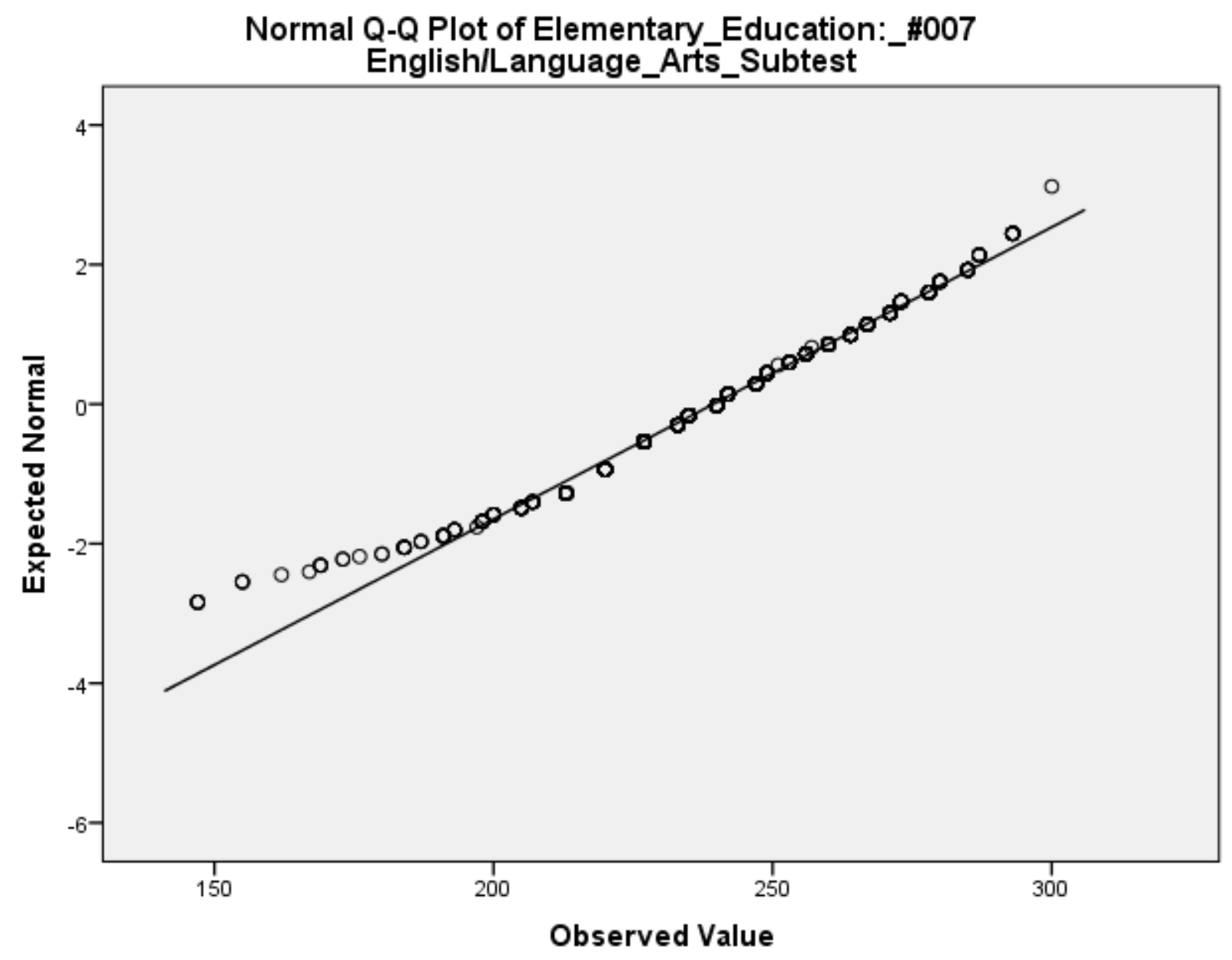

Figure 2. This Q-Q Plot indicates the English subtest follows a mainly normal distribution. The plotted dots indicate the real distribution of the data and the straight line indicate an ideal normal distribution. Except for the lower values, the distribution of score values follow the normal distribution. 
Figure 3. Normal Q-Q plot of Math Subtest

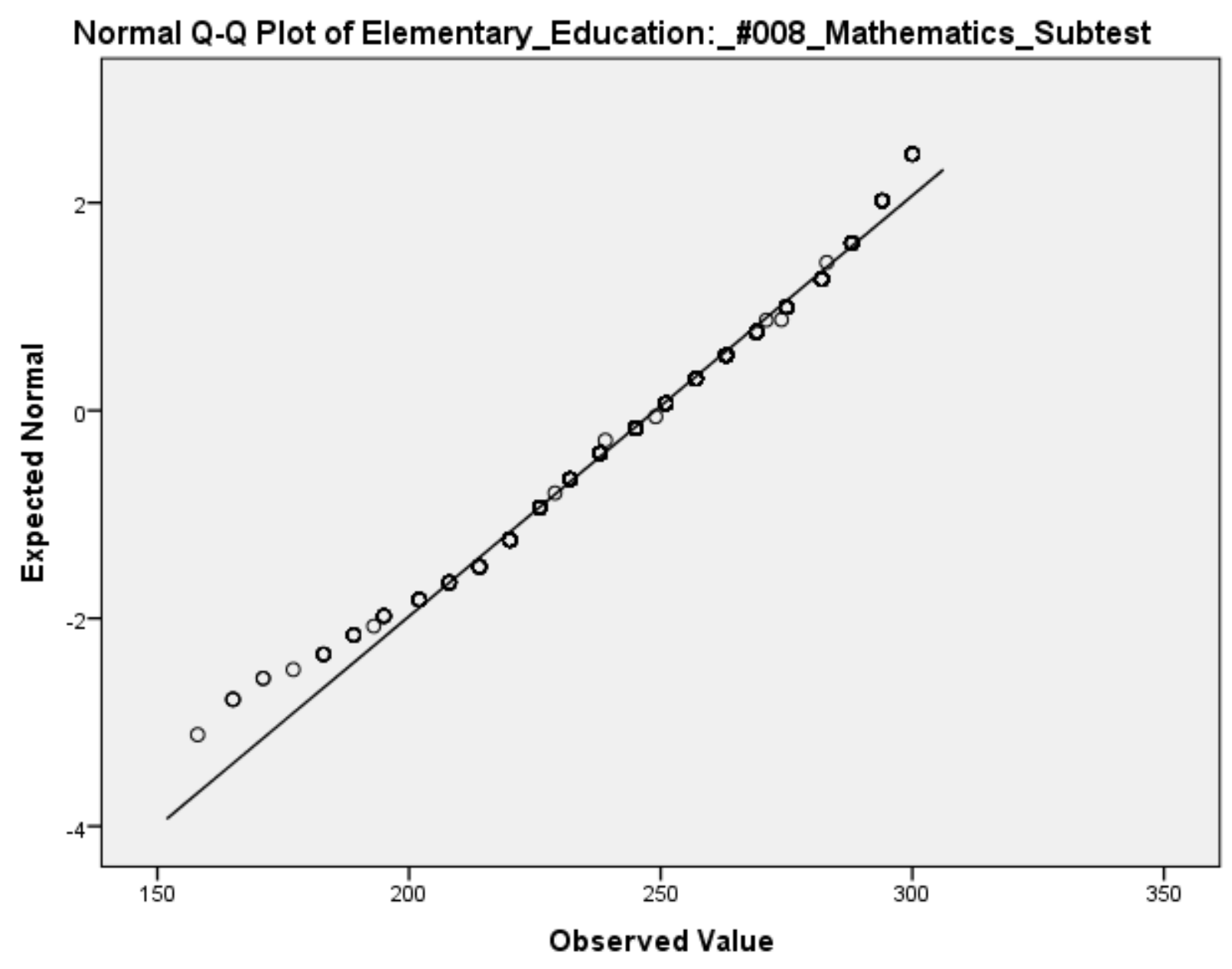

Figure 3. This Q-Q Plot indicates the math subtest follows a mainly normal distribution. The plotted dots indicate the real distribution of the data and the straight line indicate an ideal normal distribution. Except for the lower values, the distribution of score values follow the normal distribution. 
Figure 4. Normal Q-Q plot of Science Subtest

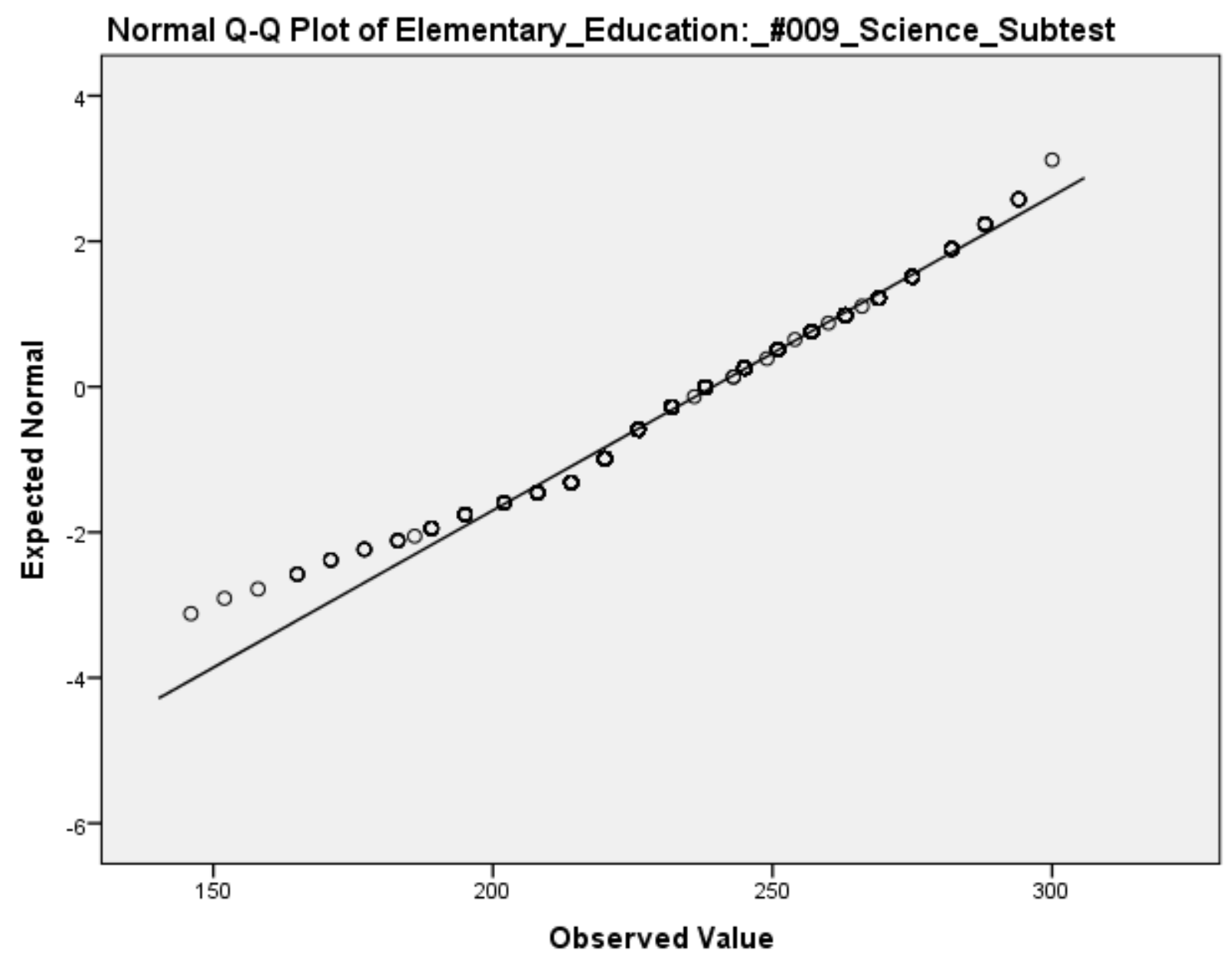

Figure 4. This Q-Q Plot indicates the science subtest follows a mainly normal distribution. The plotted dots indicate the real distribution of the data and the straight line indicate an ideal normal distribution. Except for the lower values, the distribution of score values follow the normal distribution. 
Figure 5. Normal Q-Q plot of Social Studies Subtest

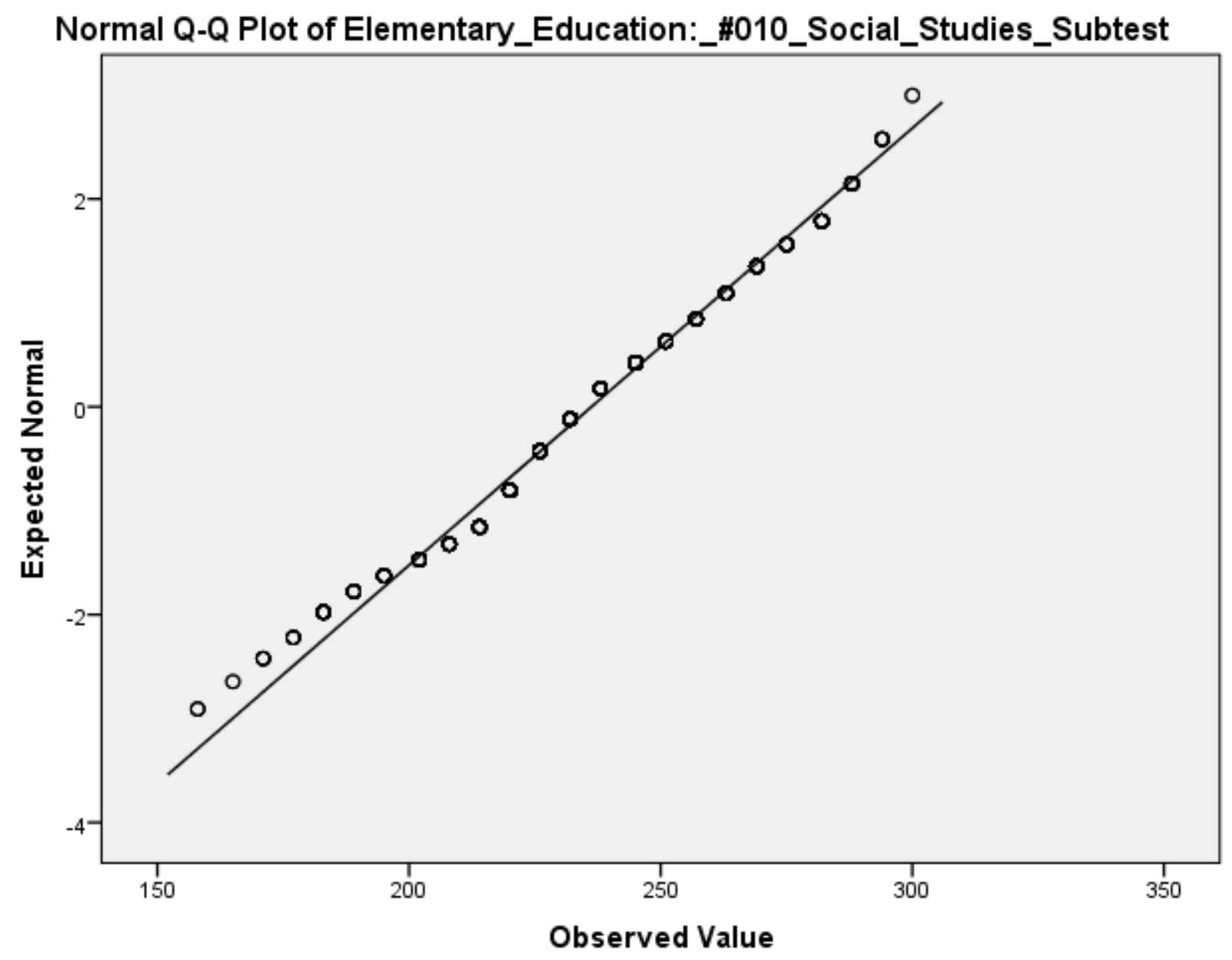

Figure 5. This Q-Q Plot indicates the social studies subtest follows a mainly normal distribution. The plotted dots indicate the real distribution of the data and the straight line indicate an ideal normal distribution. The distribution of score values follow the normal distribution. 
QUANTITATIVE ANALYSIS OF MCA

\section{SECTION SIX}

\section{SCHOLARLY PRACTITIONER REFLECTION}

The doctoral program has developed this researcher to understand organizations more fully, work with groups more effectively, read and write as a scholar, and act as an educator, advocate, and leader. This document will explain the impact of the MU Cooperative Doctoral program on my growth as a leader, scholar and advocate for social justice.

\section{Educational Leader}

\section{Organizational Analyses}

Before Bolman and Deal (2008), I had never fully grasped the different lenses that could be used to understand an organization. After reading Bolman and Deal (2008) and fully covering the topic during our first summer at the University of Missouri, I was able to apply the four lenses in my own office. I work as an assessment coordinator at an Educator Preparation Program (EPP) contained within Northwest Missouri State University. My job consists mainly of ensuring that data from our Pre-Service Teachers (PSTs) are collected and then provided to a variety of accrediting agencies. This requires the participation of faculty and students in an online assessment system known as Tk20. Ensuring that students and faculty use the system takes a great deal of my time. Another consideration is that I have no real power over the faculty to ensure that they use the system. I could potentially contact the Dean of the College of Education and ask for assistance with regards to compliance. But, that could potentially set into motion a negative relationship with faculty that I would like to avoid. This requires a difficult balancing act. 


\section{QUANTITATIVE ANALYSIS OF MCA}

With the knowledge and experience I have gained after reading Bolman and Deal (2008), I now use the political frame to understand that I had no legitimate power to coerce faculty and students into using our new assessment system. But, if I developed into an expert on the matter I could start winning over both groups on how to use the new system. I also focused on the human resource frame to try and streamline our assessment processes. I helped develop faculty experts who became more than proficient in the system, and who could help others. Also, I developed our student workers to present and educate on the system to their peers. I focused on the symbolic frame by ensuring that the system reflected the university's latest logo and colors. Finally, I developed the structural frame by ensuring that students knew if they were enrolled in a course with an assignment linked to our assessment system, and I ensured that students and faculty knew how to complete their assigned tasks to ensure accreditation.

The first and second summers at University of Missouri taught me a great deal about the importance of working with a team. Both summer groups featured extremely talented professionals, and both also brought personality clashes that could have shipwrecked our goals. By working with sources such as Levi (2013) I understood that a team of diverse thinkers is always more effective and inclusive. I took steps to defuse personality conflicts individually before and after team sessions. This ensured that long term progress continued. In addition, these individual meetings with team members acted as a way to use my previous experience in counseling. These individual sessions I had with some team members seemed to be akin to taking pressure off of a steam engine. This way it can continue to function and reach its goals without exploding. 


\section{QUANTITATIVE ANALYSIS OF MCA}

\section{Growth as a Leader}

While the previous examples explain how I have grown as an educational professional, it is more difficult to put into words how I have grown specifically as an educational leader. Previously I was someone who was pleased to do their job in a corner and provide data for the real leaders in their decision making process. However, as I grew in this program I began to realize that some leaders did not make decisions based on data that was supplied to them. The Department of Elementary and Secondary Education (DESE), for instance, has continued to use standardized, multiple choice assessments as both an admission requirement and as a Missouri teacher certification requirement. Research indicates that standardized content assessment scores are only weakly-linked to teaching ability (Wakefield, 2003), that their use removes a greater proportion of diverse PSTs from the teaching profession (Goldhaber \& Hansen, 2010), and that more diverse teachers are needed nationally (Steinberg \& Weiner, 2015, February). In addition to this general research, specific research has shown that the particular general education assessment used for admittance to Missouri Educator Preparation Programs (EPP), has shown significant differences in scores between African American, Hispanic and female PSTs and PSTs from non-marginalized populations (Edmonds, 2014). DESE responded to these findings by changing the content of the MoGEA instead of determining if an exam of this type was even reasonable for its purpose.

It was this series of realizations that drove me to become a leader of some kind both on my university campus and also in the state. My goal was to determine if the assessment suite known as Missouri Educator Gateway Assessments (MEGA) was reducing diversity in the teaching profession in Missouri. It was through this that I feel 


\section{QUANTITATIVE ANALYSIS OF MCA}

that I have developed, or am attempting to develop, along the seven transformations of leadership, put forth by Rook and Torbert (2011).

I believe that I began my transformation as a diplomat. A diplomat is focused on getting the job done in a way that will avoid conflict. I had met some professionals with DESE and considered them colleagues and comrades. I surely had no ill-will towards them. Instead, I remember distinctly during a conference when DESE staff were presenting that everyone sitting at my table flatly dismissed everything DESE staff members had to say. My tablemates informed me that any meaningful feedback given to DESE at this time would be placed into a trash can, and then DESE would write a report saying that they received feedback from all conference attendees. I defended DESE staff to my tablemates and in at least two conferences presented on their behalf. I did not want to damage my or my university relationship with DESE by discussing the level of dissent that I had witnessed.

Then I grew to the expert level of leader. The expert is defined as someone who develops their expertise and is helpful as an individual to the team. I began doing research on, at the time, the potential impact of MEGA on the state. The more research I completed, the more evidenceI gathered that indicated teacher diversity could be a victim of the MEGA assessments. I began to do calculations on the past impact of the CBASE exam, which predated the MoGEA. I used over a decade of university student testing data to indicate that the passing score of the original CBASE always indicated lower scores among African American PSTs (Wall \& McBride, 2016, March). So, I postulated on whether the MoGEA would have a lesser or greater impact. Using this data, I began to do conference presentations to raise awareness of these potential issues. DESE stopped 


\section{QUANTITATIVE ANALYSIS OF MCA}

asking me to present on their behalf. The transformation to expert leader status was not painless, but was certainly an awakening. I began collecting statewide MoGEA data for my dissertation.

My next level of development was achiever. The main attributes of an achiever are the focus to completing goals and juggling tasks. I wanted to present on this topic at as many conferences as possible. Then, I had the opportunity to provide my MoGEA data to Dr. Jeff Edmonds. At first I was hesitant, as I had hoped to use this data for my own dissertation. However, one of the best decisions I ever made at the achiever level of leadership was to provide data to Dr. Edmonds. Dr. Edmonds created a terrific dissertation. I then used those results as content for presentations, as an anchor for advocacy efforts, and as a guide for my own dissertation in practice.

At this point I believe that I am between the individualist and strategist level of leadership. The individualist finds way to weave in conflicting personal and professional ideologies. The strategist focuses on transformation of individuals and organization, and focuses on the long term. Frankly, I may have skipped the individualist level entirely. My strength has never been to think outside the box or ignore rules. However, as a strategist, I have developed relationships and plans with individuals at one of our state's MSI campuses. The goal is to help them with accreditation from an assessment standpoint. However, I would also like to develop a relationship by which our PSTs could somehow benefit from experiences in an urban, diverse setting where the MSI PSTs are based. Also, the final goal would be to safeguard this MSI from any dangers of losing accreditation. This type of strategy could develop partnerships between different 


\section{QUANTITATIVE ANALYSIS OF MCA}

EPPs around the state, in that they could assist each other to do things that they could not do singly.

\section{Educational Leadership Opportunities}

The doctoral program has prepared and encouraged me to seek out opportunities as an educational leader. This has led to opportunities to assist in accreditation efforts, advocacy and research-based collaborations. These opportunities have appeared on my campus, in my state and nationally.

Campus leadership. I have been offered several opportunities to exercise leadership abilities on my campus. My university is mid-sized, regional, Midwestern and caters to mainly students of rural, White backgrounds. In 2015 the Board of Regents requested a financial audit of each academic program. The university contracted with a third party vendor known as RPK to perform this function. RPK would deliver an output of information about each academic program's ability to maintain financial viability and retain and complete students. However, to reach this output, the vendor needed several inputs.

RPK required data regarding each program's: financial data; faculty load; and student enrollment retention and completion. This kind of data was collected on campus but by different departments and using different methods. To capture this, a team was assembled including staff from Institutional Research, the Financial Office and the Office of Human Resources. I was chosen by the Provost to lead the group on campus

I knew from Levi (2013) that a diverse team is more effective than a non-diverse team. This group came from differing offices with disparate goals, so diversity was not an issue. Our group now had a common goal of delivering data to RPK on schedule. I 


\section{QUANTITATIVE ANALYSIS OF MCA}

focused on the structural and human resources frame since a study like this had not been completed before on this campus (Bolman \& Deal). I ensured that each office had a clear understanding of its deliverable and then allowed each group complete its tasks using their own area of expertise. In addition, I tried to remain professional, courteous and understanding as team members would express frustration about the project requirements and schedule. Even through a major reorganization of the project, our team completed their deliverables on time.

State-level leadership. At the state level, this doctoral program has prepared me to collaborate with a variety of groups focused on assessment and advocacy in educator preparation. The three groups in which I currently participate are overseen by DESE. These include the Missouri Technical Advisory Committee (MoTAC) and a small consultation group focused on refining and revising the Missouri Pre-Service Teacher Assessment (MoPTA).

The MoTAC group is composed of assessment directors from Educator Preparation Programs (EPPs) in Missouri. The group discusses EPP and Pre-Service Teacher (PST) assessment changes, such as MEGA (DESE, 2014b). While the group began as a way for DESE to organize assessment directors and educate them about upcoming assessment changes, it has grown into a collaborative discussion group. MoTAC now discusses best practices in EPP assessment and looks critically at assessment strategies put forth by DESE and the MOSBOE. The group has become a seminal gathering for many other efforts, presentations and publications about EPP assessment in Missouri. 


\section{QUANTITATIVE ANALYSIS OF MCA}

The MoPTA consultancy group has been another opportunity to exercise my abilities as an educational leader. I was invited to participate in this team by a colleague from another regional Missouri EPP. The goal of this team was to formulate a list of revisions for ETS to consider making to the MoPTA. The MoPTA is a performance assessment completed during a PSTs student teaching experience. The small team of less than a dozen professionals from EPPs and Pk-12 schools after two meeting days completed a list of suggested revisions. These included simplification of directions and lowering the number of focus students from two to one. ETS has not taken these suggestions but will consider them for the MoPTA implemented in the fall 2017 semester.

National-level leadership. I have been fortunate enough to be invited to participate in a national EPP assessment professionals' best practices research group. This small group was mentioned to me by Dr. Tim Wall who suggested that I participate. The group is composed of perhaps a dozen individuals with main leadership from the American Association of Colleges of Teacher Education (AACTE). So far this group has developed a list of best practices materials with which all EPP assessment professionals should be familiar. In addition, the assessment group will conduct site visits at each other's institutions this year to learn more about assessment practices. The hope is that this activity will lead to publication in the field of assessment. The first site to be visited was our regional Midwestern EPP. Dr. Wall and I have collaborated with a group of campus experts in EPP assessment to prepare for this visit. We have settled on a visit date of November $6^{\text {th }}$ through November $8^{\text {th }}$ and are very excited about being a part of this opportunity. 


\section{QUANTITATIVE ANALYSIS OF MCA}

\section{Scholar}

My growth as a scholar during this program has been a pleasant surprise. I believe that I have been able to become a scholar who is coachable, a more effective reader and writer, and a professional that focuses on social justice as key part of educational success.

\section{Scholarly Feedback}

One of the keys to success in this program and I believe in life is the ability to take feedback and be coachable. I have seen some students in this program listen carefully to feedback from an instructor or advisor and then reply with defensiveness. The student considers himself an expert in a certain area and therefore the instructor could not offer any suggestions for changes that would lead to an improvement. One quality I have developed during this program is the ability to take feedback with an open mind and to consider my response carefully. The faculty have always made it clear that students can consider feedback and choose to use it or not. However, after seeing myself grow as a writer and researcher, I now understand that these faculty giving feedback have had years or decades more of experience as writers and researchers. Understanding this adds a great deal of credence to faculty feedback and helps me to value their thoughts.

I also believe that a key to success in this program has to be the desire and understanding to assist others. During the beginning of my program my entire focus was to study the effects of the Missouri General Education Assessment (MoGEA) on racial and ethnic diversity in Missouri teachers. The MoGEA was required of all students wishing to become admitted to teacher education programs in Missouri. I gathered data from a variety of college campuses and had completed rudimentary analysis to support 


\section{QUANTITATIVE ANALYSIS OF MCA}

my research questions. Then, my advisor, Dr. Tim Wall, contacted me with a request. Jeff Edmonds, a student from the previous cohort, ran into difficulty with his data. He would no longer be able to proceed in his analysis of data from the Chicago public schools. Dr. Wall had mentioned to Jeff that he would perhaps contact me to see if he could analyze state teacher education assessment data. Originally I was hesitant to offer the MoGEA data to Jeff. I felt ownership with this data and this plan. However, I eventually decided to assist Jeff in his work. He was in a much more advanced place in his program to use the data and complete his dissertation. So, Jeff used that data and completed a terrific dissertation. So much so that I have based most of my dissertation on his work. Helping him has most assuredly helped me more than I could have imagined in the long term.

\section{Reading and Writing as a Scholar}

Truly the most wide-ranging impact of this program has to be how I have changed as a reader and as a writer. This program turned me into an efficient reader. I can cover much more material now, focus on main points and retain what is most valuable. The growth I have experienced as a professional writer after writing my dissertation has been personally astounding. I am by nature an opinionated person who has previously only written emails to colleagues or advocacy pieces where bias is not necessarily a bad thing. However, this program has expunged so many bad habits from my writing and has especially focused on removing opinion and passion and replaced it with reason, sources and rationale. The impact of this program and the growth of my writing cannot be understated. 


\section{QUANTITATIVE ANALYSIS OF MCA}

\section{Seizing Opportunities}

My greatest growth personally occurred during our second summer at the University of Missouri during our quantitative analysis course. I had some experience using SPSS and quantitative analysis during my time as an assessment professional. So, students and faculty would seek me out with questions. At times I felt like an unofficial TA. The experience was fantastic, both for my confidence and to help me develop as an educator. I plan to use that experience as I teach my first college courses this semester. Also, I was extremely honored to present on past quantitative analysis leading to advocacy efforts with Dr. Wall that summer. To be pulled apart from my colleagues to present to them as an expert was humbling and exhilarating. I appreciated even more the chance I was given to return during the summer of 2016 and give a similar presentation to a new cohort.

The most difficult aspect of this experience has been the struggle to achieve balance between my educational, professional and personal life. This program does take a great deal of time, effort and energy. A lot of that has already been taken from my personal life before I would enter classes on Wednesday nights, or before returning to the University of Missouri after each weekend during our two summers. However, faith and great colleagues in the program have sustained me and helped me to reach this goal. And now, for my wife Brooke and our first son, Bryant Richard McBride, I am happy to say that I am finally done with this dissertation.

Another item of note is how this program has helped me to be more open to new kinds of thinking and types of research. Initially, with my assessment background, my focus was on the use of quantitative data. I considered qualitative data to simply be "feel 


\section{QUANTITATIVE ANALYSIS OF MCA}

good" anecdotes. Qualitative data could be used in advocacy efforts, but not for serious research. However, I now see the use of qualitative data, specifically focus groups, can have a powerful impact in directing nascent research. Qualitative data strategies seem to be more like the use of telescopes, and quantitative data like microscopes. Qualitative data helps in determining where quantitative analysis should best be used. Using both in the correct measures can advance research much more than the use of one alone.

\section{Teaching}

This doctoral program has prepared me for an opportunity that I would not have considered previously. This opportunity is the chance to teach at the college level. While I have worked in assessment in educator preparation for five year, I have never had the privilege to teach yet. But, I have always been interested. I enjoy presenting to groups, whether it is faculty or students. To get a chance to teach is truly an honor.

The semester of Fall, 2016 I began to teach the freshmen university seminar course at our regional Midwestern university. This was mainly a chance to see if teaching really interested me and to help prepare freshmen for the rigors of college and independence away from their parents. I had an excellent Peer Advisor, who is a sophomore. As an education major, I think she has taught me more about actual teaching than I would have known otherwise. Besides this small, humble attempt at teaching, I have had an opportunity this semester which was even more surprising.

I was offered an opportunity to teach the graduate Action Research course in the fall 2016 semester. This was a huge honor, as this class is completed by graduate students in teaching and educational leadership programs. I was assigned 25 students. Through my recent growth as a scholar, I have focused on developing these students as 


\section{QUANTITATIVE ANALYSIS OF MCA}

scholars. This has let me to focusing on several important concepts. One of our first priorities was to ensure that all students knew how to develop a research question that was measurable and repeatable (Creswell, 2014). In addition, I wanted to ensure that all of my students understood how to complete rudimentary quantitative statistical analyses. This was a requisite for this course. But, it was difficult as these students represented a variety of levels of quantitative experience. I have focused on the essentials and tried to avoid deep mathematical analyses. As Dr. Wall taught us, I attempted to share with these students how best to develop an engaging literature review with a great deal of synthesis throughout. Finally, these students will for the most part work as a group, which is a valuable lesson for any profession (Levi, 2013).

Following these scholarly and specifically teaching opportunities, I hope to teach one day in the doctoral program. This goal may be years away. However, it will keep me focused on developing myself as a scholar and educational leader.

\section{Diversity and Social Justice}

One important facet of this program in relation to my development has been an emphasis on diversity and social justice. During the first summer at the University of Missouri it was a pleasure listening to Dr. Simmons explore the breadth and depth of this topic and how it weaves into our lives as professionals and researchers. I have used my positions as both an educational leader and scholar to strive for more social justice in my field.

I have used my role as an educational leader to promote diversity in my office. I have the ability to hire student workers who assist with my office duties. The responsibilities of these student workers include a great deal of work on our online 


\section{QUANTITATIVE ANALYSIS OF MCA}

assessment system. While my previous hires have been education majors, after my first summer in the doctoral program, I experimented with hiring a computer science major who happened to be Indian. This proved to be a successful partnership and I have continued to hire computer science students who were all either Indian or Nepalese for my student worker positions since. These student workers have brought their culture and skills to my office and I have been very grateful for their contributions.

As a scholar, I have focused even more on how educator preparation assessments impact the diversity of teachers in Missouri and across the nation. I have participated in studying how the CBASE and the MoGEA screened many diverse PSTs from the pool of prospective teachers before they could enter a preparation program. My dissertation in practice is focused on the use of the Missouri Content Assessments as a final screen to remove even more diverse PSTs from the teacher pool. My future research will focus on whether the Missouri Pre-Service Teacher Assessment (MoPTA) and the Missouri Educator Profile (MEP) contribute towards inequity as part of the MEGA assessments. I will also continue to advocate for modifications to assessment policy in order to remove inequity from educator assessment strategies.

\section{Conclusions}

My experience in the doctoral program has been overwhelmingly positive. Even the struggles and difficulties made me grow as a scholar and leader. I think of the missed sleep, arguments during group work and dissertation rewrites, and I remember that they were part of the path that brought me where I am now. I want to be a contributor. I want to develop other people into leaders and scholars, if they are willing. This program has 
QUANTITATIVE ANALYSIS OF MCA

raised not only my skills and abilities but the field of education across Missouri. I am

honored to be a part of that legacy. 


\section{References}

ACT. (2016). National distributions of cumulative percents for ACT test scores ACTtested high school graduates from 2013, 2014 and 2015. Retrieved from http://www.act.org/content/dam/act/unsecured/documents/NormsChartMCandCo $\underline{\text { mposite-Web2015-16.pdf }}$

American Association of Colleges for Teacher Education. (2013). Minority-Serving Institutions Vital to Preparing Minority Educators. Retrieved from https://secure.aacte.org/apps/rl/resource.php?resid=334\&ref=rl

American Association of Colleges for Teacher Education. (2016a). Journal of Teacher Education. Retrieved from http://aacte.org/resources/journal-of-teacher-education American Association of Colleges for Teacher Education. (2016b). Participation map. Retrieved from http://edtpa.aacte.org/state-policy

American Board. (2016). American Board. Retrieved from http://abcte.org/

Ameter, A. P., Douglas, C., Ferris, G. R., \& Goka, H. (2004). A social relationship conceptualization of trust and accountability and organizations. Human Resources Management Review, 14, 47-65. doi:10.1016/j.hrmr.2004.02.003

Anderson, J. D. (1988). The education of blacks in the South, 1860-1935 [Google Books version]. Retrieved from https://books.google.com/books?hl=en\&lr=\&id=sQ3Gd5DZ_TUC\&oi=fnd\&pg= $\underline{\text { PR13\&dq }=\text { anderson+freedman }+ \text { bureau\&ots=1_SXRAbwAi\&sig=HwCSv1fctSX }}$ bl1IMX6lyHuhmehs\#v=onepage \&q\&f=false 
QUANTITATIVE ANALYSIS OF MCA

Anderson, J. (2009). Illusions of accountability: Credit and blame sensemaking in public administration. Administrative Theory and Praxis, 31(3) 322-339. doi: 10.2753/ATP1084-1806310302

Angrist, J. D., \& Guryan, J. (2004). Teacher testing, teacher education and teacher characteristics. Teacher Quality, 94(2), 241-246. Retrieved from http://economics.mit.edu/files/2209

Annie E. Casey Foundation. (2006). Race matters: Unequal opportunities for school readiness. Retrieved from http://www.aecf.org/resources/race-matters-unequalopportunities-for-school-readiness-1/

Argyris, C. (1982). Reasoning, learning, and action: Individual and organizational. San Francisco, CA: Jossey-Bass.

Aud, S., Fox, M. A., KewalRamami, A. (2010). Status and trends in the education of racial and ethnic groups. (NCES Report 2010-015). Retrieved from National Center for Education Statistics website http://nces.ed.gov/pubs2010/2010015.pdf

Bardach, E., \& Lesser, C. (1996). Accountability in human services collaboratives: For what? And to whom? Journal of Public Administration Research and Theory 6(2), $197-224$.

Behn, R. D. (2001). Rethinking democratic accountability. Washington, DC: Brookings Institution Press.

Bennett, C. I., McWhorter, L. M., \& Kuykendall, J. A. (2006). Will I ever teach? Hispanic and African American students' perspectives on Praxis I. American Educational Research Journal, 43(3), 531-575. doi:

$10.3102 / 00028312043003531$ 


\section{QUANTITATIVE ANALYSIS OF MCA}

Berk, R. A. (1995). Something old, something new, something borrowed, a lot to do! Applied Measurement in Education, 8(1), 99-109.

Bill and Melinda Gates Foundation. (2010). Student perceptions and the MET project. Retrieved from http://www.metproject.org/downloads/Student_Perceptions_092110.pdf

Blackford, K., Olmstead, G., \& Stegman, C. (2012). Teacher licensure and qualified teachers: Are certification examinations enough? American Journal of Educational Studies, 5(1), 5-19.

Blake, R. R. \& McCanse, A. A. (1991). Leadership dilemmas, grid solutions. Retrieved from http://www.corwin.com/upm-data/27197_175.pdf

Blanchard, O. (2013). I quit Teach for America. The Atlantic. Retrieved from http://www.theatlantic.com/education/archive/2013/09/i-quit-teach-foramerica/279724/

Bock, J., \& Addo, K. (2015, June 16). Prospective Missouri teachers are failing a new batch of exit exams at high rates. The St. Louis Post Dispatch. Retrieved from http://m.stltoday.com/news/local/education/more-prospective-teachers-inmissouri-failing-exit-exams/article_9d242748-9bf9-5f8d-9c24687f73889d36.html?mobile touch=true

Bolman, L. G., \& Deal, T. E. (2008). Reframing organizations: Artistry, choice and leadership (4th ed.). San Francisco, CA: Jossey-Bass

Boser, U. (2014a). Return on educational investment: 2014: A district-by-district evaluation of U.S. educational productivity. Retrieved from Center for American 
QUANTITATIVE ANALYSIS OF MCA

Progress website: https://cdn.americanprogress.org/wpcontent/uploads/2014/07/ROI-report.pdf

Boser, U. (2014b). Teacher diversity revisited: A new state-by-state analysis. Retrieved from Center for American Progress website: http://www.americanprogress.org/issues/race/report/2014/05/04/88962/t eacher-diversity-revisited/

Brooks, M., West-Olatunji, C., African Blackmon, A. T., Froelich, K., De La Torre, W., Montano, T., \& Smith, R. J. (2012). Minority-serving institutions and their contribution to advancing multicultural teacher education pedagogy. Education, 133(2), 349-360. Retrieved from http://ezproxy.nwmissouri.edu:2067/Library/IPChecking.asp?http://ezproxy.nwmi ssouri.edu:2057/login.aspx?direct=true \&AuthType=cookie,ip, uid \&db=afh\&AN= $\underline{84303947 \& \text { site }=\text { ehost-live }}$

(Cadima, Peixoto, \& Leal, 2014). Observed classroom quality in first grade: associations with teacher, classroom, and school characteristics. European Journal of Psychology of Education, 29(1), 139-158.

Cataldi, E. F., Laird, J., \& KewalRamani, A. (2009). High school dropout and completion rates in the United States: 2007 (NCES 2009-064). National Center for Education Statistics, Institute of Education Sciences, U.S. Department of Education.

Washington, DC. Retrieved

from http://nces.ed.gov/pubsearch/pubsinfo.asp?pubid=2009064 


\section{QUANTITATIVE ANALYSIS OF MCA}

Cayci, B. (2011). The relationship between the elementary Pre-Service Teachers' teacher efficacy and their attitudes towards the profession of teaching. Education 132(2), 402-418.

Chung, R. R. (2008). Beyond assessment: Performance assessments in teacher education. Teacher Education Quarterly, Winter 2008, 7-28. Retrieved from https://scale.stanford.edu/system/files/Chung_Beyond_Assessment$\underline{\text { TEQ_Scanned.pdf }}$

Cibulka, J. (1990). American educational reform and government power. Educational Review, 42, 97-109. doi:10.1080/0013191900420202

Clark, M., Ponjuan, L., Orrock, J., Wilson, T., \& Flores, G. (2013). Support and barriers for Hispanic male students' educational pursuits: Perceptions of counselors and administrators. Journal of Counseling \& Development, 91(4), 458-466. doi: 10.1002/j.1556-6676.2013.00118.x

Columbia Daily Tribune. (2014, August 28). NCTQ to appeal syllabi case to Missouri Supreme Court. Columbia Daily Tribune. Retrieved from http://www.columbiatribune.com/news/education/nctq-to-appeal-syllabi-case-tomissouri-supreme-court/article_4d441469-c47b-5d3c-b07c-a1ad12ad3764.html

Council on the Accreditation of Educator Preparation. (2013). CAEP 2013 accreditation standards. Retrieved from file:///C:/Users/mam77/Downloads/final-boardamended-20150612.pdf

Council for the Accreditation of Educator Preparation. (2015). What is accreditation? Retrieved from http://caepnet.org/accreditation/about-accreditation/what-is$\underline{\text { accreditation }}$ 


\section{QUANTITATIVE ANALYSIS OF MCA}

Council for the Accreditation of Educator Preparation. (2016). Council for the Accreditation of Educator Preparation. Retrieved from http://www.ncate.org/

Cowan, J., \& Goldhaber, D. (2015). National board certification and teacher effectiveness: evidence from Washington. (CEDR Working Paper 2015-3). Retrieved from Center for Data \& Research website: http://www.cedr.us/papers/working/CEDR\%20WP\%202015-

\section{3_NBPTS\%20Cert.pdf}

Creswell, J. W. (2014). Research design: Qualitative, quantitative and mixed methods approaches. ( $4^{\text {th }}$ ed.). Los Angeles, CA: Sage.

Darling-Hammond, L., Amrein-Beardsley, A., Haertel, E., \& Rothstein, J. (2012). Evaluating teacher evaluation. Education Week. Retrieved from http://www.edweek.org/ew/articles/2012/03/01/kappan_hammond.html

Denner, P.R., Norman, A.D., Salzman, S.A., \& Pankratz, R.S. (2003). Connecting teaching performance to student achievement: A generalizability and validity study of the renaissance teacher work sample assessment. Paper presented at the annual meeting of the Association of Teacher Educators, Jacksonville, FL.

Department of Elementary and Secondary Education. (2013). Teacher standards. Retrieved from https://dese.mo.gov/sites/default/files/TeacherStandards.pdf Department of Elementary and Secondary Education. (2014a). Comprehensive guide to the annual performance report for educator preparation programs: 2014 official internal report edition. Retrieved from http://DESE.mo.gov/sites/default/files/files_group_files/Comprehensive\%20Guid e\%20-1-19-15-final.pdf 


\section{QUANTITATIVE ANALYSIS OF MCA}

Department of Elementary and Secondary Education. (2014b). Missouri Educator

Gateway Assessments. Retrieved from

https://dese.mo.gov/sites/default/files/Educator-Preparation-Memo-10-20-

2014.pdf

Department of Elementary and Secondary Education. (2014c). State board approves

qualifying score for Missouri Content Assessments. Retrieved from

https://dese.mo.gov/communications/news-releases /state-board-approves-

qualifying-scores-missouri-content-assessments

Department of Elementary and Secondary Education. (2015a). Ensure equitable access to excellent educators. Retrieved from

https://dese.mo.gov/sites/default/files/Educator-Equity-Plan-Missouri.pdf

Department of Elementary and Secondary Education. (2015b, September 23). MoPTA

webinar. Retrieved from https://dese.mo.gov/communications/webinar/mopta-

$\underline{\text { webinar }}$

Department of Elementary and Secondary Education. (2015c). Recruitment and retention of teachers in Missouri public schools: a report to the Missouri General Assembly. Retrieved from

file:///P:/Mike\%20Files/Data\%20Requests/Shawn\%20Wake\%20SBE\%20request/ DESE\%20recruitment\%20and\%20retention\%20report\%202015-RR-Report.pdf

Department of Elementary and Secondary Education. (2016a). Commissioner history.

Retrieved from https://dese.mo.gov/state-board-

education/commissioner/commissioner-history 


\section{QUANTITATIVE ANALYSIS OF MCA}

Department of Elementary and Secondary Education. (2016b). Educator Preparation Programs. Retrieved from https://dese.mo.gov/educator-quality/educatorpreparation/programs

Department of Elementary and Secondary Education. (2016c). Facts about the Missouri state board of education. Retrieved from https://dese.mo.gov/state-board$\underline{\text { education/about-state-board }}$

Department of Elementary and Secondary Education. (2016d). Office of Educator Quality. Retrieved from http://dese.mo.gov/educator-quality

Department of Elementary and Secondary Education. (2016e). Routes to certification. Retrieved from https://dese.mo.gov/educator-quality/certification/routescertification

Department of Elementary and Secondary Education. (2016f). Top 10 by 20. Retrieved from http://dese.mo.gov/top-10-by-20

Dobbie, W. (2011). Teacher characteristics and student achievement: Evidence from Teach for America. Education Week. Retrieved from http://blogs.edweek.org/edweek/teacherbeat/teachercharacteristicsjuly2011.pdf

Duckworth, A. L., Peterson, C., Matthews, D. M., \& Kelly, D. R. (2007). Grit: Perseverance and passion for long-term goals. Journal of Personality and Social Psychology, 92(6), 1087-1101. doi: 10.1037/0022-3514.92.6.1087

Dundar, S. (2014). Reasons for choosing the teaching profession and beliefs about teaching: A study with elementary school PSTs. College Student Journal (48)3, 445-460. 


\section{QUANTITATIVE ANALYSIS OF MCA}

Edelenbos, J., \& Erik-Hans, K. (2007). Trust in complex decision-making networks: A theoretical and empirical exploration. Administration \& Society 39(1), 25-50.

Edmonds, J. M. (2014). Missouri General Education Assessment: examination of PST scores and predictor variables (Unpublished doctoral dissertation). University of Missouri, Columbia.

Engelhard, G., Jr., Hansche, L., \& Rutledge, K. E. (1990). Accuracy of bias review judges in identifying differential item functioning on teacher certification tests. Applied Measurement in Education, 3(4), 347-360.

Evaluation Systems Pearson. (2009). Fairness and diversity in testing. Amherst, MA: Pearson Education.

Field, A. (2013). Discovering statistics using IBM SPSS Statistics (4th ed.). Thousand Oaks, CA: Sage.

Flippo, R. F., \& Canniff, J. G. (2000). Teacher competency whitewash: How one highstakes test eliminates diversity from the teaching force. Connection: New England's Journal of Higher Education and Economic Development, 15(2), 2831.

Gitomer, D. H., Latham, A. S., \& Ziomek, R. (1999). The academic quality of prospective teachers: The impact of admissions and licensure testing. (ETS Research Report No. RR-14-35). Princeton, NJ: Educational Testing Service. http://www.ets.org/Media/Research/pdf/RR-03-35.pdf

Goldhaber, D., \& Hansen, M., (2010). Race, gender, and teacher testing: How informative a tool is teacher licensure testing? American Educational Research Journal, 1-34. doi: 10.3102/0002831209348970 


\section{QUANTITATIVE ANALYSIS OF MCA}

Haberman, M. (1991). The rational for training adults as teachers. In C. Sleeter (Ed.), Empowerment through multi-cultural education (pp. 275-286). Albany, NY: State

Hairston, G. (2014, August 7). Building a continuous improvement model for Missouri educators. Retrieved from https://www.relcentral.org/wpcontent/uploads/2014/08/Presentation-Slides-Hairston.pdf

Halpern, D., Aronson, J., Reimer, N., Simpkins, S., Star, J., \& Wentzel, K. (2007). Encouraging girls in math and science: IES practice guide (NCER 20072003). Washington, DC: Institute of Educational Sciences, U.S. Department of Education. Retrieved from http://ies.ed.gov/ncee/wwc/pdf/practice_guides/20072003.pdf

Hanushek, E. A., Piopiunik, M., \& Wiederhold, S. (2014). The value of smarter teachers: International evidence of teacher cognitive skills and student performance. (NBER Working Paper 20727). Retrieved from National Bureau of Economic Research website http://www.nber.org/papers/w20727

Harmon, M. M. (1995). Responsibility as paradox: A critique of rational discourse on government. Thousand Oaks, CA: Sage.

Harris, E. A. (2015, June 5). Judge rules second version of the New York teachers' exam is also racially biased. The New York Times. Retrieved from http://mobile.nytimes.com/2015/06/06/nyregion/judge-rules-second-version-ofnew-york-teachers-exam-is-also-racially-biased.html?referrer\&_r=1

Henry, G. T., Kershaw, D. C., Zulli, R. A., \& Smith, A. A. (2012). Incorporating teacher effectiveness into teacher preparation program evaluation. Journal of Teacher Education, 63(5), 335-355. doi: 10.1177/0022487112454437 


\section{QUANTITATIVE ANALYSIS OF MCA}

Higher Learning Commission. (2016). Higher Learning Commission. Retrieved from https://www.hlcommission.org/

Hodge, G. A. \& Carsten G. (2005). The challenge of public-private partnerships:

Learning from international experience. Northampton, MA: Edward Elgar.

Honawar, V. (2007). Performance test for new California teachers approved. Education Week, 27(8), 6 .

Horn, C. L. (2003). High-stakes testing and students: Stopping or perpetuating a cycle of failure? Theory into Practice, 42(1), 30-41.

Ingersoll, R., \& May, H. (2011). Recruitment, retention and the minority teacher shortage. (Research Report No. 69). Retrieved from Consortium for Policy Research in Education website: http://www.cpre.org/recruitment-retention-and$\underline{\text { minority-teacher-shortage }}$

Irons, P. (2004). Jim Crow's Schools. Retrieved from American Federation of Teachers website: http://www.aft.org/periodical/american-educator/summer-2004/jimcrows-schools

Isett, K. R., \& Provan, K. G. (2005). The evolution of dyadic interorganizational relationships in a network of publicly funded nonprofit agencies. Journal of Public Administration Research and Theory, 15(1), 149-165. Retrieved from http://localgov.fsu.edu/readings_papers/regional\%20governance/Isset_Provan_Ev olution_of_Dyadic_Network_Relatioships.pdf

Katnik, P. (2016, January). Teacher labor market. Presented at the Missouri State Board of Education meeting, Jefferson City, MO. 


\section{QUANTITATIVE ANALYSIS OF MCA}

Kellow, J. T., \& Jones, B. D. (2008). The effects of stereotypes on the achievement gap: Reexamining the academic performance of African American high school students. Journal of Black Psychology, 34(1), 94-120.

Kenis, P., \& Provan, K. G. (2007). Modes of network governance: Structure, management, and effectiveness. Journal of Public Administration Research and Theory 18(2). 229-252.

Kirk, J. A. (2009). The NAACP campaign for teachers' salary equalization: African American women educators and the early civil rights struggle. The Journal of African American History, 94(4), 529-552

Kritzer, J. B., \& Ziebarth-Bovill, J. (2012). Teaching diversity issues to pre-service teachers in rural setting. Eastern Education Journal, 41(1), 44-56.

Larsen, L. R., \& Calfee, R. C. (2005). Assessing PST growth over time: Embedded signature assessments. The Clearing House, 78(4), 151-157. Retrieved from http://www.jstor.org/stable/30185900?seq=1\#page_scan_tab_contents

Levi, D. J. (2013). Group dynamics for teams (4th ed.). Los Angeles, CA: Sage.

Levine, A. (2006). Educating school teachers. (Policy Report No. 2). Retrieved from The Education Schools Project website: http://www.edschools.org/pdf/Educating_Teachers_Report.pdf

Lewis, W. D., \& Young, T. V. (2013). The politics of accountability: Teacher education policy. Educational Policy, 27(2), 190-216. doi: 10.1177/0895904812472725

Lindkvist, L \& Llewellyn, S. (2003). Accountability, responsibility and organization. Scandinavian Journal of Management. 19, 251-273. 


\section{QUANTITATIVE ANALYSIS OF MCA}

Louis, R. A., \& Mistele, J. M. (2012). The differences in scores and self-efficacy by student gender in mathematics and science. International Journal of Science and Mathematics Education, 10(5), 1163-1190. Retrieved from http://search.proquest.com/docview/1140139882?accountid=14576

Metzger, W. (2006). Laws of seeing. Cambridge, MA: MIT Press.

Milton, J. S., \& Arnold, J. C. (2003). Introduction to probability and statistics: Principles and applications for engineering and computing sciences. $\left(4^{\text {th }} \mathrm{ed}.\right)$. Crawfordsville, IN: McGraw-Hill.

Missouri Department of Higher Education. (2016). Admissions selectivity categories. Retrieved from http://dhe.mo.gov/policies/admissions-selectivity.php

National Center for Education Statistics. (2010). The condition of education, 2010. Retrieved from http://nces.ed.gov/pubs2010/2010028.pdf

National Center for Education Statistics. (2014). Projection of education statistics to 2022. Retrieved from https://nces.ed.gov/pubs2014/2014051.pdf

National Center for Education Statistics. (2015). School composition and the Black-White achievement gap. Retrieved from https://nces.ed.gov/pubsearch/pubsinfo.asp?pubid=2015018

National Commission on Excellence in Education. (1983). A nation at risk [Scanned online version]. Retrieved from http://teachertenure.procon.org/sourcefiles/anation-at-risk-tenure-april-1983.pdf

National Council on Teacher Quality. (2013). Mission. Retrieved from http://www.nctq.org/about/ 


\section{QUANTITATIVE ANALYSIS OF MCA}

Neter, J., Kutner, M. H., Nachtsheim, C. J., \& Wasserman, W. (1996). Applied linear statistical models. Boston, MA: McGraw-Hill.

Nettles, M. T., Scatton, L. H., Steinberg, J. H., \& Tyler, L. L. (2011). Performance and passing rate differences of African American and White prospective teachers on Praxis examinations. (Research report ETS RR-11-08). Retrieved from http://files.eric.ed.gov/fulltext/ED523733.pdf

Northouse, P. G. (2013). Leadership: Theory and practice (6th ed.). Los Angeles, CA: Sage.

Phillion, J., Miller, C. M., \& Lehman, J. D. (2005). Providing field experiences with diverse populations for preservice teachers: Using technology to bridge distances and cultures. Multicultural Perspectives, 7(3). 3-9.

Phillips, C. A. (1911). A history of education in Missouri: The essential facts concerning the history and organization of Missouri's schools. [Google ebook-free version]. Retrieved from https://books.google.com/books?hl=en\&lr=\&id=tjNDAQAAMAAJ\&oi=fnd\&pg= $\underline{\text { PA1\&dq=normal+schools+missouri+history \&ots=4wzN5NFnMj\&sig=te41OaufC }}$ $\underline{\mathrm{rCutCSgLgOUOe} 9 \mathrm{pwHs} \# \mathrm{v}=\text { onepage \&q\&f=false }}$

Proctor, T. J., Rentz, N. L., \& Jackson, M. W. (2001). Preparing teachers for urban schools: The role of field experiences. The Western Journal of Black Studies, 25(4), 219-227.

Ransdell, M., \& Maxwell, S. A. (2006). Initiating elementary PSTs: A structured design approach. Professional Educator, 28(1), 1-11, Retrieved from http://files.eric.ed.gov/fulltext/EJ773847.pdf 


\section{QUANTITATIVE ANALYSIS OF MCA}

Ravitch, D. (2003, August 23). A brief history of teacher professionalism. [Web log post]. Retrieved from

http://www2.ed.gov/admins/tchrqual/learn/preparingteachersconference/ravitch.ht

$\underline{\mathrm{ml}}$

Ravitch, D. (2013). Reign of error: The hoax of the privatization movement and the danger to America's public schools. New York, NY: Knopf.

Rockoff, J. E., Jacob, B. A., Kane, T. J., \& Staiger, D. O. (2008). Can you recognize an effective teacher when you recruit one? (Working Paper 14485). Retrieved from National Bureau of Economic Research website: http://www.nber.org/papers/w14485

Romzek, B. S., \& Dubnick, M. J. (1987). Accountability in the public sector: Lessons from the Challenger tragedy. Public Administration Review 47(3), 227-238.

Romzek, B. S., LeRoux, K., \& Blackmar, J. M. (2012). A preliminary theory of informal accountability among network organizational actors. Public Administration Review, 72(3). 442-453.

Rook, D, \& Torbert, W. R. (2011). Seven transformations of leadership. In Harvard Business Review's (Eds.), HBR's ten must reads on leadership (pp. 137-161). Boston, MA: Harvard Business Review Press.

Sawchuk, S. (2010). State group piloting teacher prelicensing exam. Education Week, $30(2), 1,12-13$.

Scott, M. B., \& Lyman, S. M. (1968). Accounts. American Sociological Review, 33, 4662.

Schillemans, T. (2008). Accountability in the shadow of hierarchy: The horizontal 
QUANTITATIVE ANALYSIS OF MCA

accountability of agencies. Public Organization Review 8(2), 175-194.

Semin, G. R., \& Manstead, A. S. R. (1983). The accountability of conduct: A social psychological analysis. New York, NY: Academic Press.

Sleeter, C. E. (2001). Preparing teachers for culturally diverse schools: Research and the overwhelming presence of whiteness. Journal of Teacher Education, 52(2), 94106. Retrieved from http://www.unco.edu/cebs/diversity/pdfs/Sleeter_Preparing\%20Teachers\%20for\% 20Culturally\%20Diverse\%20Schools.pdf

Steinberg, J. (2015, September). Utilizing licensure performance data to increase teacher diversity and improve educator preparation programs. Presented at the 2015 Fall CAEPCon Conference, Washington, DC.

Steinberg, J., \& Weiner, S. (2015, February). The imperative of educational preparation programs to improve teacher diversity. Presented at the $67^{\text {th }}$ Annual Meeting of the AACTE, Atlanta, GA.

Stenning, P. C. (1995). Accountability for criminal justice. Toronto, Canada: University of Toronto Press.

Sum, A., Khatiwada, I., McLaughlin, J., \& Palma, S. (2009). The consequences of dropping out of high school: Joblessness and jailing for high school dropouts and the high cost for taxpayers. Center for Labor Market Studies Northeastern University. Retrieved from: http://www.northeastern.edu/clms/wpcontent/uploads/The_Consequences_of_Dropping_Out_of_High_School.pdf

Svennson, J., Trommel, W., \& Lantink, T. (2008). Reemployment services in the Netherlands: A comparative study of bureaucratic, market, and network forms of 
QUANTITATIVE ANALYSIS OF MCA

organization. Public Administration Review 68(3), 505-515.

Taylor, M. L. (2013). African American teachers and state licensing examination in metropolitan Atlanta: A Case study. (Doctoral dissertation, University of Nevada, Las Vegas). Retrieved from http://digitalscholarship.unlv.edu/cgi/viewcontent.cgi?article=2898\&context=thes esdissertations

Teach for America. (2016). Teach for America. Retrieved from https://www.teachforamerica.org/

Tetlock, P. (1992). The impact of accountability on judgment and choice: Toward a social contingency model. In M. Zanna (Ed.), Advances in experimental social psychology (pp. 331-376). San Diego, CA: Academic Press.

Thorndike, R. M. (2005). Measurement and evaluation in psychology and education ( $7^{\text {th }}$ ed.). Upper Saddle River, NJ: Pearson Prentice Hall.

U.S. Department of Education. (2000). Update on federal reporting requirements for educator preparation institutions and programs. Washington, DC: U.S. Department of Education.

U.S. Government Accountability Office (2006). Highlights of a U.S. GAO forum:

Federal acquisition challenges and opportunities in the 21 st century. (GAO-0745SP). Retrieved from http://www.gao.gov/assets/210/202977.pdf

Van Slyke, D. M. (2007). Agents or stewards: Using theory to understand the government-nonprofit social service contracting relationship. Journal of Public Administration Research and Theory 17(2), 157-187. 


\section{QUANTITATIVE ANALYSIS OF MCA}

Villegas, A. M., \& Irvine, J. J. (2010). Diversifying the teaching force: An examination of major arguments. Urban Rev 42, 175-192. doi: 10.1007/s11256-010-0150-1

Villegas, A. M., Strom, K., \& Lucas, T. (2012). Closing the racial/ethnic gap between students of color and their teachers: An elusive goal. Equity and Excellence in Education, 45(2), 283-301. doi: 10.1080/10665684.2012.656541

Wakefield, D. (2003). Screening PSTs: Problems with high-stakes testing. Educational Forum, 76(4), 380-388.

Wall, T. J. (2008). Evaluation of the impact of the participation in the T.E.S.T. examination preparation program on elementary education PST C-Base and Praxis II performance. (Doctoral Dissertation, University of Missouri). Retrieved from https://mospace.umsystem.edu/xmlui/bitstream/handle/10355/5609/research.pdf?seq $\underline{\text { uence }=3 \mathrm{e}}$

Wall, T. J., \& McBride, M. A. (2016, March). MO assessments MO problems. Presented at the Spring 2016 MACTE Conference, Lake Ozark, MO.

Weick, K. (1995). Sensemaking in organizations. Thousand Oaks, CA: Sage.

Williams, R. P. (2009). Business and marketing teacher preparation in Missouri: A study of characteristics and influencing factors. (Doctoral dissertation, University of Missouri). Retrieved from https://mospace.umsystem.edu/xmlui/bitstream/handle/10355/7010/research.pdf?s equence $=3$ 


\section{APPENDIX}

Figure A1. IRB approval from the University of Missouri

Help
Scanned from a Xer... $\times$
$\begin{aligned} & \text { McBride, Michael A } \\ & \begin{array}{l}\text { From: } \\ \text { Sent: } \\ \text { To: } \\ \text { Subject: }\end{array}\end{aligned} \begin{aligned} & \text { McBride, Michael A. (MU-Student) <mamce7@mail.missouri.edu> } \\ & \text { Friday, September 23, 2016 9:35 AM } \\ & \text { McBride,Michael A } \\ & \text { Fw: IRB Determination Notice Project \#2005689 Review \#215528 }\end{aligned}$

From: McBride, Michael A. (MU-Student)

Sent: Wednesday, June 22, 2016 10:09 AM

To: mam77@nwmissouri.edu

Subject: Fw: IRB Determination Notice Project \#2005689 Review \#215528

From: McBride, Michael A. (MU-Student)

Sent: Wednesday, June 8, 2016 4:12 PM

Tot mam77@nwmissouri.edu

Subject: Fw: IRB Determination Notice Project \#2005689 Review \#215528.

From: MU eCompliance <ecompliance@missouri.edu>

Sent: Friday, May 6, 2016 1:44 PM

To: McBride, Michael A. (MU-Student)

Subject: IRB Determination Notice Project \#2005689 Review \#215528

\section{\% eCompliance}

MU Office of Research ecompliance

ecompliance.missouri.edu

Compliance management system for the Office of Research at the University of Missouri. Submit or update your outside interest report for review by the MU Conflict of

IRB Determination Notice Project \#2005689 Review \#215528: 


\section{QUANTITATIVE ANALYSIS OF MCA}

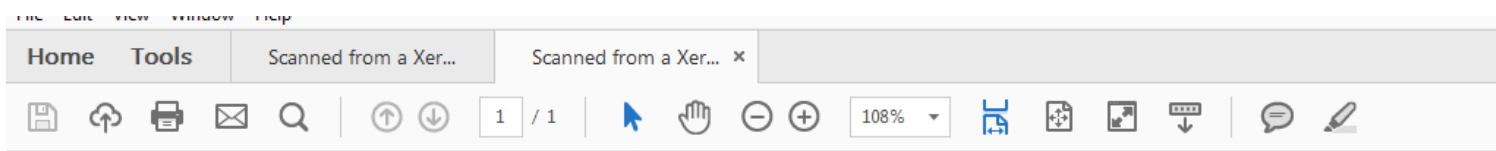

Project \#2005689

Project Title: The Missouri Content Assessment as an accountability instrument for teacher candidates and educator preparation programs

Principal Investigator: Michael A McBride

Primary Contact: Michael A McBride

Dear Investigator,

The MU Institutional Review Board reviewed your application and supportive documents. It has been determined that this project does not constitute human subjects research according to the Department of Health and Human Services regulatory definitions. As such, there are no further IRB requirements.

If you have questions, please feel free to contact the IRB office at 882.3181 .

Sincerely,

MU Institutional Review Board 


\section{VITA}

Michael McBride was born in Hermann, Missouri. By his memory, he had a terrific childhood that in retrospect may have been too sheltered. But, he was kept out of most trouble until he reached college. Michael's interests grew in two areas: mathematics and helping lost causes. He attended the University of Missouri for his undergraduate degrees in statistics and psychology, as well as his graduate degree in counseling psychology. Michael met his wife Brooke while at the University of Missouri and they now have one child, Bryant. He has worked in alcohol and drug abuse prevention, vocational rehabilitation and educator preparation. Nearly all of his professional experience has occurred in higher education. His professional interests include increasing the recruitment and completion of future educators from historically marginalized populations and pursuing journal publications. His personal interests include spending time with his family and perhaps one day relaxing. 